\title{
Techno-Economic Analysis Of A Solar Adsorption Cooling System For Residential Applications In Canada
}

\author{
by \\ Jordan McNally
}

A thesis submitted to the Faculty of Graduate and Postdoctoral Affairs in partial fulfillment of the requirements for the degree of

Master of Applied Science

in

Mechanical Engineering

Carleton University

Ottawa, Ontario

(C) 2020, Jordan McNally 


\section{Abstract}

The demand for space cooling is increasing worldwide due to the increase of population as well as the rising global temperatures. This increase in demand increases the peak load distribution on the electricity grid. Solar cooling technologies such as adsorption cooling have shown to be capable at reducing and shifting the electrical loads required for cooling. In this thesis, an adsorption system was simulated and tested in various cities across Canada in order to compare its performance to conventional HVAC systems. Areas where natural gas is available for a low cost, like Saskatchewan and Alberta, were found to have a much lower economic benefit for this type of system but would receive the largest reductions in carbon dioxide emissions of all the other provinces. A solar adsorption system in Toronto was found to reduce the buildings electrical consumption, greenhouse gas emissions, and annual cost of electricity by significant amounts when compared to a waterto-water heat pump and air conditioner with electric or natural gas heating. The findings from this thesis depend on a number of factors, such as location, greenhouse gas intensity of the local electrical grid, local utility rates, and weather conditions. When using the adsorption chiller on a district heating setup, the payback period was reduced to be within the system's life expectancy and in some cases more cost effective than currently installed consumer systems. The main limiting factor for adsorption cooling is acquiring a heat source that can have a large thermal output either from solar or waste heat. Depending on the area available on the roof of a building, vacuum tube collectors may need to be used. Additionally, the optimization of the control system has a large effect on the chillers capabilities to operate effectively. 


\section{Acknowledgements}

I would like to thank my supervisor, Dr. Cynthia Cruickshank, for the opportunity and support throughout this project.

I would also like to give a special thanks to Chris Baldwin from whom I learned a vast amount about plumbing, data collection, and simulation. I would like to thank my other colleagues for their patience, friendship, and ability to listen when I rant about my frustrations. This includes Tyler Ulmer, Calene Treichel, Brock Conley, Chris Campbell, Belal Daouk, Kayla Lewry, Ben Beauchamp, and many others.

I would like to acknowledge the financial support provided by the Canadian Federation for Innovation (CFI) and Ontario Research Fund (ORF) for their contribution which allowed for the purchase and installation of the experimental setup utilized in this study, and to the Natural Science and Engineering Research Council of Canada (NSERC) for financially supporting this study.

Lastly, I would like to thank my family and girlfriend Kayla Crupi for their love, support, and motivation they have provided me over the past two years. 


\section{Table of Contents}

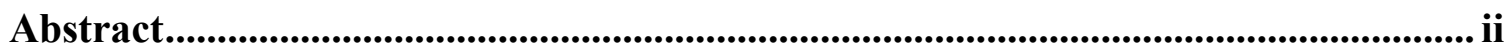

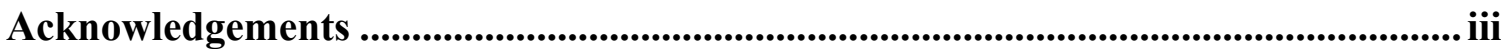

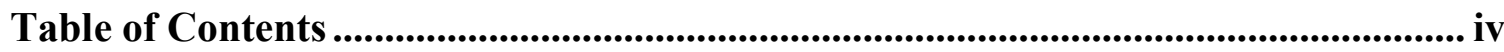

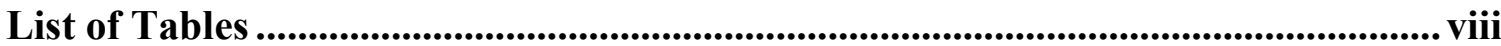

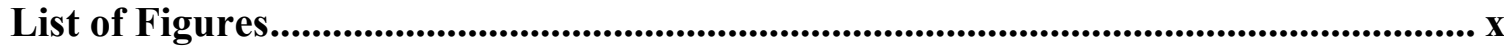

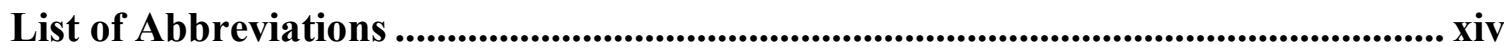

List of Symbols .................................................................................................................... $\mathrm{xv}$

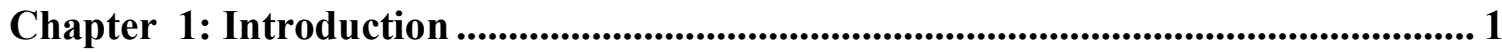

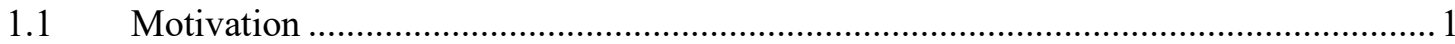

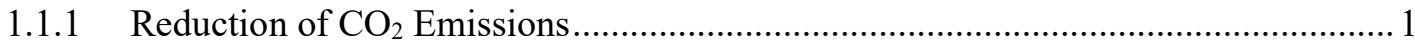

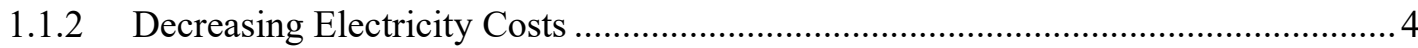

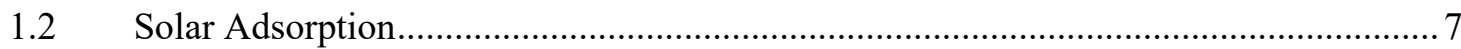

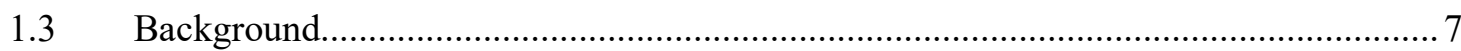

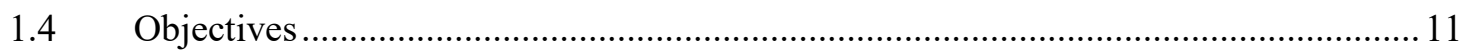

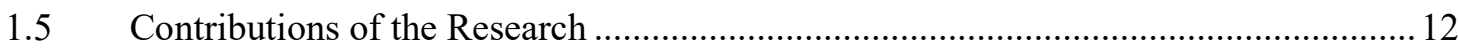

Chapter 2: Literature Review .................................................................................. 14

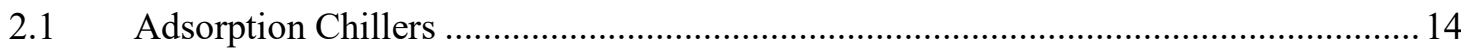

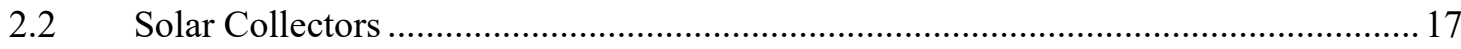

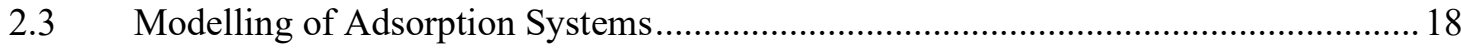

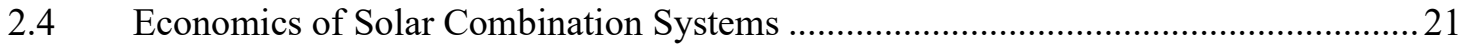

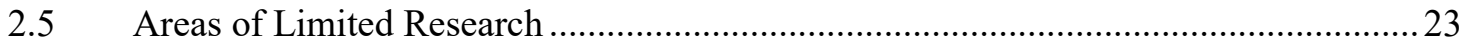

Chapter 3: Experimental Setup .......................................................................................... 25

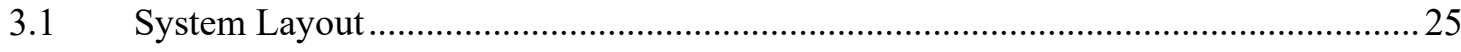

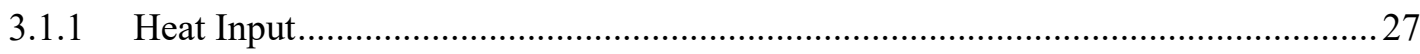




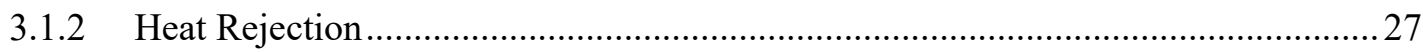

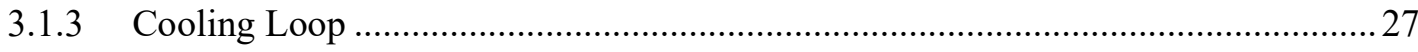

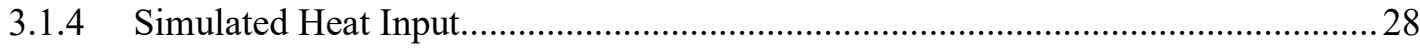

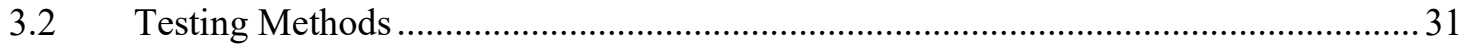

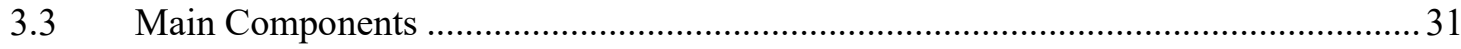

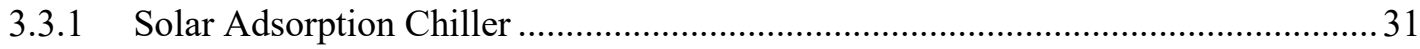

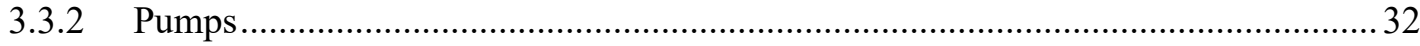

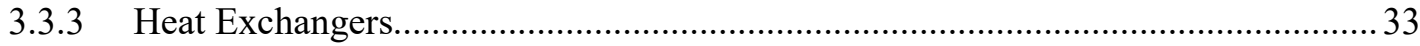

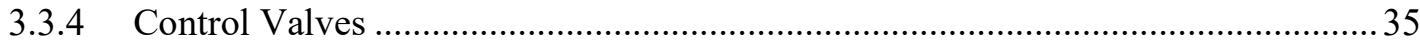

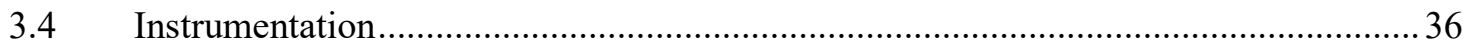

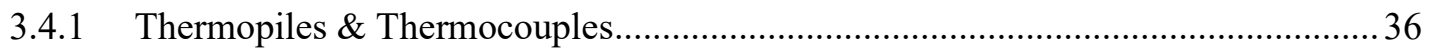

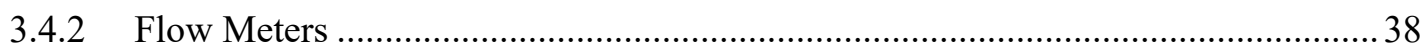

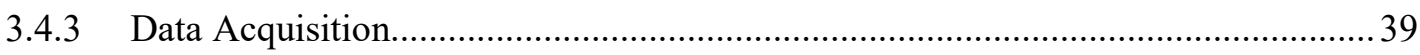

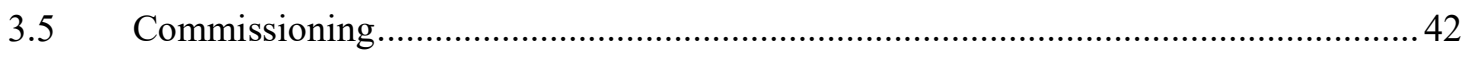

Chapter 4: Calibration and Uncertainty Analysis........................................................... 45

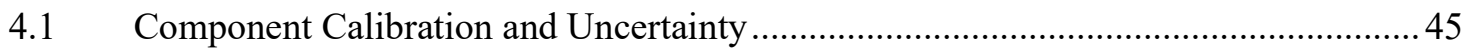

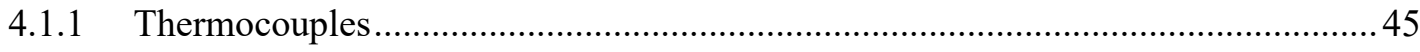

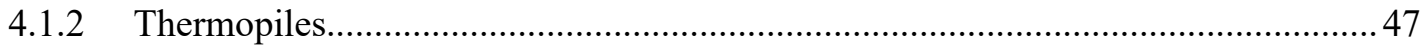

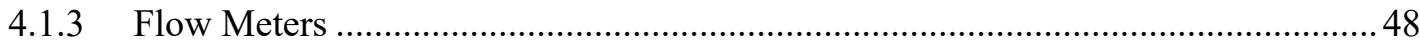

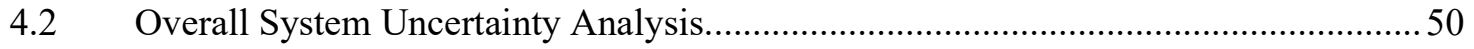

4.2.1 Uncertainty on Heat Transfer Calculations ........................................................ 50

4.2.2 Uncertainty on the COP of the Adsorption Chiller ...............................................52

Chapter 5: Modelling Methodology ……............................................................................ 53

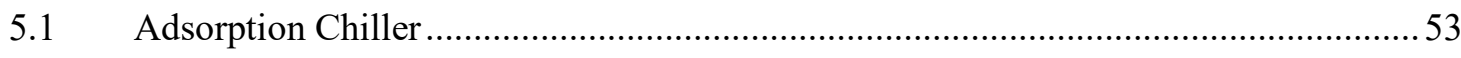

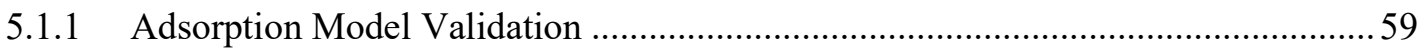

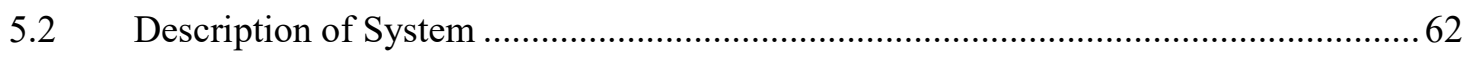




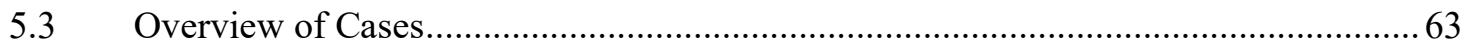

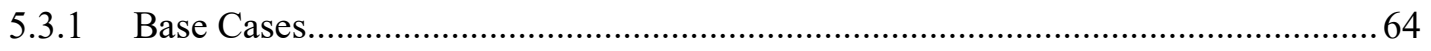

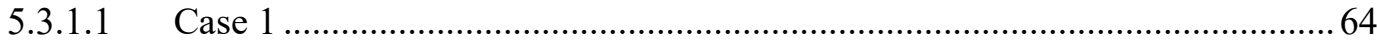

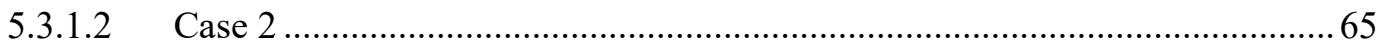

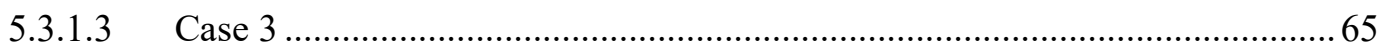

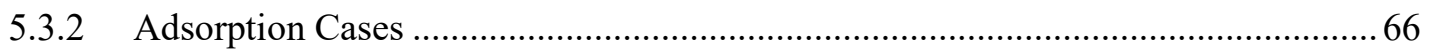

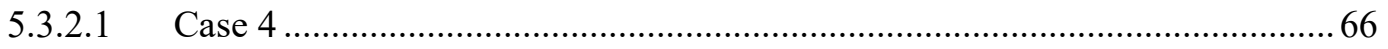

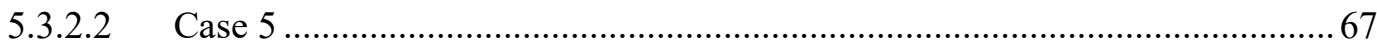

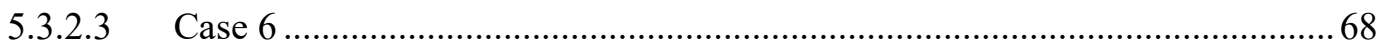

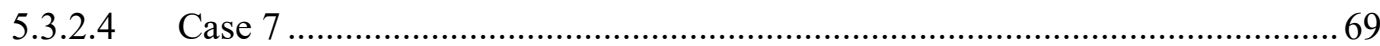

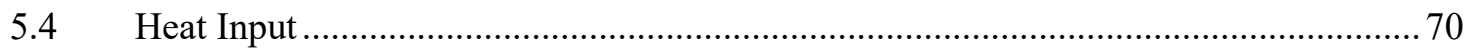

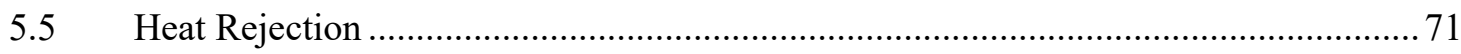

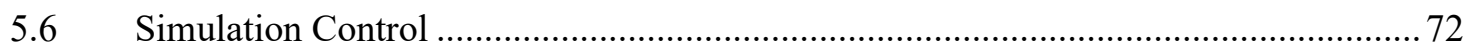

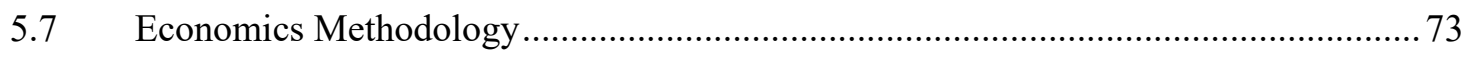

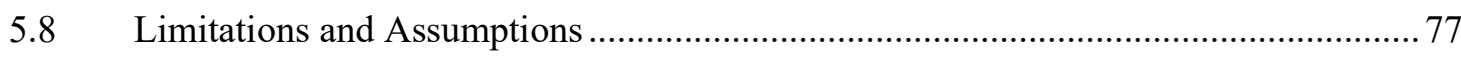

Chapter 6: Results and Discussion .................................................................................... 79

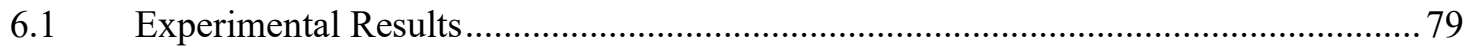

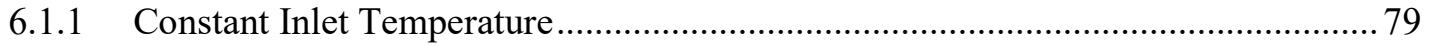

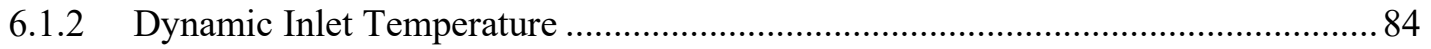

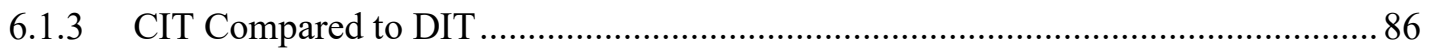

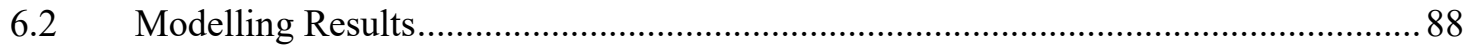

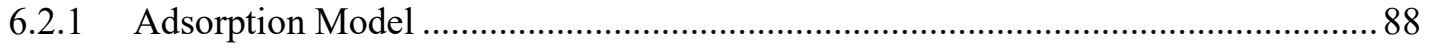

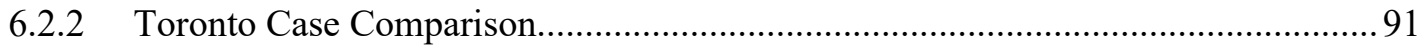

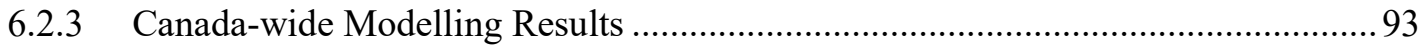

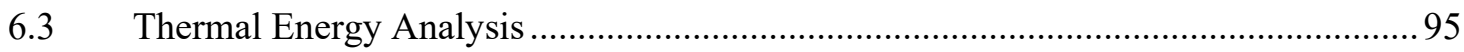

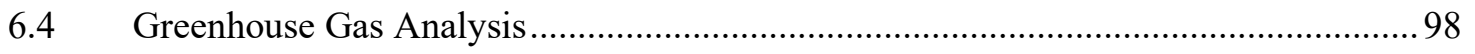




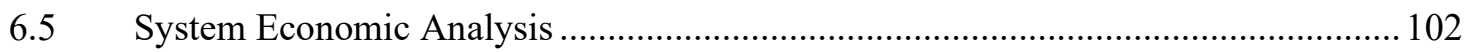

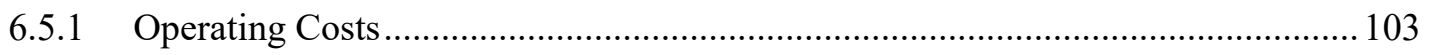

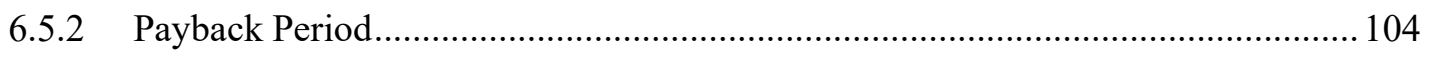

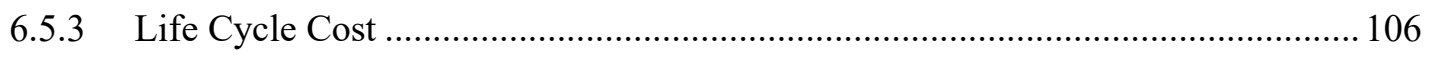

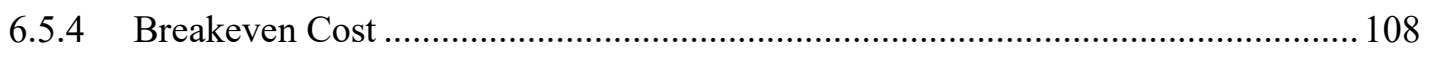

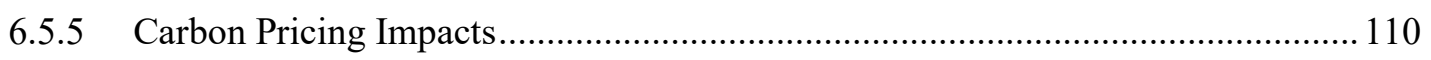

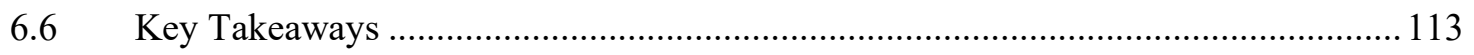

Chapter 7: Conclusions and Future Work ............................................................. 114

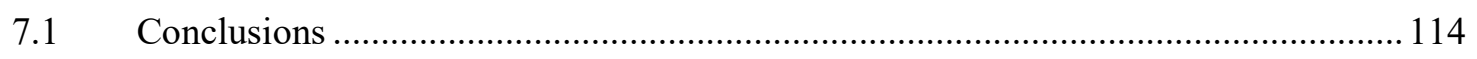

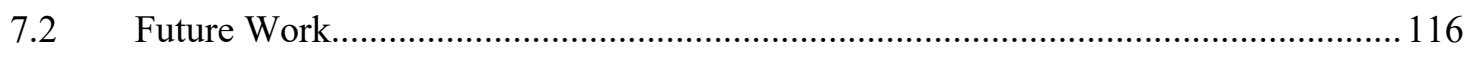

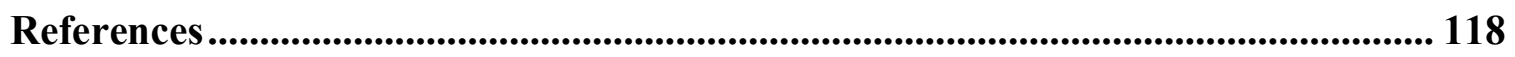

Appendices......................................................................................................................... 124

Appendix A - Full Experimental Schematic (Spans two pages) ........................................ 124

Appendix B - Adsorption Performance Map Input File .................................................... 126

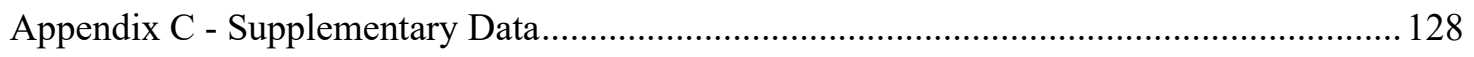

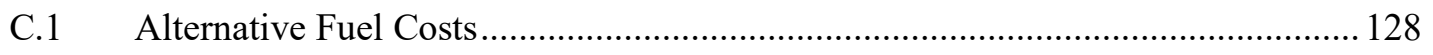

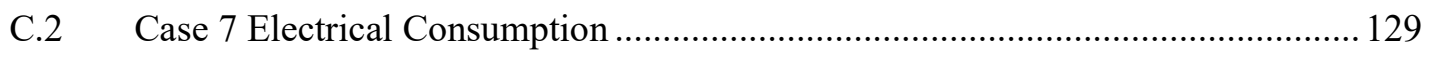




\section{List of Tables}

Table 1.1: Comparison of market available chillers [13] .............................................. 10

Table 3.1 Flat plate solar collector IAM-angle relations ................................................. 29

Table 3.2: Simulated solar collector data.......................................................................... 30

Table 3.3: Adsorption chiller test setup specifications ..................................................... 32

Table 3.4: Achieved chiller performance as stated by manufacturer................................ 32

Table 3.5: Installed flow meter specifications .................................................................... 39

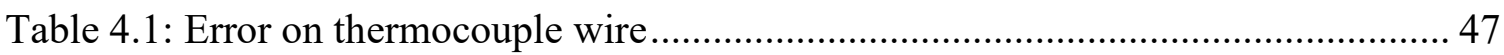

Table 4.2: Error on a thermopile .................................................................................... 48

Table 4.3: Flow meter specification required for uncertainty analysis............................ 49

Table 4.4: Flow meter uncertainty with varying time intervals........................................ 49

Table 4.5: Sensitivity factors for each hydraulic line …………..................................... 51

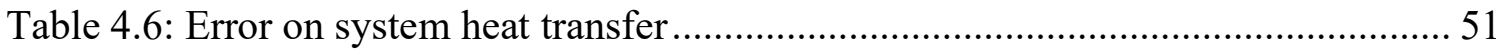

Table 5.1: Difference between measured and simulated outlet temperatures .................. 62

Table 5.2: Difference between measured and simulated heat transfer .............................. 62

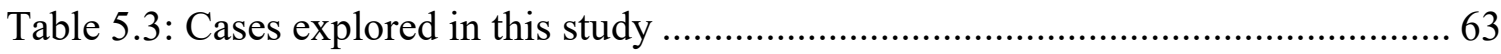

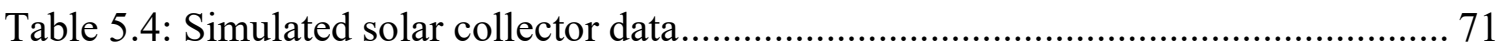

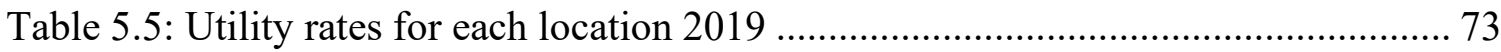

Table 5.6: Costs associated with installing an adsorption system ................................... 74

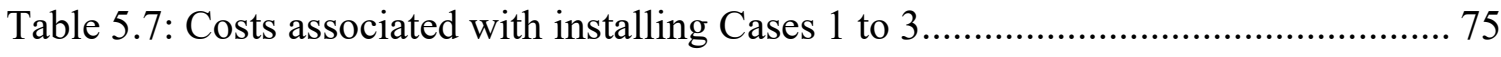

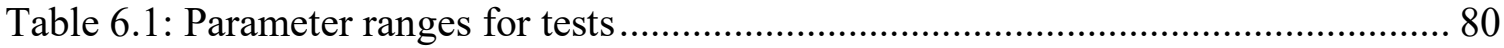

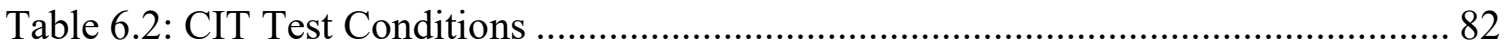

Table 6.3: DIT Test Conditions ................................................................................... 84 
Table 6.4: Comparison of integrated thermal power between the CIT simulation and test 89

Table 6.5: Comparison of integrated thermal power between DIT simulation and test ... 90

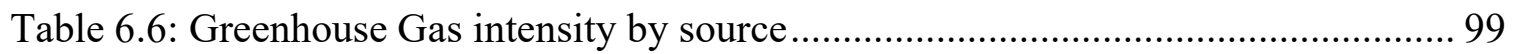

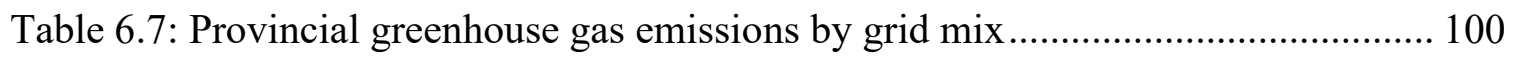

Table C.1: Electrical and fuel rates for each city (alternative units) 2019 rates............ 128 


\section{List of Figures}

Figure 1.1: Residential space cooling energy use in Canada 1990-2014 [1], [2] .............. 2

Figure 1.2: Hourly electrical supply by energy source for the Ontario grid on June 26th,

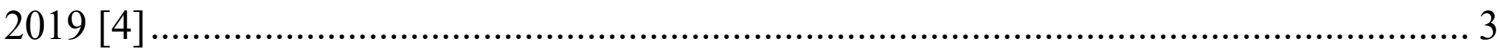

Figure 1.3: Residential electrical peak demand by end-use in California [3].................... 4

Figure 1.4: Time-of-use periods for Ontario (24-Hour) [7] .......................................... 5

Figure 1.5: Ontario electricity TOU rates from 2006-2020 [9] ....................................... 6

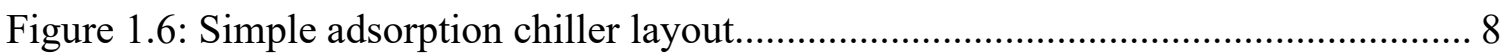

Figure 3.1: Experimental system schematic …………............................................... 26

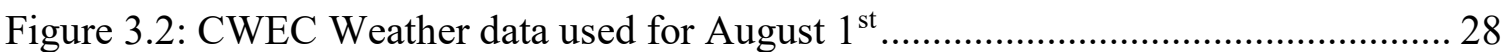

Figure 3.3: CWEC Weather data used for September 29th ............................................ 28

Figure 3.4: Simulated heat input following requested power input................................. 30

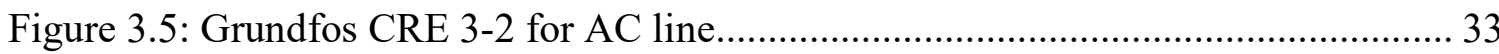

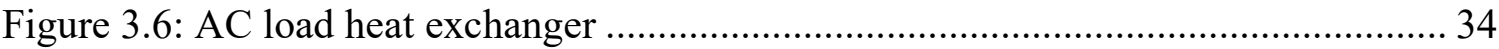

Figure 3.7: Proportional valve used to modulate load on AC line..................................... 35

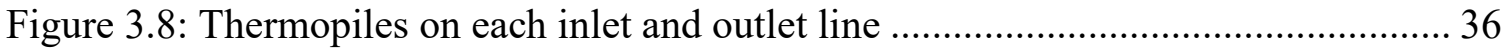

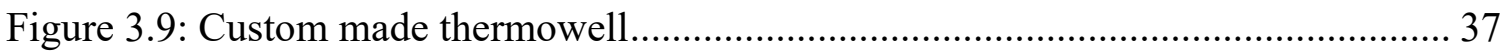

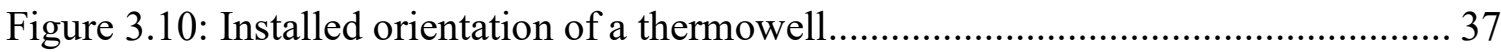

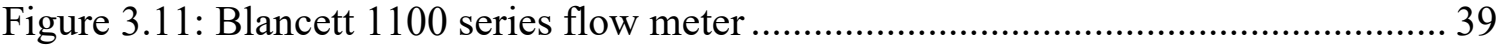

Figure 3.12: NI Data Acquisition equipment............................................................... 40

Figure 3.13: NI LabVIEW virtual interface................................................................. 41

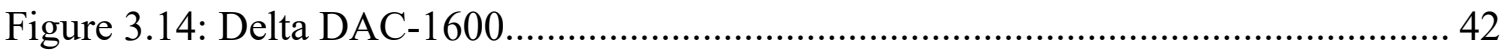

Figure 3.15: Initial commissioning tests varying HR temp …........................................ 43 
Figure 3.16: Initial commissioning tests varying AC temp ..................................... 43

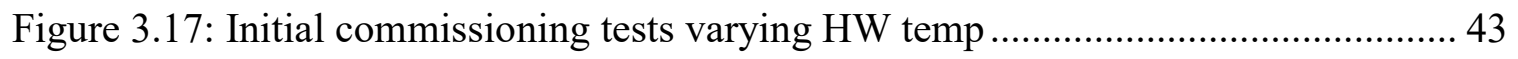

Figure 5.1: Experimentally determined performance map for a SorTech Adsorption

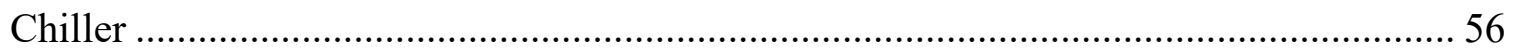

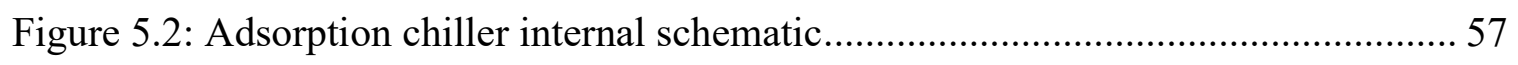

Figure 5.3: Adsorption chiller results displaying cyclic nature ..................................58

Figure 5.4: Preliminary modelling results for the TRNSYS adsorption chiller model .... 59

Figure 5.5: Comparison of measured and simulated outlet temperatures....................... 60

Figure 5.6: Comparison of measured and simulated heat transfers through the chiller ... 61

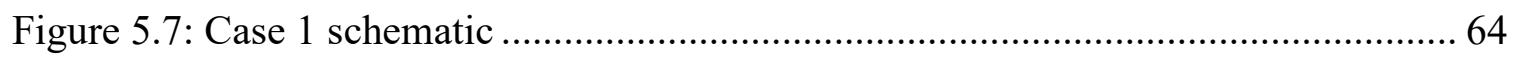

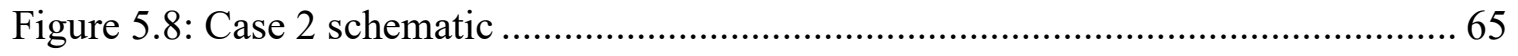

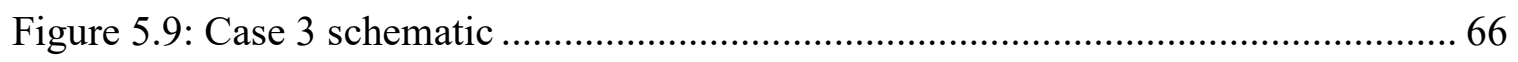

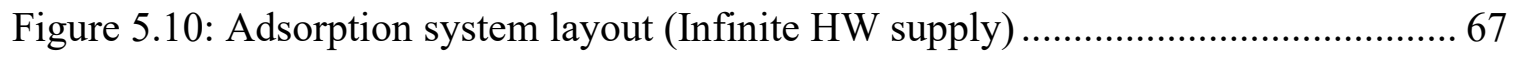

Figure 5.11: Adsorption system layout with solar (HP uses infinite HW supply) ........... 68

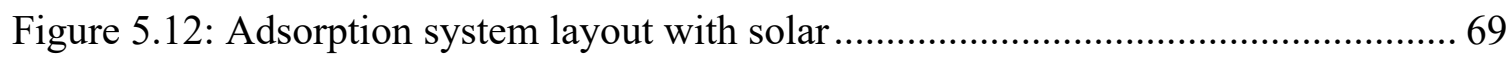

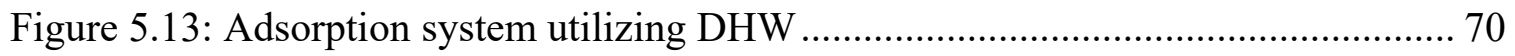

Figure 5.14: Efficiency curve for Apricus solar collector ..................................... 71

Figure 6.1: Relationship between cooling capacity and varying HR inlet ..................... 80

Figure 6.2: Relationship between cooling capacity and varying AC inlet .................... 81

Figure 6.3: Relationship between Cooling capacity and varying HW inlet ................... 81

Figure 6.4: HW inlet and cooling capacity for two cycles of a constant inlet temperature

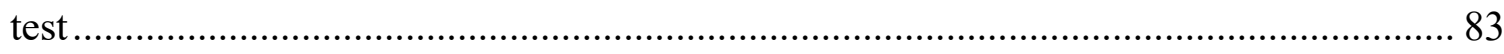


Figure 6.5: Chiller inlet and outlet temperatures for two cycles of a constant inlet

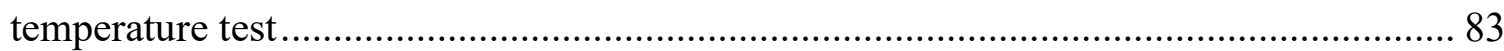

Figure 6.6: Hot water vs solar radiation over test duration......................................... 85

Figure 6.7: Cooling capacity vs hot water inlet over test duration .............................. 85

Figure 6.8: Cooling capacity vs solar radiation over test duration ............................. 86

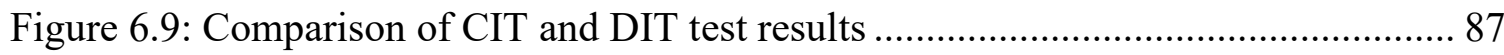

Figure 6.10: Integrated simulated thermal power values for a continuous inlet temperature

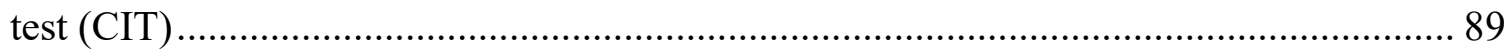

Figure 6.11: Integrated thermal power for a dynamic inlet temperature test (DIT) ........ 90

Figure 6.12: Simulated annual thermal and electrical consumption for house model in

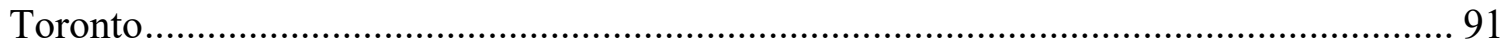

Figure 6.13: Simulated annual electrical consumption breakdown by time-of-use rate... 92 Figure 6.14: Economic and environmental costs/impacts for each experimental case in

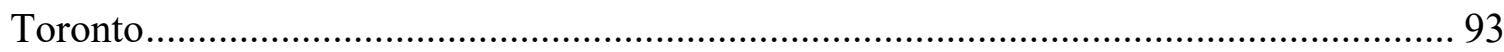

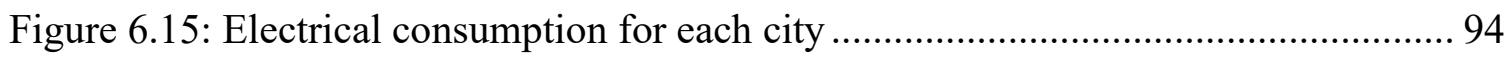

Figure 6.16: Cooling power provided to each city ................................................. 95

Figure 6.17: Heating power provided to each city ............................................... 96

Figure 6.18: Cooling season temperature for Canadian cities .................................... 97

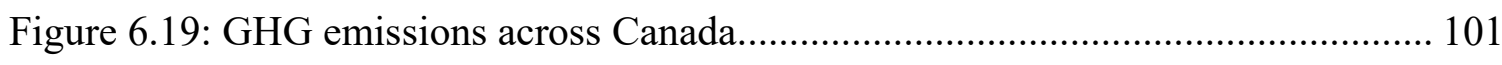

Figure 6.20: Percent reduction in GHG emissions by switching to a solar adsorption

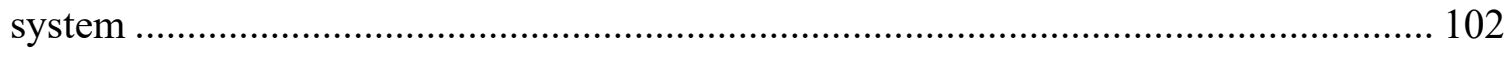

Figure 6.21: Annual operation costs across Canada .............................................. 103 
Figure 6.22: Payback period for an adsorption system compared to a heat pump system 104

Figure 6.23: Payback period for an adsorption system compared to an electric system 105 Figure 6.24: Payback period for an adsorption system compared to a natural gas system

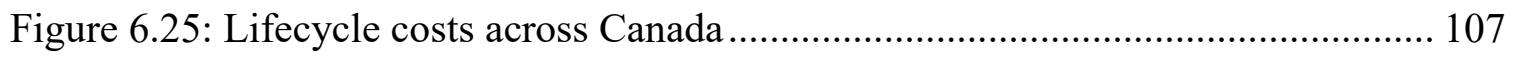

Figure 6.26: Breakeven costs for an adsorption system without solar ........................ 108

Figure 6.27: Breakeven costs for an adsorption system with solar............................. 109

Figure 6.28: Breakeven costs with carbon pricing for an adsorption system without solar

Figure 6.29: Breakeven costs with carbon pricing for an adsorption system with solar 112

Figure 7.1: Laboratory and mechanical room schematic..................................... 125 


\section{List of Abbreviations}

\begin{tabular}{|c|c|}
\hline $\mathrm{AC}$ & Air conditioning line \\
\hline CAD & Canadian Dollar (\$) \\
\hline CIT & Continuous inlet temperature \\
\hline const. & Constant \\
\hline $\mathrm{COP}$ & Coefficient of performance \\
\hline DAQ & Data acquisition unit \\
\hline DIT & Dynamic inlet temperature \\
\hline DOE & Department of Energy \\
\hline FPC & Flat plate collector \\
\hline GHG & Greenhouse gas \\
\hline HR & Heat rejection line \\
\hline HW & Hot water line \\
\hline HX & Heat exchanger \\
\hline LCC & Lifecycle cost $(\$)$ \\
\hline PBP & Payback period (years) \\
\hline PI & Proportional-integral \\
\hline PID & Proportional-integral derivative \\
\hline PV & Photovoltaic \\
\hline USD & Jnited States of America Dollar $(\$$ \\
\hline
\end{tabular}




\section{List of Symbols}

\begin{tabular}{|c|c|}
\hline$A$ & Area $\left(\mathrm{m}^{2}\right)$ \\
\hline$C$ & Capital cost (\$) \\
\hline$C_{\mathrm{BE}}$ & Breakeven cost $(\$)$ \\
\hline$C_{\text {fuel }}$ & Cost of fuel (\$/unit) \\
\hline CJC & Cold junction temperature $\left({ }^{\circ} \mathrm{C}\right)$ \\
\hline$C P$ & Carbon Price $(\$ / \mathrm{kg})$ \\
\hline$C_{\mathrm{P}}$ & Specific heat capacity $(\mathrm{kJ} / \mathrm{kgK})$ \\
\hline$d$ & Discount rate \\
\hline dir. & Direction \\
\hline eff. & Efficiency \\
\hline$G H G_{\text {offset }}$ & Greenhouse gas offset $\left(\mathrm{kgCO}_{2} \mathrm{e}\right)$ \\
\hline$I$ & Efficiency factor \\
\hline$i$ & Inflation rate \\
\hline$I A M$ & Incident angle modifier (unitless) \\
\hline$K$ & K-factor (pulse/L) \\
\hline$M$ & Maintenance cost (\$) \\
\hline$\dot{m}$ & Mass flow rate $(\mathrm{kg} / \mathrm{s})$ \\
\hline$n$ & Number of panels / Lifetime (years) \\
\hline$P$ & Power $(\mathrm{W})$ \\
\hline$Q$ & Heat transfer $(\mathrm{kW})$ \\
\hline$q_{\mathrm{AC}}$ & Cooling power $\left(\mathrm{kW}_{\text {th }}\right)$ \\
\hline
\end{tabular}




\begin{tabular}{|c|c|}
\hline$q_{\text {capacity }}$ & Maximum cooling capacity $\left(\mathrm{kW}_{\text {th }}\right)$ \\
\hline$r$ & Interest rate \\
\hline $\mathrm{rad}$ & Radiation $\left(\mathrm{kJ} / \mathrm{m}^{2}\right)$ \\
\hline$S$ & Subsidy rate $(\$)$ \\
\hline$T$ & Temperature $\left({ }^{\circ} \mathrm{C}\right)$ \\
\hline$T_{\mathrm{f}}$ & Average fluid temperature $\left({ }^{\circ} \mathrm{C}\right)$ \\
\hline$T_{\mathrm{a}}$ & Average air temperature $\left({ }^{\circ} \mathrm{C}\right)$ \\
\hline$t$ & Time (seconds) \\
\hline$U$ & Uncertainty \\
\hline$V$ & Voltage (V) \\
\hline$\dot{V}$ & Volumetric flow rate (L/min) \\
\hline$W$ & Cost of electricity (\$) \\
\hline$X$ & Operating cost $(\$)$ \\
\hline$\rho$ & Density $\left(\mathrm{kg} / \mathrm{m}^{3}\right)$ \\
\hline$\theta$ & Panel tilt $\left(^{\circ}\right)$ or Sensitivity factor \\
\hline
\end{tabular}




\section{Chapter 1: Introduction}

This section discusses the motivation behind this research, an introduction on how adsorption cooling can reduce $\mathrm{CO}_{2}$ emissions and electricity costs, some background information of how an adsorption system works, the research objectives and the contributions of this research.

\subsection{Motivation}

The demand for space cooling in Canada is growing yearly due to the rise in average temperatures and the increasing population. This increase in demand for cooling directly relates to a demand for electrical power during the hottest portions of the day, which are also the times of day the solar potential is the highest. If the electrical demand from space cooling equipment were reduced, it would not only reduce the electrical costs but also the greenhouse gas emissions attributed with providing the power. Using a thermally driven cooling system rather than a mechanically driven cooling system (with a compressor) allows for an inherent reduction in electrical consumption. The thermal power required for such a system can be produced during the portion of the day that has the highest solar potential, which is also the period of the day which requires the most cooling. An adsorption chiller is a thermally driven cooling system selected for this research due to its potential to be used with a flat plate solar collector system for residential applications.

\subsubsection{Reduction of $\mathrm{CO}_{2}$ Emissions}

Over the last twenty-five years the demand for space cooling in Canada has increased by approximately $170 \%$ and continues to increase as displayed by Figure 1.1, where the trend for space cooling and total floor area from 1990 to 2014 is shown. 


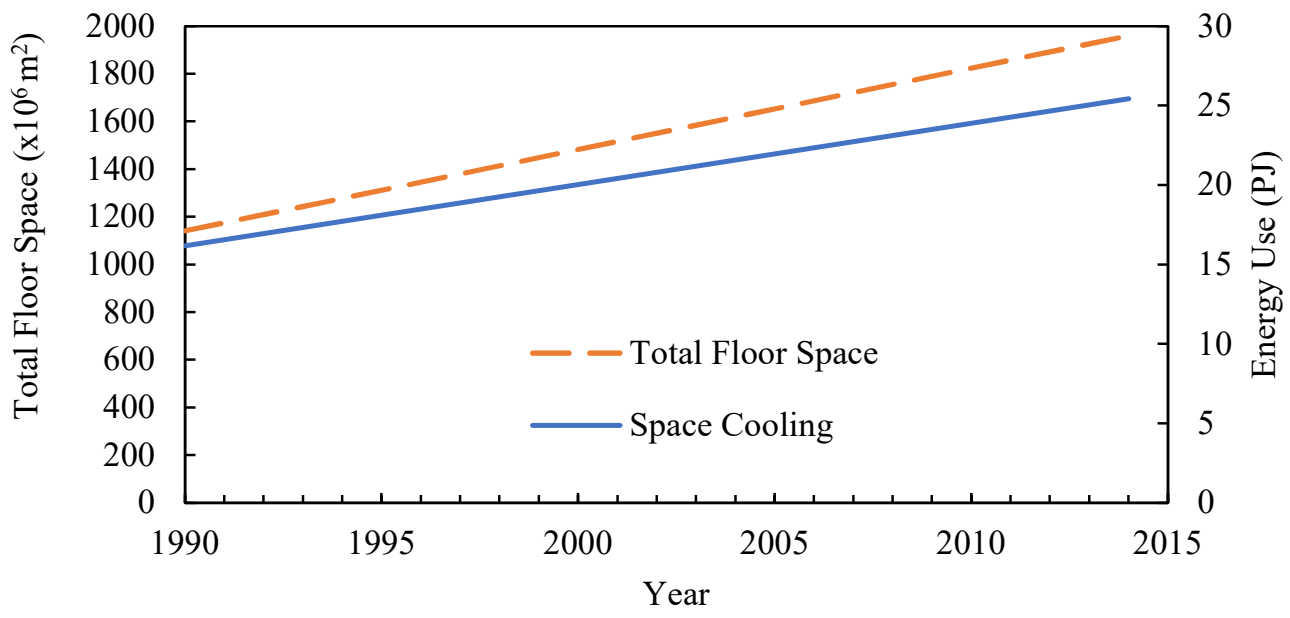

Figure 1.1: Residential space cooling energy use in Canada 1990-2014 [1], [2]

Total floor space has been steadily increasing over the past two decades and continues to rise due to increase in population and new homes being built. This causes the total amount of space cooling to also increase steadily and can be expected to continue to rise. Increasing space cooling loads leads to increasing peak electrical loads, which cause stress on the electrical grid if the demand is not accurately predicted [3]. Peak electrical loads cause power facilities to match the difference between the baseload and demand loads. In Ontario, this can cause gas and biofuel burning power facilities to ramp up their production of electricity, causing an increase in carbon dioxide when compared to the average $\mathrm{CO}_{2} / \mathrm{kWh}$ across the grid. A typical breakdown of the hourly supply distribution to the Ontario grid for a weekday is shown in Figure 1.2. 


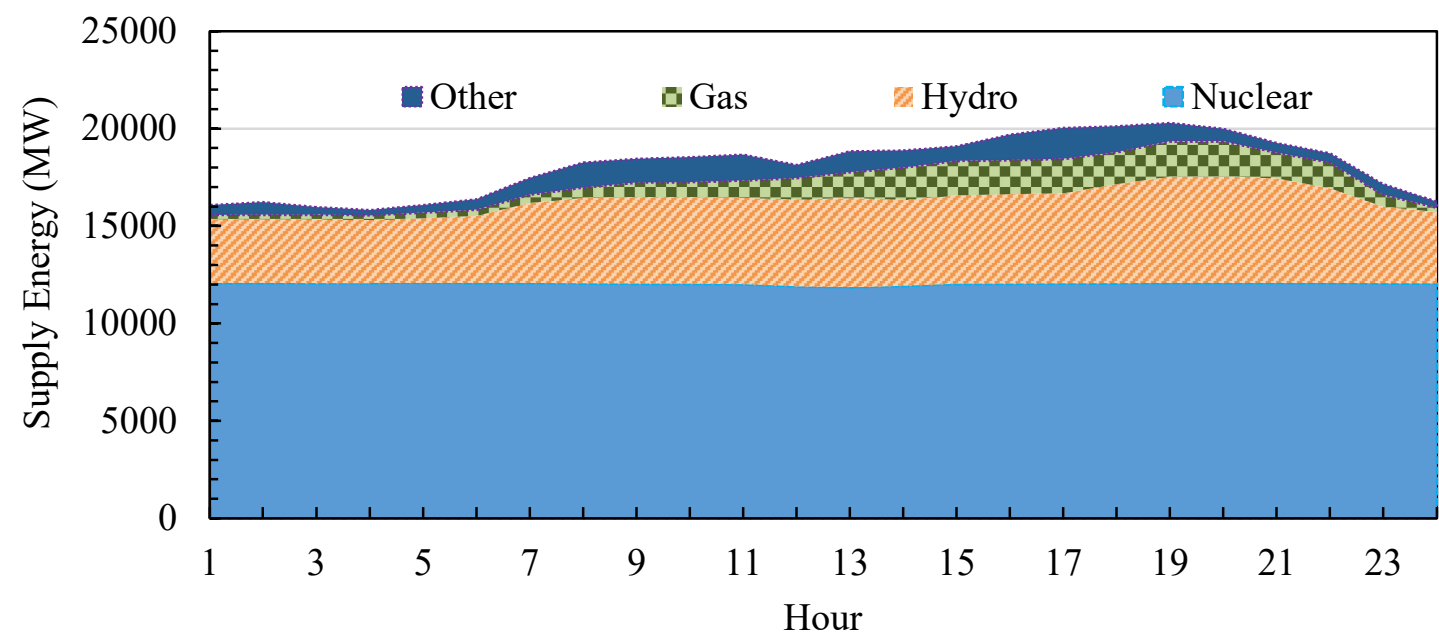

Figure 1.2: Hourly electrical supply by energy source for the Ontario grid on June 26th, 2019 [4]

This figure shows that during the peak and mid-peak hours (7-18), gas burning power facilities are ramped up to meet the increased consumption, which the nuclear and hydro facilities cannot match themselves. This electrical peak occurs during the hottest part of the day and when people are awake, meaning air conditioning is turned on and appliances are used. The increasing in cooling is predominantly a result of the increase in solar radiance during these periods, providing an excellent opportunity to capture this energy to meet cooling demand via an adsorption chiller.

The increase of GHG emissions during peak periods can be greatly reduced by reducing the peak electrical load caused by air conditioning. Figure 1.3 displays the breakdown of the electrical peak consumption in California, where in Ontario (Canada) a similar trend would be seen in the summer months just with different magnitude. The breakdown of electrical peak demand by end-use would remain relatively similar over time or increase because as the electrical efficiency of air conditioners is increasing [5], the total cooled floor space is also increasing [6]. 


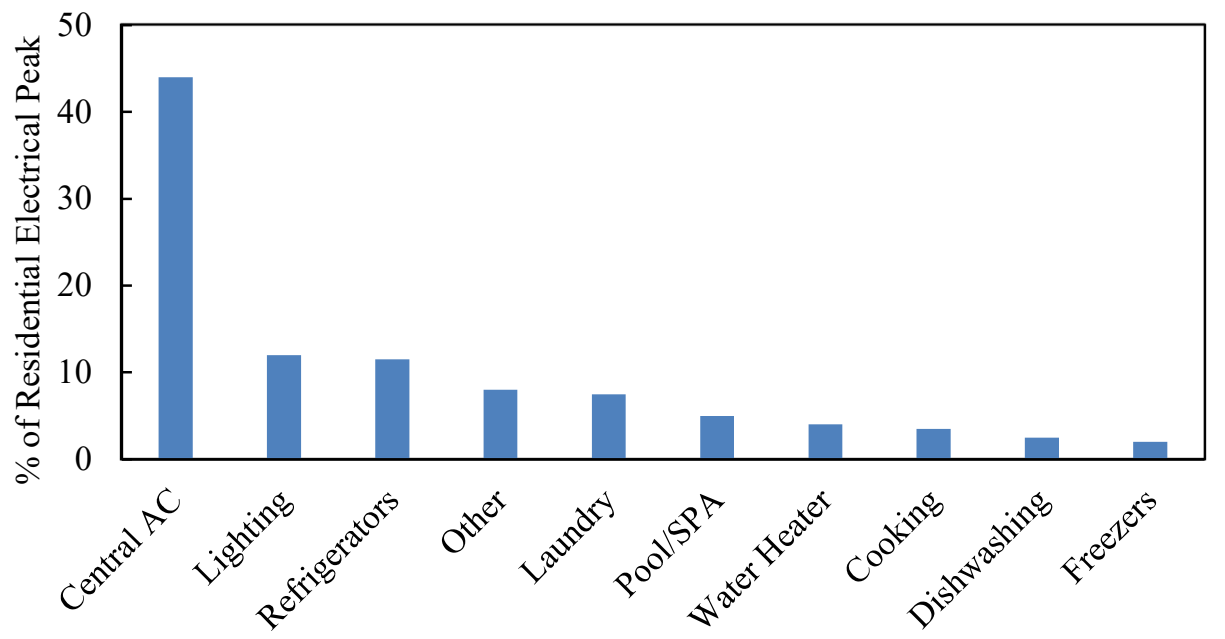

Figure 1.3: Residential electrical peak demand by end-use in California [3]

In the residential sector of California, the peak electrical load is approximately 18,000 MW while the air-conditioning demand contributes to about 7,500 MW. By reducing the peak demand caused by air conditioning the overall electrical peak demand would be significantly decreased, especially in the summer months. Another motivation for reducing the peak load caused by air conditioning is to reduce costs for the consumer when billed on a time-of-use basis, which charges higher rates during peak periods.

\subsubsection{Decreasing Electricity Costs}

For the majority of Ontario and therefore approximately $40 \%$ of the Canadian population, the cost of electricity is determined using a time-of-use billing method where there are typically three periods of rates during the weekday, which in order of cost are onpeak, mid-peak, and low-peak. The time at which these rates are applied is shown in Figure 1.4. 

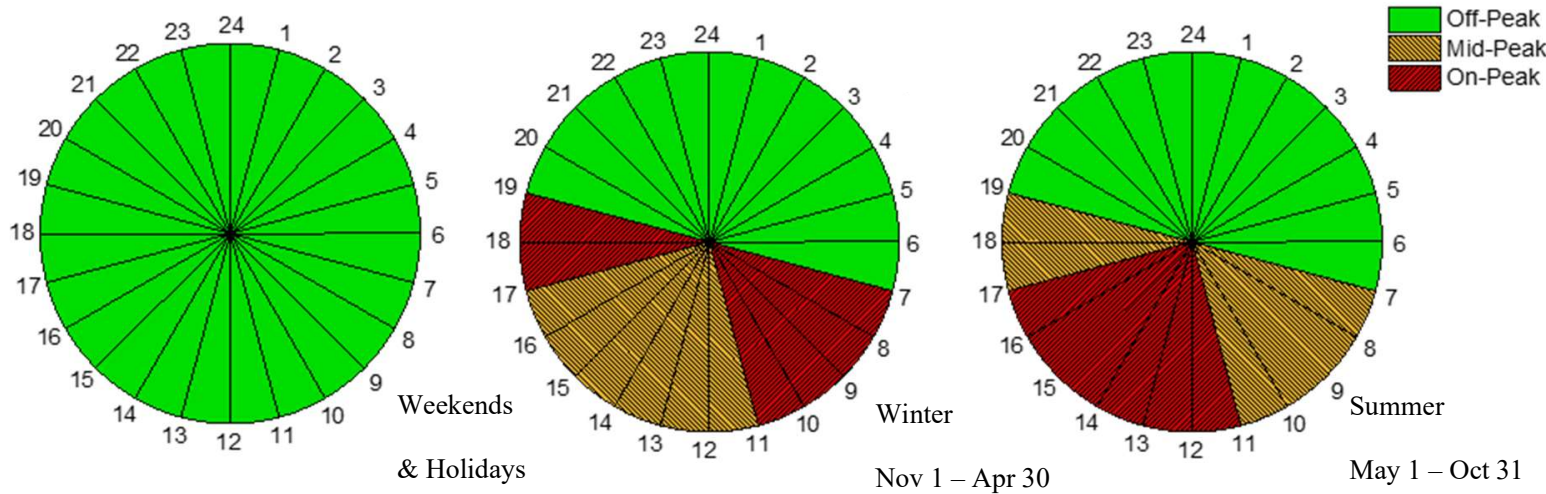

Figure 1.4: Time-of-use periods for Ontario (24-Hour) [7]

Figure 1.4 shows the winter and summer times where the electrical peak rates are billed, in red. The green represents the off-peak rates periods while yellow signifies midpeak rates, and weekends and statutory holidays are billed as off-peak periods.

The electricity rates have been steadily increasing until about 2014 where the rate began to increase by a larger amount until 2016, as seen in Figure 1.5. The on-peak price is proportionally much higher than the mid- and off-peak rates, and as such significant cost savings could be had through the reduction of peak consumption. Additionally, certain regions in Ontario employ a regulated price plan (RPP), where there are two set rates determined by the usage of electricity. The rates will increase after an amount of electricity is consumed above the seasonal threshold which is $600 \mathrm{kWh} /$ month in the summer and $1000 \mathrm{kWh} /$ month in the winter [8]. 


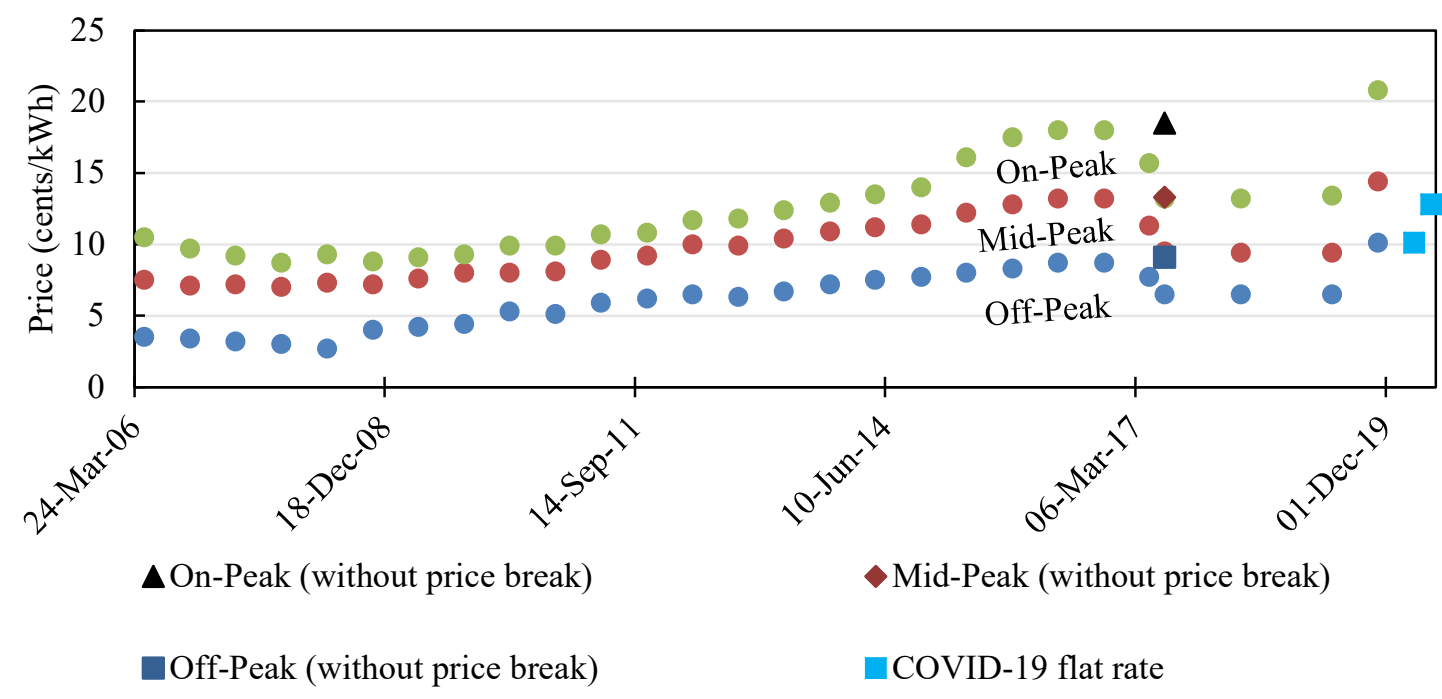

Figure 1.5: Ontario electricity TOU rates from 2006-2020 [9]

There has been an approximately $150 \%$ increase in electricity rates from 2006 to 2017 in Ontario, at which point a significant drop occurred due to a change in government policy and the introduction of new government subsidies through their Fair Hydro Act [10]. Through this legislation, the cost of electricity has been temporarily subsidized by the government, resulting in an approximate decrease of 25 percent compared to the true cost of generation and transmission. The points on the graph indicate where the projected electricity rates would be without the Fair Hydro Act. Once this temporary act expired in November 2019, the rates increased back to where they otherwise would be following the growth pattern. During this current time there is another temporary reduction in electricity rates due to many people working from home during the COVID-19 pandemic where all the rates are billing at the same value. These rates can be assumed to jump back up to their previous rate or higher (following the increase trend) once restrictions due to the ongoing pandemic allow employees to return to work in-person, rather than remotely from home.

Using cooling solutions that require less electricity will help our electrical grid to move away from generation using carbon fuels and towards a more sustainable electrical 
grid. Which also reduces electrical costs, especially during peak periods. Reducing the peak periods of electrical consumption by using a solar cooling system such as an adsorption chiller can produce significant cost saving and reductions in carbon dioxide emitted from peak power production [11].

\subsection{Solar Adsorption}

This cooling technology uses hot water as its driving force, allowing it to consume very little electricity. The only parts in an adsorption chiller that draw electrical power are the controller, pumps (to compensate for pressure drop) and control valves. Due to the much lower power draw of an adsorption chiller, in comparison to a vapour compression air conditioner, the peak electrical load caused by air conditioning can be greatly reduced. An adsorption chiller can be paired with a solar water heater to provide the hot water needed or connected to a district heating system. Newer units can generate thermal power from hot water temperatures as low as 50 to $70^{\circ} \mathrm{C}$; this is an improvement from requiring supply temperatures higher than $70^{\circ} \mathrm{C}[12]$. Additionally, in the winter months, the solar collector system could also be used to provide hot water to a water-source heat pump. Another benefit to reducing the peak electrical load and greenhouse gas emissions is to reduce the cost of electricity. Adsorption cooling is being adopted more often for industrial applications where waste heat is available and can provide cooling for office spaces in factories [13]. This shows that this technology is feasible in certain situations and proven for industrial use.

\subsection{Background}

An adsorption chiller uses hot water as the driving energy source to produce cooling, which can be provided from a solar collector system. Solar collector systems can 
provide hot water to drive the chiller at very little operating cost with the main drawback being the need for lots of consistent solar radiation to provide adequate temperatures, where using waste heat would have a constant supply. In industrial applications waste heat may be in abundance, so an adsorption chiller can provide what is often referred to as 'free cooling'. However, in residential applications hot water is often heated by an electric or a gas water heater, so this hot water is not nearly as 'free' as in an industrial application, as the consumer would have to pay for the gas or electricity consumed to heat the water.

An adsorption chiller is a type of refrigeration unit that uses liquid water as its working fluid (refrigerant) and a solid sorption material such as silica or zeolite. Typically, an adsorption chiller has a double barrel design consisting of two adsorber/desorbers and two condenser/evaporators seen in Figure 1.6. While one barrel is adsorbing and producing cooling, the other is desorbing and charging up. This way there is a continuous cooling output over the time of operation.

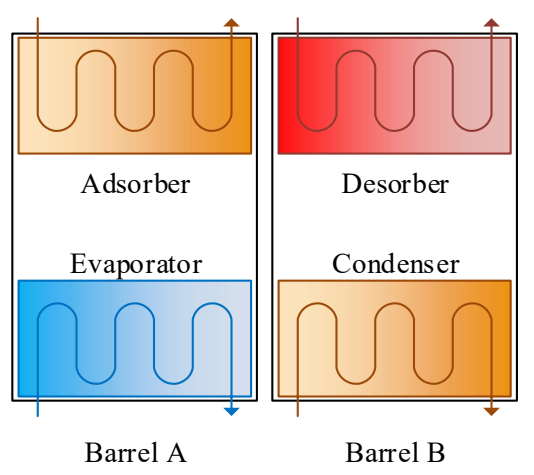

Figure 1.6: Simple adsorption chiller layout

The cooling phenomenon in an adsorption chiller occurs within the evaporator where the working fluid can evaporate at very low temperatures due to the lower than atmospheric pressure inside the barrels. The solid sorbent inside the adsorption chamber also reduces humidity which aids evaporation and attracts the working fluid. The phase 
change of the working fluid removes heat from the evaporator causing a cooling effect on the remaining water and cooling loop (AC line) within the evaporator. Water vapor and heat are removed from the gel in the adsorber as it flows into the condenser where the heat rejection loop expels it. Additionally, the hot water source is circulated through the desorber (saturated adsorber) to release the water vapour adsorbed by the silica gel to the condenser, where the heat rejection loop expels it. Once the adsorber becomes saturated and the desorber expels the vapour previously collected these heat exchangers flip and the condenser begins evaporating the fluid and the cycle repeats [14].

Recently, some commercially available adsorption chillers have been developed to be able to provide cooling at lower hot water driving temperatures, as low as $45^{\circ} \mathrm{C}$ where traditionally the driving temperature required was in the 65 to $75^{\circ} \mathrm{C}$ range. This opens the possibility for a flat plate solar water heater to be used due to its appeal of lower costs than an evacuated tube collector. A solar water heater typically has a temperature range of 40 to $75^{\circ} \mathrm{C}$ where a commercially ready adsorption chiller used has an operating range of 45 to $95^{\circ} \mathrm{C}$ [15]. This pairs well with adsorption chillers as the surplus heat in the summer can be used to cool a house while during the winter the solar heating system can be used for heating.

Absorption chillers operate under the same premise as adsorption chillers in regard to using a thermally driven cooling cycle rather than being mechanically driven. However, there are some important differences as an absorption system's cycle is similar to the vapor compression refrigeration cycle with the compressor being replaced by an absorber and generator. Compared to an adsorption chiller where a solid sorbent such as silica gel is used, an absorption chiller uses a liquid sorbent such as lithium bromide or an ammonia 
water solution. The premise of the absorption chiller is to separate and recombine the refrigerant and absorbent in order to create the cooling effect which is much different than that of an adsorption chiller [16]. The main benefit to using an adsorption chiller compared to an absorption chiller is that there is no chance for a sorbent leakage as it is solid, noncorrosive, lower electricity draw, much longer lifespan, less maintenance, lower maintenance cost, and lower driving hot water temperatures [17]. However, absorption chillers typically can produce larger amounts of cooling and at a higher coefficient of performance.

Table 1.1 displays a comparison between some small-scale absorption and adsorption chillers that are available on the market for residential applications. Where HW, $\mathrm{HR}, \mathrm{AC}$ are the hot water, heat rejection, and air conditioning (cold water) inlet temperatures, and COP is the thermal coefficient of performance. Floor area and electrical power consumption are for the chiller units themselves and not for any additional equipment or storage tanks.

Table 1.1: Comparison of market available chillers [13]

\begin{tabular}{l|llll}
\hline Company & Climatewell & SolarNext & SorTech & SJTU \\
\hline Product & Climatewell 10 & chillii ${ }^{\circledR}$ PSC10 & ACS 08 & SWAC-10 \\
Type & $\mathrm{H}_{2} \mathrm{O} / \mathrm{LiCl}$ & $\mathrm{NH}_{3} / \mathrm{H}_{2} \mathrm{O}$ & $\mathrm{H}_{2} \mathrm{O} /$ Silica gel & $\mathrm{H}_{2} \mathrm{O} /$ Silica gel \\
Cooling Capacity & 10 & 10 & 7.5 & 10 \\
$(\mathrm{~kW})$ & $83 /-$ & & & \\
$\mathrm{HW}\left({ }^{\circ} \mathrm{C}\right)$ & $30 /-$ & $85 / 78$ & 75 & 85 \\
$\mathrm{HR}\left({ }^{\circ} \mathrm{C}\right)$ & -115 & $12 / 6$ & $27 / 32$ & $30 / 36$ \\
$\mathrm{AC}\left({ }^{\circ} \mathrm{C}\right)$ & 0.68 & 0.63 & $18 / 15$ & $15 / 10$ \\
$\mathrm{COP}$ & 0.48 & 0.53 & 0.39 \\
Floor Area $\left(\mathrm{m}^{2}\right)$ & 0.96 & 0.84 & 2.16 \\
Electrical Power & 170 & 300 & 0.87 & 200 \\
Consumption $(\mathrm{W})$ & & & & \\
\hline
\end{tabular}


Currently, the price of adsorption chiller units is still high due to their low production volume. As more units are produced on a wider scale, the cost should go down significantly. Many countries in Europe are supporting the initiative to increase the amount

and awareness of solar cooling for residential and commercial applications. Specifically, in Germany, there is a large investment in flat plate solar water heaters, which show promise for newer generation adsorption chillers. This technology has massive room for growth and development and can provide a substantial amount of potential savings [18].

\subsection{Objectives}

The overall objectives of this thesis are to determine the techno-economic feasibility of adsorption chillers in Canada and to investigate their performance with flat plate solar collectors. To address these objectives, an adsorption chiller was evaluated by experimental testing and computer simulations. A large portion of the peak electrical consumption due to air conditioning could be reduced by using an adsorption chiller with a solar water collector. This is explored by using a empirical model with an experimentally determined performance map for various locations across Canada. The model was created within Transient System Simulation Tool (TRNSYS) which is a dynamic system modelling tool commonly used to assess thermal and electrical energy systems. The adsorption system was compared to other heating and cooling systems commonly found across Canada, such as, heat pump, electric/natural gas furnace, and vapour compression air conditioning. The goal was to assess the thermal performance of the adsorption chiller in both a district heat supplied and solar supplied system for its capability to adequately cool in residential applications. The electrical consumption and GHG emissions from current HVAC and adsorption systems were compared to determine the annual costs environmentally and 
monetarily. The economic performance was determined using the payback period (PBP) and lifecycle cost (LCC) as major factors to compare common HVAC systems to that with a solar adsorption system.

\subsection{Contributions of the Research}

Contributions from this work are:

1. Modification of an existing experimental setup with three fluid loops, air conditioning, heat rejection, and hot water, to meet temperature and flow rate requirements for the adsorption chiller;

2. Experimental testing of the adsorption chiller over full operation range to create performance map of the adsorption chiller to be used for modelling and simulation;

3. TRNSYS model of adsorption chiller using the Type-909 component and the experimentally determined performance map;

4. Validation of an empirical adsorption chiller model with various sets of experimental inlet conditions and results, with deviation from the measured results within the bounds of experimental error;

5. TRNSYS models for simulating various HVAC systems, such as water-sourced heat pump, vapor compression air conditioner, and electric and natural gas furnace, as well as district and solar adsorption systems across Canada for residential applications; and

6. Environmental and economic analysis of simulation results for each location studied in Canada (every province and one territory) by a GHG analysis with LCC, PBP, breakeven costs and effects of carbon pricing. 
The experimental results from this work were published in two peer-reviewed conference papers (citations shown below). A journal article, currently in preparation, will present the overall economic findings of this study.

J. McNally, C. Baldwin, and C. A. Cruickshank, "Using Adsorption Cooling and Thermal Solar Collection for Residential Cooling Applications in Canada," in Proceedings of the ASME 2018 International Mechanical Engineering Congress and Exposition. Volume 6A: Energy. Pittsburgh, USA. Nov. 9-15, 2018. [Online] doi: 10.1115/imece2018-87246.

J. McNally and C. A. Cruickshank, "Performance and Greenhouse Gas Analysis of a Solar Adsorption Chiller for Canadian Residential Applications", in Proceedings of the ISES Solar World Congress 2019 and IEA SHC International Conference on Solar Heating and Cooling for Buildings and Industry, Santiago, Chile. Nov. 4-7, 2019. [Online] doi: 10.18086/swc.2019.55.08. 


\section{Chapter 2: Literature Review}

Solar cooling technologies have been gaining interest in the past 15 to 20 years [19]. The performance of this technology has also been improving in terms of efficiency, size, effectiveness of the adsorbent, and the temperature range it can operate within. The residential applications of adsorption chillers are still not fully proven in terms of reliability, performance, and cost savings. There have been numerous successful installations in industrial settings where waste heat could be utilized, which further promotes the question of how feasible this system would be for residential use. This section presents an overview of past research conducted on adsorption chillers performance, solar collectors, modelling of adsorption systems and economics of thermal systems. In addition, a description is provided on past work done on this topic at Carleton University. Finally, a summary of the research gaps is presented.

\subsection{Adsorption Chillers}

New models of adsorption chillers require less floor space and have greater power density. Some units can produce cooling with driving heat temperatures as low as $50^{\circ} \mathrm{C}$, which is much lower when compared to the hot water temperatures required 10 years ago $\left(65\right.$ to $\left.75^{\circ} \mathrm{C}\right)$ [12]. These improvements in adsorption cooling increase the feasibility of the technology for use in residential applications with solar water heating, and not just for industrial waste heat or district heating applications.

Najeh et al. [20] conducted experimental testing of the performance of a silica gelwater adsorption cooling system installed in Gabes, Tunisia. They selected a silica gelwater adsorbate pair due to its ability to regenerate at relatively low temperatures. The experimental setup had a heat source from a cogeneration plant as well as a solar collector 
array. The array size was 16 collectors at $2.4 \mathrm{~m}^{2}$ each totaling a size of $38.4 \mathrm{~m}^{2}$. The hot water tank had a capacity of $1500 \mathrm{~L}$ and the adsorption chiller was a commercially available unit from the same manufacturer as the unit tested in this thesis. A mathematical model was also developed for this setup to model the results and compare to the performance of the chiller. The experimental setup was able to test from the range of 60 to $90^{\circ} \mathrm{C}$. The performance of the chiller was determined to be close to manufacturing specifications at a COP and cooling capacity of 0.62 and $5.64 \mathrm{~kW}$, respectively. The inlet and outlet temperatures determined by the mathematical model was a fair representation of the chiller's experimental result.

There are some studies of adsorption chillers for residential applications that have been able to quantify energy savings compared to a standard air conditioning unit, such as the study by Thomas et al. [21] which claims a total energy savings of $40 \%$. The chiller tested was a zeolite-water unit that has a smaller effective temperature range $\left(55\right.$ to $\left.75^{\circ} \mathrm{C}\right)$ compared to silica-gel unit at $\left(55\right.$ to $\left.95^{\circ} \mathrm{C}\right)$. This study has provided a residential experimental application where an adsorption chiller system was shown to provide significant cooling with a $28 \mathrm{~m}^{2}$ solar thermal collector array $\left(14 \mathrm{~m}^{2}\right.$ flat plate collector array with $7.2 \mathrm{~kW}$ of electrical heaters $\left[\sim 14 \mathrm{~m}^{2}\right.$ equivalent to solar thermal collector] made up the $28 \mathrm{~m}^{2}$ ). However, like many publications this study did not have an economic analysis of the two systems, which is one area that is lacking in the literature. A model is typically needed to determine a comparative economic analysis between adsorption cooling systems and typical air conditioning systems.

An example of an installation of a full small-scale setup is at the CitrinSolar Headquarters in Germany which was installed in 2007 [22]. The offices and training rooms 
are air conditioned by an adsorption chiller. The experimental setup consists of a $16.5 \mathrm{~kW}$ dry cooler, $24 \mathrm{~m}^{2}$ of a flat plate solar collector array, and a $1000 \mathrm{~L}$ thermal storage system. To prevent the situation where no significant heating was produced due to lack of solar radiation during sequential cloudy days, an additional $66 \mathrm{~m}^{2}$ of solar collectors were installed and connected to an auxiliary thermal storage system with a volume of $7500 \mathrm{~L}$. The system provided $5.5 \mathrm{~kW}$ cooling capacity at a heating temperature of around $75^{\circ} \mathrm{C}$. The installation was considered a success as cooling was provided at temperatures as low as $55^{\circ} \mathrm{C}$ and due to its large hot water capacity, can provide significant cooling for long periods without significant solar radiation [13].

Much of the research and experimental testing done in the field of solar cooling is within regions that have had large investments into solar heating systems. These regions include Asia, Europe, and the Middle East; where Germany [23] had a large government incentive program for solar heating and cooling initialized in 2011 [24]. Meanwhile research of residential applications of solar cooling remains low in North America at the present time. It is forecasted that the North American market will be the fastest growing solar heating and cooling market before the end of the next decade [25]. The slower adoption rate of this technology in North America could be attributed to the lack of large district heating systems and absence of strong solar cooling incentives. The main differences caused by the location of testing are factors due to climate and solar irradiance. The climate and feasibility of maintaining specific inlet temperatures depend on the outdoor air in cases of heat rejection and cooling temperatures required. In Canada, the chilled water outlet temperature does not need to be as low as a warmer region such as the Middle East, and due to a higher amount of heat rejection being required a cooling tower 
would be needed opposed to a dry cooler that could be used in Canada. Experimental and modelling results for solar adsorption cooling systems vary greatly depending on the weather (outdoor/indoor temperature and solar irradiance) which is determined by the location.

\subsection{Solar Collectors}

When determining what type of solar collector is to be used with a solar cooling system it is important to consider the chillers temperature range. The main benefit for a solar adsorption chiller compared to an absorption chiller is that they can be used with lower driving heat temperature, lining up well with typical hot water temperatures achieved by flat plate solar collectors (FPC). The lower cost of the FPC compared to that of a vacuum tube solar collector makes the FPC a better option in most cases, for residential applications where the capital costs need to remain low to ensure a system is desirable. However, in some applications this can require large $\left(30+\mathrm{m}^{2}\right)$ areas of southern facing roof space to be available for residential applications which may not be possible. A study done by Liu et al. [26] investigates the performance of a micro heat pipe array flat plate collector (MHPAFPC) that has the theoretical maximum instantaneous efficiency of $80 \%$. Their case study has 48 MHPA-FPC with a collection area of $2 \mathrm{~m}^{2}$ and a $5 \mathrm{~m}^{3}$ water tank. The study resulted in an achieved efficiency of $56 \%$ with a daily average of $1050 \mathrm{MJ}$ of effective heat gain and concluded that there is excellent characteristics for large scale solar water collection from MHPA-FPC under different conditions. Such a system could be beneficial to increase the thermal density of standard FPC to reduce the large collector area currently required for some systems, while keeping capital costs low. 
One of the largest complexities for using solar collectors as the driving heat source for solar cooling is their configuration. Different locations, chiller, and system sizing will require the solar collection array to be sized and configured in many different variations on a case-by-case basis where there is benefits from series vs parallel collector setups. A study done by Koussa et al. [27] compares the effect a series or parallel configuration of a solar collector array has on the achievable system temperature and resultant pressure drop. They found that systems with series connected solar collectors achieved a higher system temperature of $70^{\circ} \mathrm{C}$ with 5 collectors compared to $60^{\circ} \mathrm{C}$ of the parallel system. Similarly, a $5^{\circ} \mathrm{C}$ increase was found for the system in series with just two collectors. However, a pressure drop for the system in series was found to be about 10 times higher than that of a parallel system, which would result in a much lower flow rate. In practical applications this large increase in the pressure drop would require more powerful pumps and therefore consume more electricity. Often solar configuration is assumed when modelling solar cooling systems and not optimized due to the systems variance based on the case-by-case requirements.

\subsection{Modelling of Adsorption Systems}

There are various methods of modelling adsorption chillers such as a thermodynamic model, lumped parameter model, and heat and mass transfer model. The thermodynamic modelling approach is a relatively simple approach based on the steady state of the system and are useful for qualitative and semi-quantitative analysis of performance. Often this approach is empirically based and can be system specific. This is the preferred method for studying the influence of temperature/heat transfer on the systems COP and cooling power. Lumped parameter models can be used to assess the transient 
nature of the model in more detail shown by Sah et al. [28], and can be combined with a dynamic modelling approach to combine their strengths used in Bau et al. [29]. The heat and mass transfer approach are the most detailed modelling method and the least used due to the complex nature of the adsorption process used in Schicktanz \& Núñez [30] and Reda et al. [31]. This method uses differential equations to model the system and is the most useful approach when determining optimization design of the system shown by Pandit et al. [32]. Each of these approaches produce models that cannot be widely applicable to every model of adsorption chiller as the models are specific to the physical properties of each type of adsorption chiller (silica-water, silica-ammonia, zeolite-water, etc.), the internal hydraulic design, control strategy, and heat exchanger properties.

Many adsorption chiller models have been created and their results validated with an experimental setup where the goal is to optimize the adsorption chiller itself or the whole solar cooling system (sizing of thermal storage and collection) [29], [30]. However, few models have been used for a detailed energy and economic analysis of the solar adsorption cooling system. Additionally, most models need complex inputs that are not readily available to researchers as they are manufacturer specific, such as the type and mass of the adsorbent. This is where a model that uses experimentally determined performance maps, cycle correction factors, and chiller parameters such as flow rates, max COP and cooling capacity are useful in providing a simpler but not necessarily less accurate approach for producing results representative of the experimental results of a given unit.

As previously mentioned in the adsorption chiller section a study of a small-scale adsorption cooling by Thomas et al. [21] was also modelled. Using the cooling requirements for their research building, the adsorption unit was modelled under steady 
state conditions. Tests were run using temperatures up to $65^{\circ} \mathrm{C}$ for the average hot water inlet temperature. The tests were run over a 36-day summer period in Belgium. When compared to a standard air conditioning unit it was found that the system (chiller, cooling tower, and solar water heater) provided $40 \%$ energy savings over the 36 -day period even with a low electrical COP of 4.69 where the expected value was near 10 . The chiller was then modelled under steady state conditions and compared to the manufacturer's curves. The model was found to reflect the manufactures data for the testing range; however, it was noted that the testing range should be increased to expand the range of their model validity.

A complex mathematical model for a two-bed silica gel-water adsorption chiller was created by Chua et al. [33] to develop an accurate transient model of an adsorption chillers operation. Their chiller model considers the mathematics of heat and mass transfer resistances in the adsorption bed in addition to the temporal energetic behavior in the evaporator and condenser. The simulated results from the model were compared to their experimental results with a great deal of accuracy and were able to represent the cyclic nature of the adsorption chiller. The model that was developed was a simplified 3-D, distributed-parameter approach to determine the transient and steady state performance. In comparison, the other lumped-parameter models the cooling capacity is no longer underpredicted at off-rate conditions allowing for a much more accurate representation of their chiller's experimental performance.

A large benefit to creating a validated model is the ability to test the system in various locations, determine annual performance, and then be able to determine economic results from the simulated data. 


\subsection{Economics of Solar Combination Systems}

A major aspect for determining the feasibility of a solar cooling system for residential use is the system's economic benefits, if any, where a system with high capital costs may become a more cost-effective option when analyzed over their operating lifespan. Common metrics are the lifecycle cost and payback period. A solar combination system provides both solar space heating and cooling as well as domestic hot water from solar thermal collectors.

A study done by Alrwashdeh \& Ammari in Jordan [34], analyzes the life cycle cost between a vapour compression refrigeration system powered by a photovoltaic system and a vapour absorption refrigeration system powered by a solar evacuated tube thermal unit. Their total cost analysis included costs of acquisition, energy, repair, maintenance, disposal, and operation. A LCC method using present worth was used, as this metric considers the total cost of purchase and operation of a system over its entire lifespan with consideration for time value of money by considering inflation. The payback period was also considered where it is determined by the amount of time (in years) it takes to pay off the capital costs of the system when considering the savings from the reduction of operational costs. They found that the PV powered system has a LCC of \$15,578 and PBP of 4.2 years while the absorption system with an evacuated tube array has an LCC of $\$ 17,666$ and PBP of 3.9 years. It was determined that both systems were economically viable due to their PBP being well under the system lifespan of 25 and 20 years, respectively.

A single effect absorption chiller was analyzed in various European cities by Eicker et al. [35] for its performance and economic potential. They determined that absorption 
cooling is only economically viable with sensible and accurate system sizing, with the suggestion that under sizing in moderate climactic conditions would greatly reduce system costs. Where in warmer regions, such as Jakarta, a larger capacity chiller is used as they have the highest solar fractions. They state that the sizing of the absorption system depends on the operating hours, collector size, and additional cooling/heating required. A balance of these three parameters depend on temperatures, usage, and solar potential. Where there are higher electrical rates, the chiller should be sized larger to decrease operating cost, while lower rate regions can utilize as smaller chiller to reduce capital costs. It was found that due to the high investment costs for absorption chillers and solar thermal systems the PBP was often longer than the system lifespan with their best case having a PBP of 17 years. The environmental impact was found to be a reduction of 30 to $80 \%$ of the $\mathrm{CO}_{2}$ emissions compared to traditionally installed systems.

Narayanan [36] used TRNSYS to simulate and perform a techno-economic analysis of a single stage Type 107 absorption chiller. They determined that with a capital cost of $\$ 82,000$ for the solar adsorption system compared to $\$ 13,000$ for an air conditioner system (16 unit) provided a simple payback period of 13.6 years, where it takes 15.5 years for the solar absorption system to pay off its initial investment. They noted that the inflation of electricity prices was not taken into consideration. Due to the large potential for solar radiation in India they found that this type of system is feasible for larger scale applications but may not necessarily scale down to smaller residential use.

A solar thermal-driven two-bed adsorption chiller was economically analyzed by Alahmer et al. [37] for Australian applications. The system used an adsorption chiller capable of reaching $11 \mathrm{~kW}$ of cooling output connected to a $38 \mathrm{~m}^{2}$ solar collector. The 
capital cost of the adsorption chiller was $\$ 2100$ USD per $\mathrm{kW}$ and $\$ 260$ USD per $\mathrm{m}^{2}$ for the solar collectors. This system was found to have a PBP of 11 years and LCC savings of $\$ 3500$. They determined that with a solar collector cost lower then $\$ 700 / \mathrm{m}^{2}$ the solar cooling system would be feasible for residential applications. This system is similar to size of the system analyzed in this thesis, however in this analysis the installation and maintenance costs do not seem to be considered, whereas a salvage return of $20 \%$ of the capital cost is. The standard system the adsorption chiller system is being compared to is also not specifically mentioned.

\subsection{Areas of Limited Research}

Some areas where more solar cooling research needs to be done are the experimental, simulation, and economical analysis of an adsorption cooling systems in a Canadian climate for residential, specifically with a flat plate solar water collector. In comparison there is a larger amount of research on absorption chillers in North America, likely due to their higher efficiency compared to adsorption chillers. Compared to other locations investigated commonly researched, Ottawa has low-mid potential of solar irradiance. The annual solar potential for Ottawa is about $1200 \mathrm{kWh} / \mathrm{m}^{2}$ while it is approximately 2100, 1500, and $1100 \mathrm{kWh} / \mathrm{m}^{2}$ for Los Angeles, New York City, and Munich, respectively [41]. Due to a large difference in global location, solar insolation and zenith angle vary with latitude. Additionally, Ontario has higher cooling loads in short time periods (large peak loads) during the summer months due to air conditioning loads. This thesis provides an insight for the potential performance capabilities of adsorption cooling in Ontario. Often models are created for the purpose of optimizing the design of an adsorption chiller, which requires precise and accurate calculations of the processes 
occurring within each component of the adsorption chiller. Creating a model that can determine these temperatures with a relatively high degree of accuracy using a performance map from experimental results will allow for systems to be analyzed for feasibility for residential building loads. This thesis uses an empirical model of a silica-gel adsorption chiller with a solar water heater for performance analysis of residential buildings in various cities across Canada. The adsorption chiller model uses data from an experimentally determined performance map to calculate the heat transfer rates from the cooling, heat rejection, and heating loop. Using the adsorption model, a solar adsorption system model was created to be simulated in different locations across Canada. Additionally, traditional heating and cooling systems were also simulated to be compared with the performance of the adsorption system. The annual results are then used to perform an economic analysis and determine locations in Canada that benefit the most from residential applications. Comparing costs used to other studies it seems there is a large variance in the accepted value for solar collectors, which can make it very difficult to cross compare results from different studies. In this thesis, an economic analysis is performed using realistic values for solar collection based off present data. This approach provides a look at the PBP for solar adsorption systems in Canada and suggests how the future trends for electrical rates and carbon prices may influence the technologies economic feasibility. 


\section{Chapter 3: Experimental Setup}

As described in Chapter 2, the literature is limited on the topic of the economic feasibility for adsorption chillers especially for regions in Canada. An experimental setup was created to test the adsorption chiller and create a performance map that would later be used in an empirical model. Using this model, a techno-economic analysis was conducted for various locations across Canada to determine system performance, PBP, LCC, etc. This section describes the equipment used and how the system was configured and calibrated. An uncertainty analysis is presented at the end of the chapter.

\subsection{System Layout}

Previous work conducted at Carleton University by Bowie et al. [38] involved the evaluation of an absorption chiller which used lithium bromide as the working medium. In this study a silica-gel adsorption chiller replaced the previous absorption chiller, and the system was modified to provide the higher flow rates required. The general layout of the lab equipment can be seen in Figure 3.1. A more detailed schematic can be found in Appendix A, showing the dry cooler, heat exchanger and control valve for the hot water loop. 


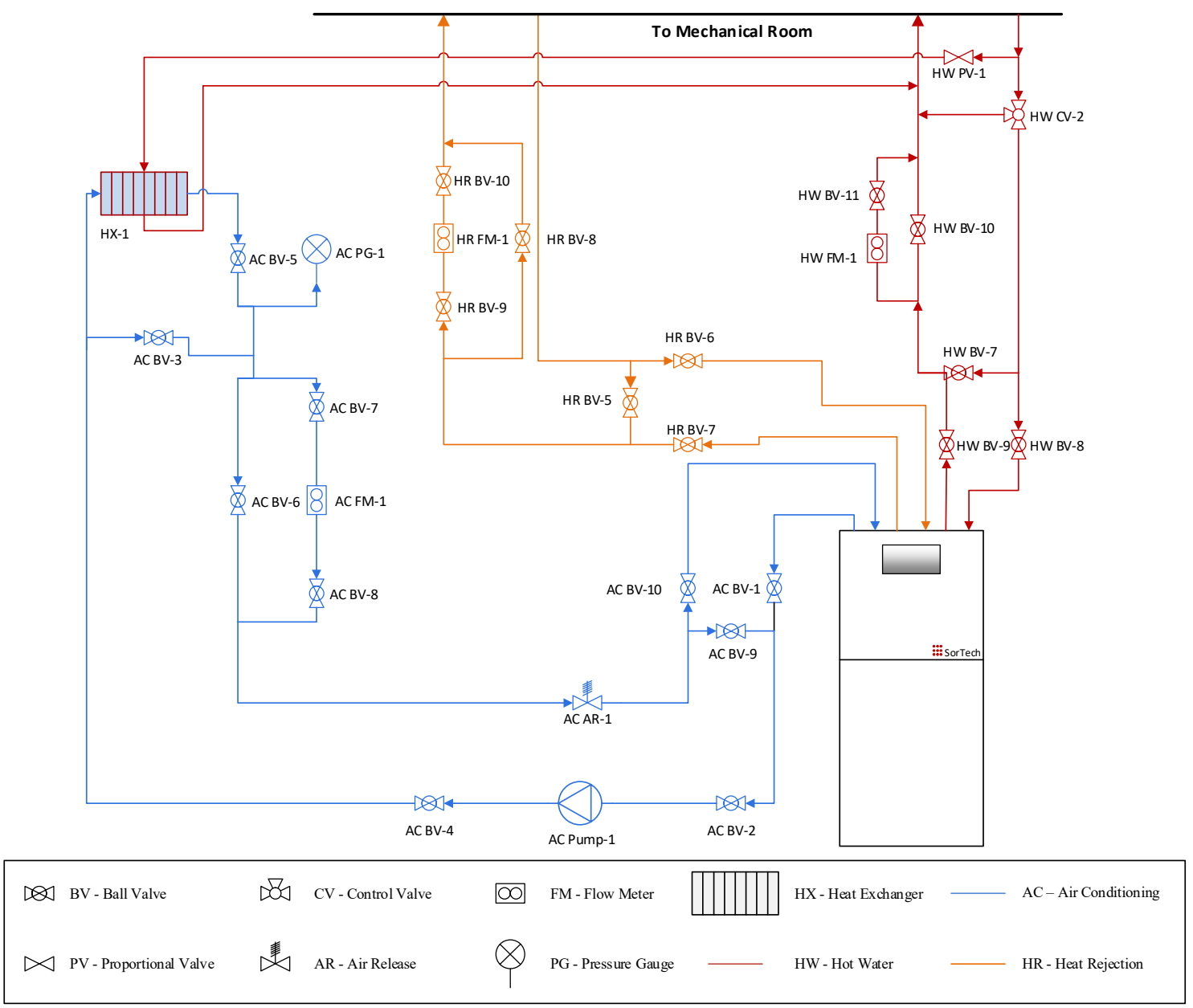

Figure 3.1: Experimental system schematic

The modifications required increasing the flow potential in the cold-water loop and connecting all the inlets and outlets of the chiller up to their respective partners of the existing setup. The air-conditioning (AC) loop was modified to provide a constant AC inlet temperature by adding heat through a heat exchanger (seen as $\mathrm{HX}-1$ in Figure 3.1) to simulate a building load using the cooling power provided. There are 3 main loops for this setup: the hot water (HW), heat rejection (HR), and air conditioning (AC) loops. These loops are explained in further detail in the following sections. 


\subsubsection{Heat Input}

The system has a hot water (HW) supply line that is connected to the buildings steam supply through a heat exchanger and modulated by a control valve, allowing for control of the water temperature up to a programmed maximum allowed temperature of $95^{\circ} \mathrm{C}$ due to safety restrictions. The range the system can vary between is 50 to $95^{\circ} \mathrm{C}$ with a flow rate of up to $42 \mathrm{~L} / \mathrm{min}$.

\subsubsection{Heat Rejection}

A heat rejection (HR) line is connected to a dry cooler on the roof of the building capable of rejecting $40 \mathrm{~kW}_{\text {th }}$ at a temperature difference of $5^{\circ} \mathrm{C}$. The range for this line is 22 to $30^{\circ} \mathrm{C}$ with a flow rate of 70 to $80 \mathrm{~L} / \mathrm{min}$. The highest efficiencies for the HR line occur at the lower end of the temperature range, allowing for more heat to be rejected. In parallel with the dry cooler on the roof, the system is connected to the chilled cooling water in the building, allowing for temperatures to be consistently met year-round, even when the outdoor dry bulb temperature exceeds the required testing setpoint.

\subsubsection{Cooling Loop}

The chilled water line $(\mathrm{AC})$ is a closed loop from the chiller outlet to the inlet with an intermediate heat exchanger which reheats the line to the AC inlet setpoint. The flow through the HW line is controlled by a proportional valve to allow some flow through the heat exchanger. In a practical application the cooling water would be passed through a liquid to air heat exchanger to cool the air circulating throughout a house, while the cooled fluid in excess could be stored in a water tank for use later. The temperature range for this line is 10 to $22^{\circ} \mathrm{C}$ with a flow rate of $48 \mathrm{~L} / \mathrm{min}$. 


\subsubsection{Simulated Heat Input}

The experimental setup was modified to modulate the heat input to the hot water line in order to simulate the heat input from a flat plate solar collector in order to test the performance of the chiller over a day using solar driven heat. A program was created that used a Canadian Weather Year for Energy Calculation dataset 2016 (CWEC) file for the Ottawa International Airport $\left(45^{\circ} 19^{\prime} 12.0^{\prime \prime} \mathrm{N} 75^{\circ} 40^{\prime} 12.0^{\prime \prime} \mathrm{W}\right)$ to calculate the solar heat input that could be produced by a flat plate solar collector. The calculated solar heat input was then converted into a voltage value and sent to a PI controller that actuates the control valve which varies the heat transfer from the steam line into the hot water line. Examples of the solar profiles used can be seen in Figures 3.2 and 3.3.

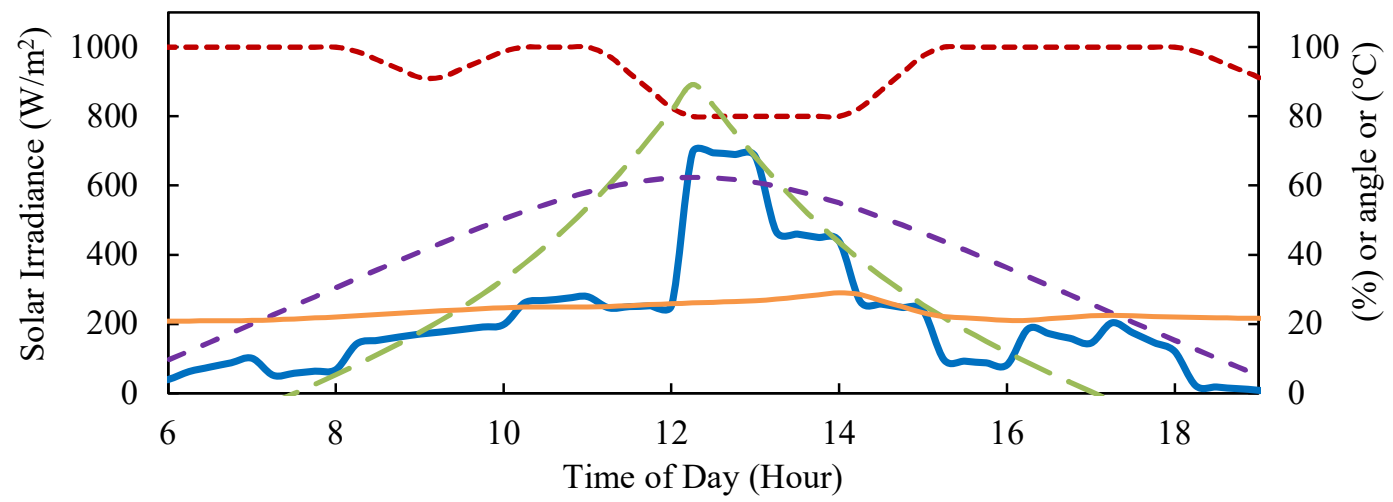

Radiation ----. Cloud Cover - - Azimuth - - Zenith — Amb. Temperature

Figure 3.2: CWEC Weather data used for August $1^{\text {st }}$

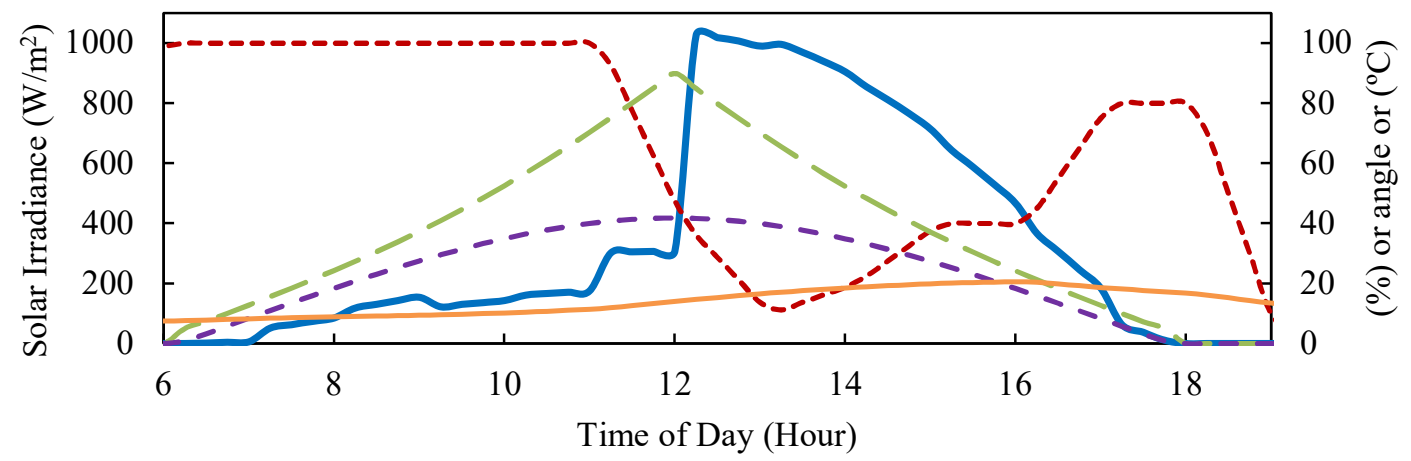

Radiation ----Cloud Cover - - Azimuth - - Zenith — Amb. Temperature

Figure 3.3: CWEC Weather data used for September 29th 
Figure 3.2 represents a summer day (August 1st) with high cloud cover while Figure 3.3 represents an early fall day with high cloud cover during half the day. In the summer day with high cloud cover the amount of radiation available is fairly suppressed, with the exception of around noon. The cloud cover in the fall day suppresses the radiation during the morning but once the clouds clear the typical parabolic trend of radiation returns.

The heat input from a solar array was calculated using Equation 3.1,

$$
P=A \cdot n \cdot \mathrm{rad} \cdot \mathrm{IAM} \cdot \mathrm{eff} .
$$

where $P$ is the power input (in watts) to the hot water line, $A$ is the solar collector panel area, $n$ is the number of panels in the array, rad. is the solar irradiance available, IAM is the incident angle modifier which is an effect of the sun angles, and eff. is the heating efficiency which is affected by the difference of the water and ambient temperature. From the efficiency graph of commercially available flat plate solar collector [42], the Equation 3.2 was created.

$$
e f f=e f f_{\max }-\frac{\left(T_{f}-T_{a}\right)}{I}=0.75-\frac{\left(T_{f}-T_{a}\right)}{200}
$$

where $T_{\mathrm{f}}$ is the average fluid temperature throughout the solar collector, $T_{\mathrm{a}}$ is the ambient air temperature, $I$ is the efficiency factor of the panel, and $e f f_{\max }$ is the maximum panel efficiency factor. The IAM must be considered for both the azimuth and zenith angles of the sun relative to the solar collector's position. The data from Table 3.1 was used to find the IAM for these angles [43].

Table 3.1 Flat plate solar collector IAM-angle relations

\begin{tabular}{|c|c|c|c|c|c|c|c|c|c|c|}
\hline Angle & $0^{\circ}$ & $10^{\circ}$ & $20^{\circ}$ & $30^{\circ}$ & $40^{\circ}$ & $50^{\circ}$ & $60^{\circ}$ & $70^{\circ}$ & $80^{\circ}$ & $90^{\circ}$ \\
\hline IAM & 1.0 & 1.0 & 0.99 & 0.98 & 0.96 & 0.93 & 0.87 & 0.74 & 0.38 & 0 \\
\hline
\end{tabular}


The angle specified is that of the sun with respect to the center of the solar collector, where $0^{\circ}$ is perpendicular to the collector and $90^{\circ}$ is parallel to the collector. The necessary information used for testing regarding the solar collector can be found in Table 3.2.

Table 3.2: Simulated solar collector data

\begin{tabular}{c|cc}
\hline Variable & Value & Unit \\
\hline$A$ & 2.8 & $\mathrm{~m}^{2}$ \\
$n$ & 10 & panels \\
$\theta$ & 45 & $\circ$ \\
dir. & Due South & N/A \\
\hline
\end{tabular}

Where $\theta$ is the angle of the solar collector with respect to the horizontal (ground) and dir. is the direction the solar collector is oriented.

Using performance data from a solar collector available on the market, the angle of incidence and solar collector efficiency were included in the calculated heat input. From the calculated heat input, and using the hot water loop flow rate, the increase of power into the line was determined and the control valve controlling the heat input to the hot water line was adjusted accordingly using a PID controller to follow the requested (calculated) heat input. This hot water control system can be seen to closely match the requested heat input by Figure 3.4 .

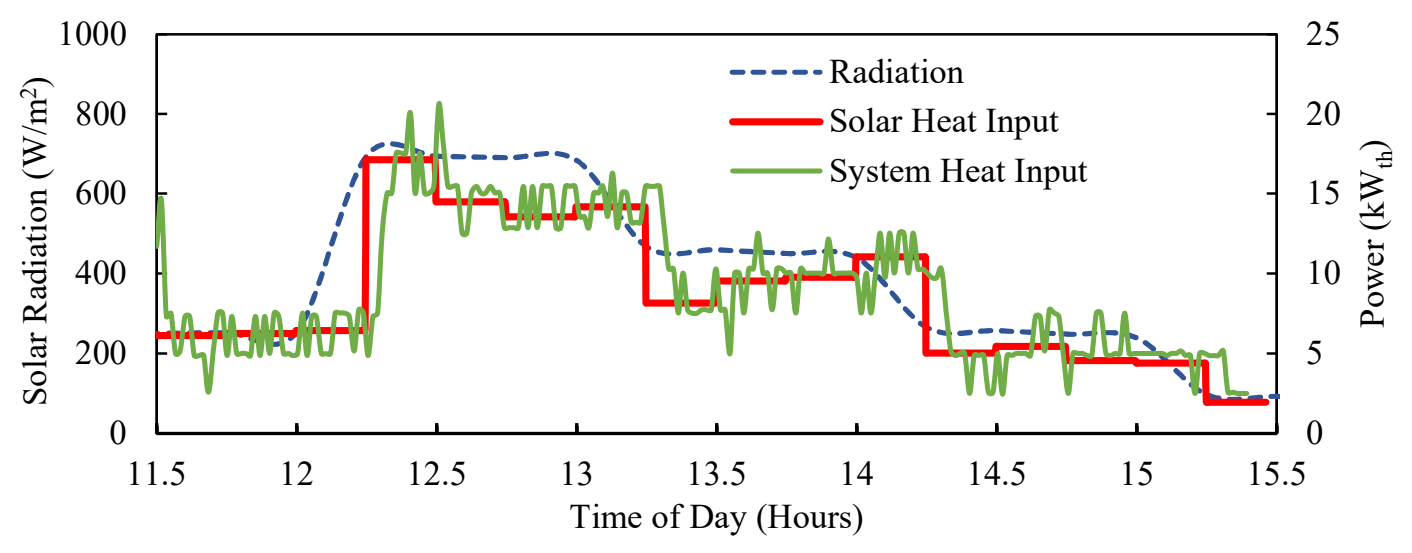

Figure 3.4: Simulated heat input following requested power input 
The solar heat input $\left(\mathrm{kW}_{\text {th }}\right)$ is shown in orange where the actual heat input to the system from our control system is shown in grey and it followed the pattern of the radiation closely.

\subsection{Testing Methods}

Two types of tests were run, one with a constant hot water inlet temperature (CIT) and another with a varying hot water inlet temperature. The test using a varying hot water inlet temperature is used to simulate hot water temperatures from using a flat plate solar collector array. The temperature dynamically adjusts during the test based off the heat input calculated by equations for a flat plate solar collector (Equation 4.1) using radiation data from a weather file. This test is referred to as a dynamic inlet temperature test (DIT).

\subsection{Main Components}

This section will go over the main pieces of equipment for the system, their specifications, and where they are used in the system.

\subsubsection{Solar Adsorption Chiller}

The adsorption chiller used for this research was purchased directly from the manufacturer, SorTech. The unit purchased was a SorTech eCoo 2.0 Silica gel IP20 Adsorption Chiller which has a max cooling capacity of $16 \mathrm{~kW}$ th. The system requirements and ranges of operation can be seen in Table 3.3 and tested performance of the chiller as stated by the manufacturer is shown in Table 3.4. 
Table 3.3: Adsorption chiller test setup specifications

\begin{tabular}{c|cc}
\hline Parameter & Value & Unit \\
\hline Cooling capacity & 16 & $\mathrm{~kW}_{\text {th }}$ \\
COP & 0.6 & - \\
HW inlet & $50-95$ & ${ }^{\circ} \mathrm{C}$ \\
HW FR & 42 & $\mathrm{~L} / \mathrm{min}$ \\
HR inlet & $22-35$ & ${ }^{\circ} \mathrm{C}$ \\
HR FR & 80 & $\mathrm{~L} / \mathrm{min}$ \\
AC inlet & $8-22$ & ${ }^{\circ} \mathrm{C}$ \\
AC FR & 48 & $\mathrm{~L} / \mathrm{min}$ \\
\hline
\end{tabular}

Table 3.4: Achieved chiller performance as stated by manufacturer

\begin{tabular}{|c|c|c|c|}
\cline { 2 - 4 } \multicolumn{1}{c|}{} & \multicolumn{3}{|c|}{ Cooling output } \\
\cline { 2 - 4 } \multicolumn{1}{c|}{} & $13.5 \mathrm{~kW}_{\text {th }}$ & $11 \mathrm{~kW}_{\text {th }}$ & $10 \mathrm{~kW}_{\text {th }}$ \\
\hline $\mathrm{HW}\left({ }^{\circ} \mathrm{C}\right)$ & 85 & 85 & 65 \\
$\mathrm{HR}\left({ }^{\circ} \mathrm{C}\right)$ & 27 & 27 & 27 \\
$\mathrm{AC}\left({ }^{\circ} \mathrm{C}\right)$ & 15 & 12.7 & 16 \\
\hline
\end{tabular}

The performance as stated by the manufacturer was able to be achieved by the experimental setup, allowing the chiller to be determined to be in good working order.

\subsubsection{Pumps}

Each hydraulic line for this system has its own pump feeding the chiller, allowing for the internal pumps to only need to make up for the pressure drop across the chiller itself. The AC line has a Grundfos CRE 3-2, shown in Figure 3.5, the HR and HW line each have a Grundfos CR 5-4. A control loop was developed within LabVIEW to keep a constant flow rate through a changing $0-10 \mathrm{~V}_{\mathrm{DC}}$ signal sent to the pump. These pumps all have onboard variable speed drives allowing them to be controlled with a 0 to $10 \mathrm{~V}$ signal from the LabVIEW program's setpoint. The HR and HW pumps are located within the mechanical room and are not seen in Figure 3.1. 


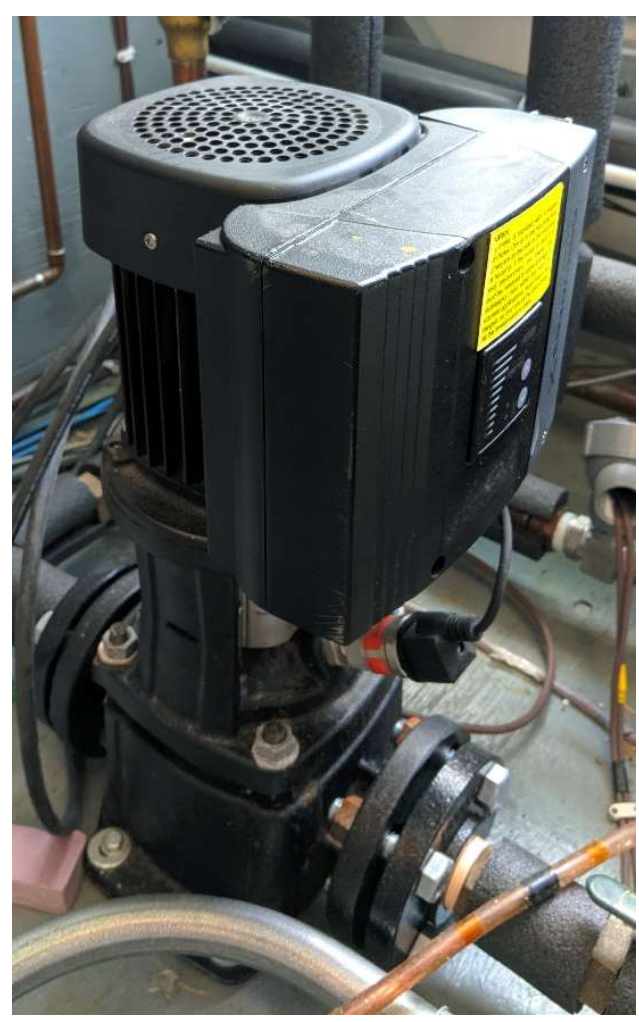

Figure 3.5: Grundfos CRE 3-2 for AC line

\subsubsection{Heat Exchangers}

There is one heat exchanger located within the lab and three located in the mechanical room. The heat exchanger in the lab space is connected to the $\mathrm{AC}$ line and heats the chilled AC fluid to the desired AC inlet temperature, mimicking a building load. This heat exchanger is a HEX BL26C-30D and a capacity of 5kW, shown in Figure 3.6. 


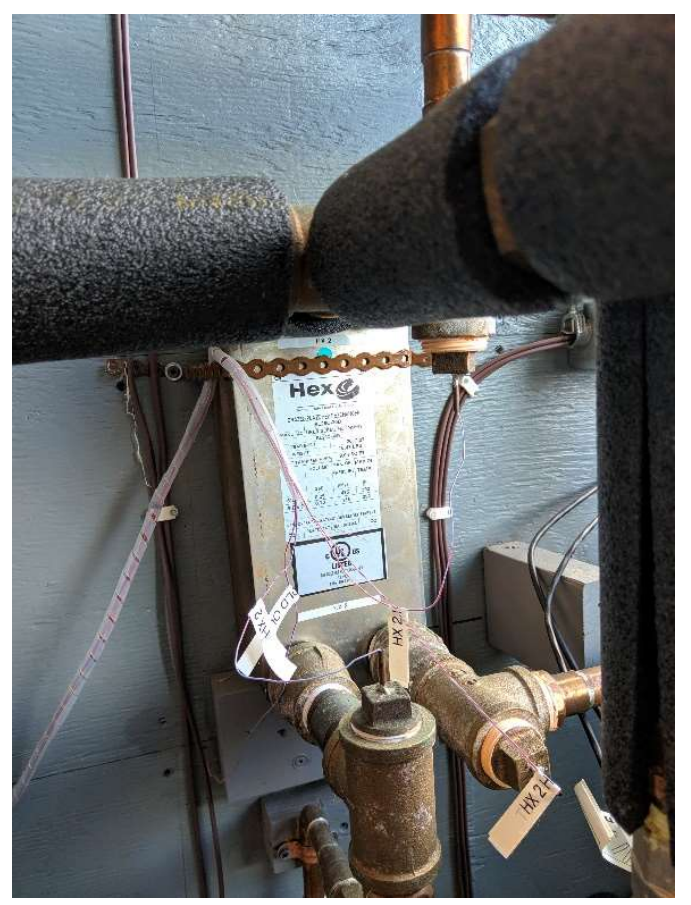

Figure 3.6: AC load heat exchanger

This heat exchanger has fluid from the AC line circulating from the bottom left to the top left, while fluid that was branched off the hot water line flows through the heat exchanger from top right to bottom right.

In the mechanical room there is a heat exchanger which is responsible for supplying the heat to the HW line from the building steam supply line. This heat exchanger is a Preston Phillips Inc. PPSCF-300-11W capable of $200 \mathrm{~kW}_{\text {th }}$ but will not exceed $30 \mathrm{~kW}_{\text {th }}$ due to latent heat loss within the heat exchanger. The remaining heat exchangers are connected to the HR line, where the Alfa Laval CB30-70H heat exchanger with $42.8 \mathrm{~kW}_{\text {th }}$ capacity is connected to the dry cooler's glycol line and the Alfa Laval CB27-34L heat exchanger with $46.5 \mathrm{~kW}_{\text {th }}$ capacity is connected to the building's chiller water line. The dry cooler used in the system is capable of $20 \mathrm{~kW}_{\text {th }}$ at a temperature difference of $5^{\circ} \mathrm{C}$. 


\subsubsection{Control Valves}

There is a proportional control valve (BELIMO TFB24-SR) that is controlled by the LabVIEW program to supply hot water to the heat exchanger which is heating the AC line up to the desired inlet temperature, ranging from $\left(10\right.$ to $\left.22^{\circ} \mathrm{C}\right)$, and is pictured in Figure 3.7.

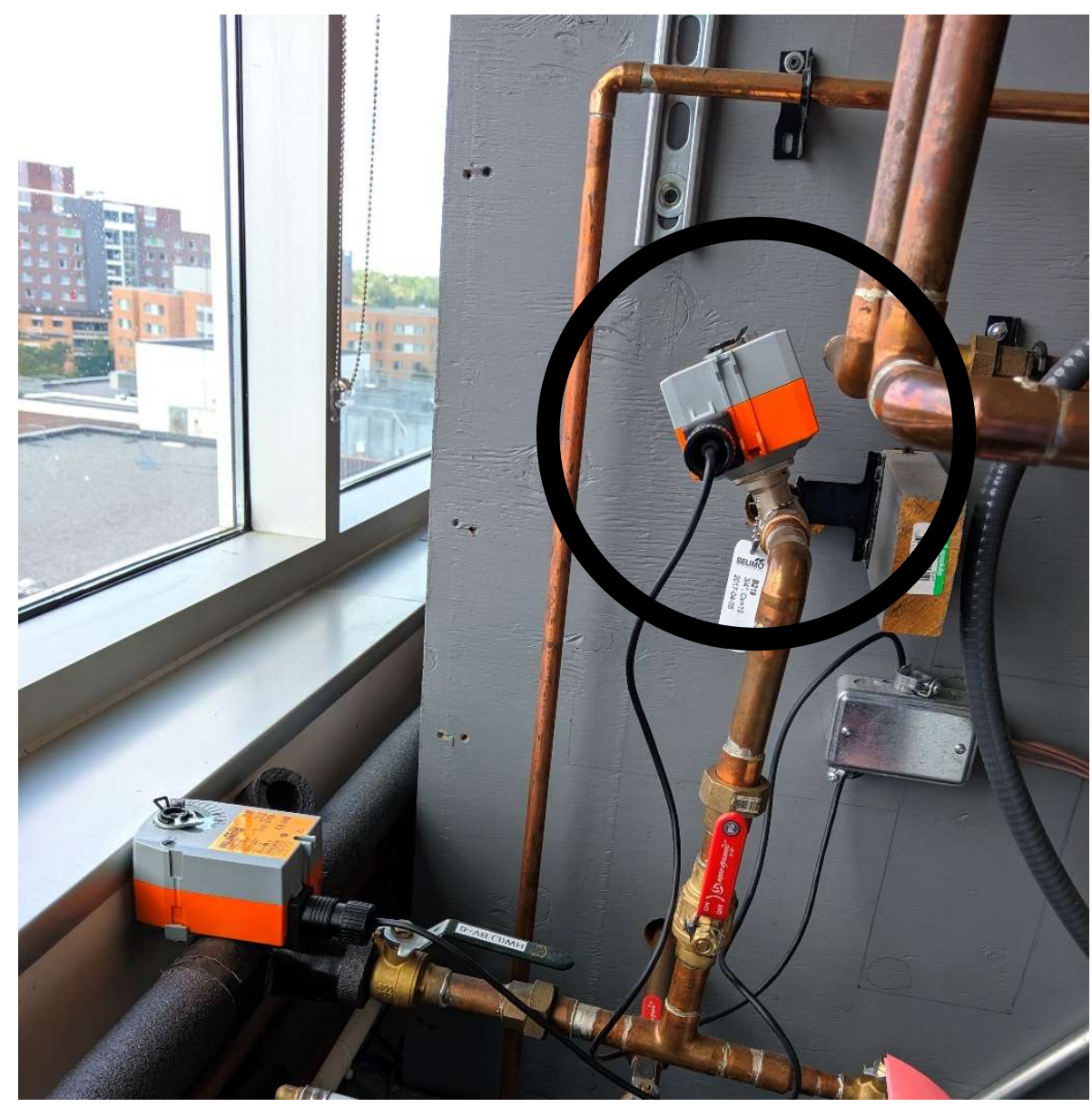

Figure 3.7: Proportional valve used to modulate load on AC line

There are control valves in the mechanical room (BELIMO LF24-SR) that vary position based off season and by the LabVIEW program. In the winter when it is cold outside the mains water is used rather than diverting fluid outside to prevent the glycol solution from freezing. The amount of heat being allowed into the HW line is adjusted by 
a control valve supplying the steam to the heat exchanger, this is controlled through a Delta controller which was also integrated into the main LabVIEW program.

\subsection{Instrumentation}

The following section describes the instrumentation used in this experimental setup and their specifications.

\subsubsection{Thermopiles \& Thermocouples}

The thermopiles and thermocouples were installed into this system by a previous graduate student and the exact details on the calibration and installation can be found in Baldwin [44].

The inlet and outlet temperatures for each hydraulic line to the chiller are measured by thermopiles which consist of 5 type-T thermocouples, which is shown in Figure 3.8.

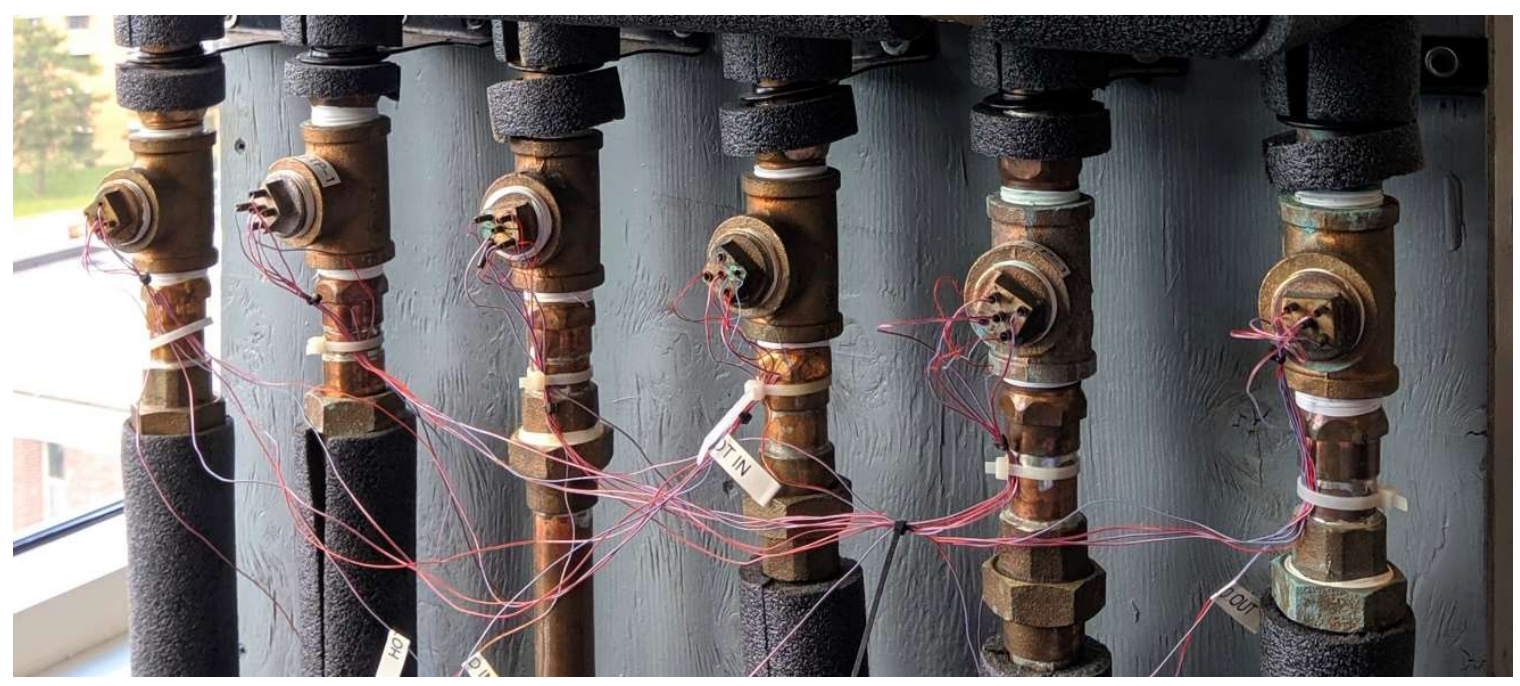

Figure 3.8: Thermopiles on each inlet and outlet line

The thermocouples are constructed using 30-gauge type-T thermocouple wire made of copper and a copper-nickel alloy (constantan). The thermocouples were inserted into custom built thermowells to measure the fluid stream rather than the pipe wall. Making use 
of a standard brass plumbing tee and a brass cap, a small $3.175 \mathrm{~mm}[0.125$ "] copper pipe 101.6mm [4.0"] long was inserted and soldered to the brass cap, pictured in Figure 3.9.

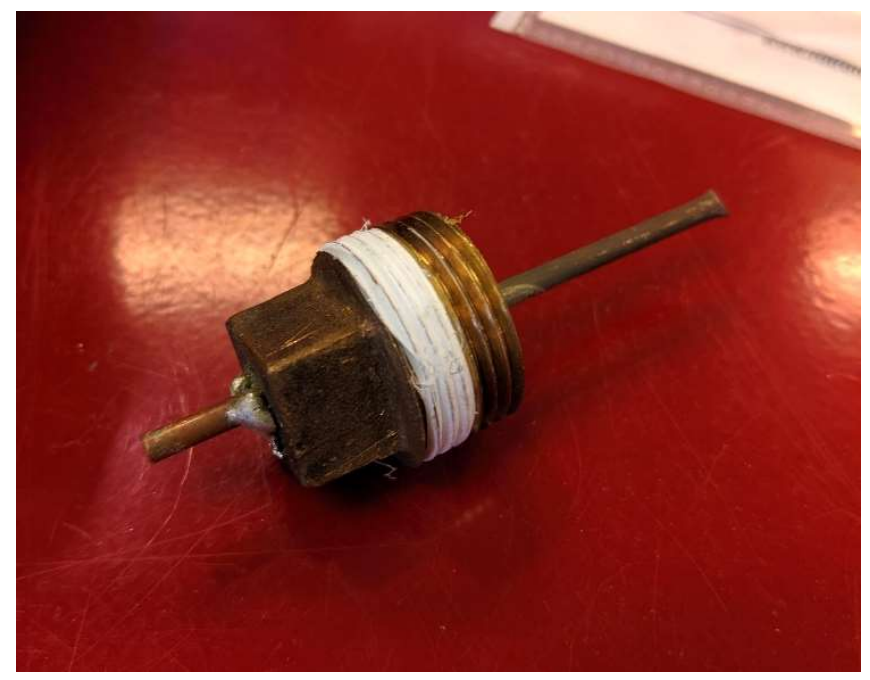

Figure 3.9: Custom made thermowell

A thermocouple was inserted into this small pipe, where the end of the pipe was crimped preventing fluid from entering. This was installed into the brass tee in the direction of the flow, as indicated by the white arrows in Figure 3.10. The back side of the small pipe was covered in tape to prevent air from entering and contacting the thermocouple.

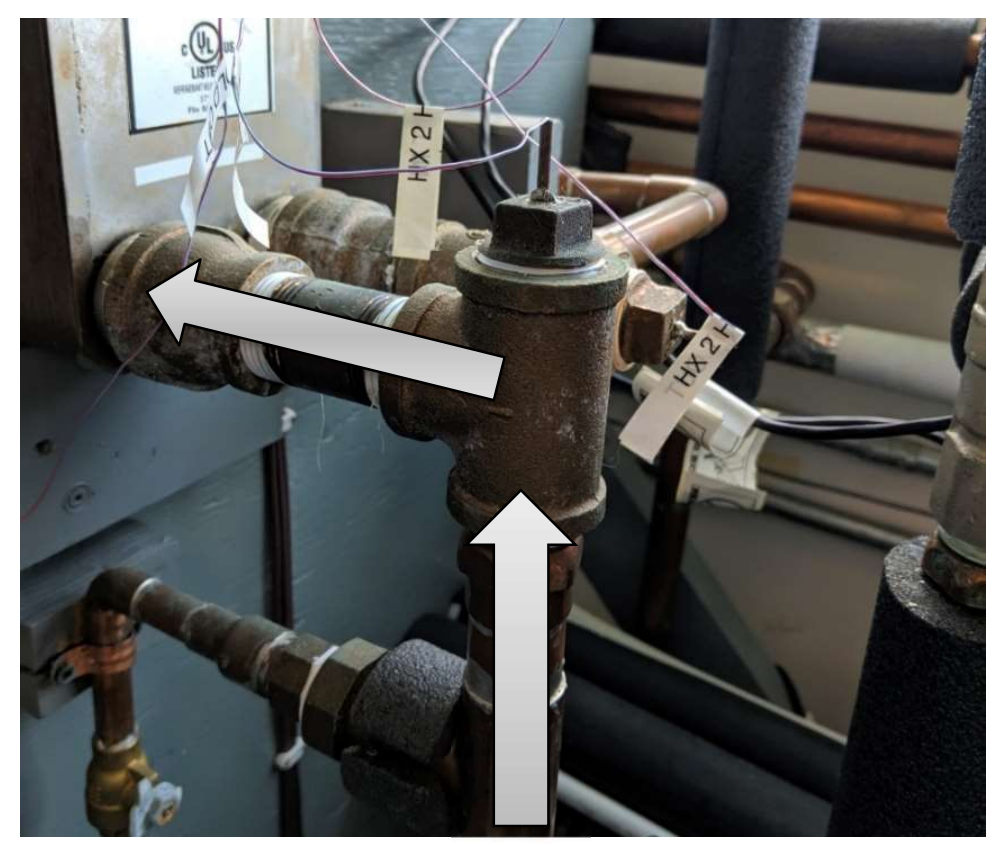

Figure 3.10: Installed orientation of a thermowell 
A thermopile uses multiple thermocouples to reduce the error on the emf reading from the data acquisition unit, allowing for a higher accuracy reading across the inlet and outlet for each fluid line. A thermopile considers the temperature difference between the hot and cold side of the fluid line they are installed in, so the error associated with determining the cold junction temperature is eliminated as the cold side acts as the cold junction temperature. Four junction thermopiles were used in this experiment. The reading error from having one thermocouple $\pm 0.7^{\circ} \mathrm{C}$ is reduced to only $\pm 0.15^{\circ} \mathrm{C}$ for having a thermopile.

The thermocouples were all calibrated using a constant temperature bath, more details can be found in Baldwin [44] and a summary is given in Chapter 4: Calibration and Uncertainty Analysis.

\subsubsection{Flow Meters}

The flow rates (FR) for each hydraulic line are measured after exiting the chiller and the mass flow rates are calculated at this point. The mass flow rate is assumed to be constant throughout the unit due to the integrated pumps within the chiller that make up for the pressure drop. Blancett 1100 series turbine style flow meters, seen in Figure 3.11, were used with Blancett B220-885 K-factor scalers which convert the signal from the magnetic pickup to a digital signal for the DAQ to process. 


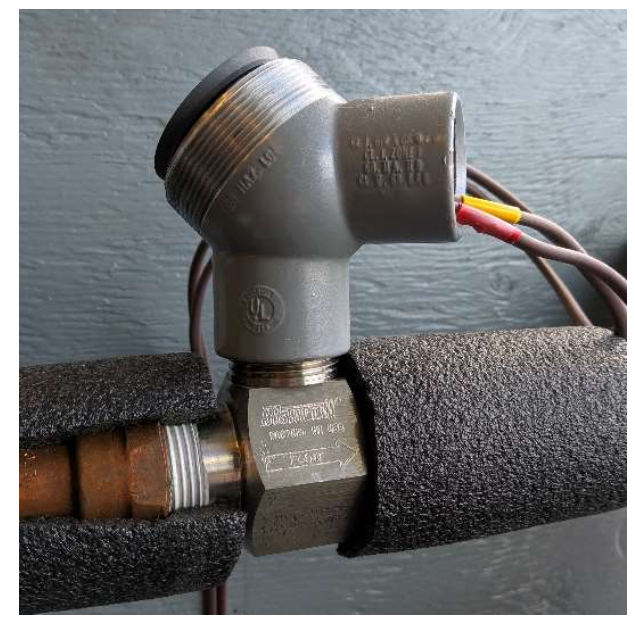

Figure 3.11: Blancett 1100 series flow meter

The turbine flow meters have a small turbine in line with the flow which spins as fluid passes through. The magnetic pulse is picked up by the K-factor scaler, which is above the turbine, and converts the magnetic pulse to an electrical pulse which is read by the DAQ. Using a counting card in the DAQ, the total fluid that passed during a given period can be determined using the K-factor for the specific flow meter. The specifications of the flow meters can be seen in Table 3.5.

Table 3.5: Installed flow meter specifications

\begin{tabular}{c|c|c|c}
\hline Fluid Line & Model \# & Capacity L/min [GPM] & K-factor \\
\hline HW & IB39-B110-875 & $7.5-57.0[2.0-15.0]$ & 305 \\
\hline HR & IB39-B110-750 & $11.0-113.5[3.0-30.0]$ & 25 \\
\hline AC & IB39-B110-875 & $7.5-57.0[2.0-15.0]$ & 30 \\
\hline
\end{tabular}

\subsubsection{Data Acquisition}

All the instrumentation installed in this system, not including the internal sensors in the chiller, are connected to a National Instruments NI cRIO 9024 CompactRIO data acquisition system. This system allowed for monitoring of instrumentation and the sending of signals through its various input output (I/O) cards controlled by a LabVIEW program. 
This system uses 6 cards in the lab; there are three NI 9214 isothermal thermocouple input cards used to measure the thermocouples and thermopiles, one NI 9476 $24 \mathrm{~V}$ digital output card used to provide power to the flow meters, one NI 92640 to $10 \mathrm{~V}$ analog output card to provide control signals to the pumps and control valves, and one NI $942224 \mathrm{~V}$ sink/source to count the digital pulses from the flow meters. The NI 9476 card can be seen in Figure 3.12 connected to the cRIO chassis.

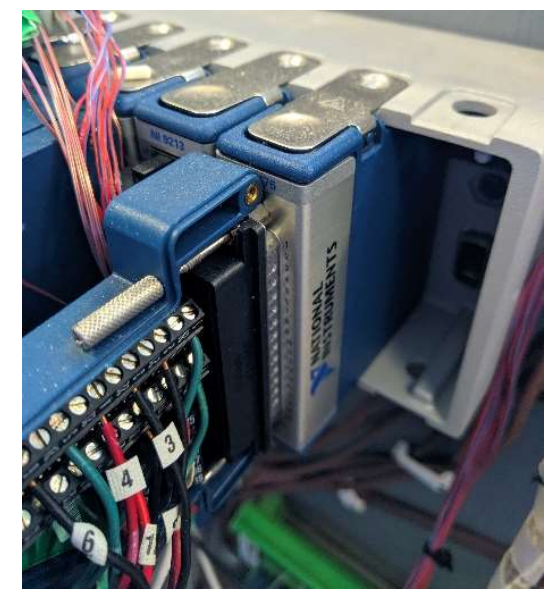

Figure 3.12: NI Data Acquisition equipment

A custom virtual interface (VI) created in LabVIEW us used to control and operate the experimental setup, shown as Figure 3.13. During operation of the system data files are generated as comma separated values (.csv) to be processed in Excel or MATLAB. 


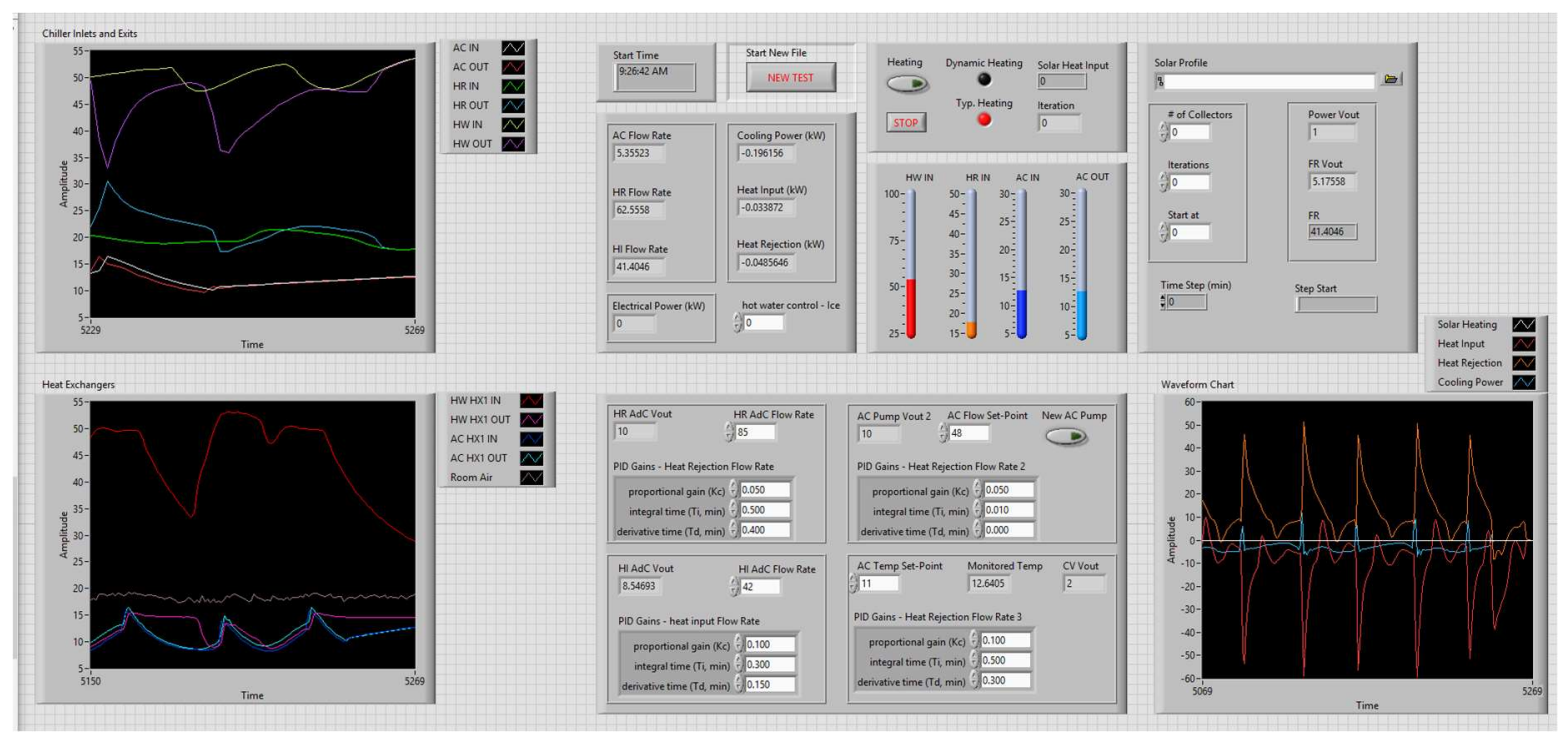

Figure 3.13: NI LabVIEW virtual interface

The lab is located in a building that uses Delta controls for building automation so in order to control diversion of steam (heat source) to our lab's hot water line a small delta controller (DAC-1600) is used to relay LabVIEW outputs into the Delta system, which is shown in Figure 3.14. 


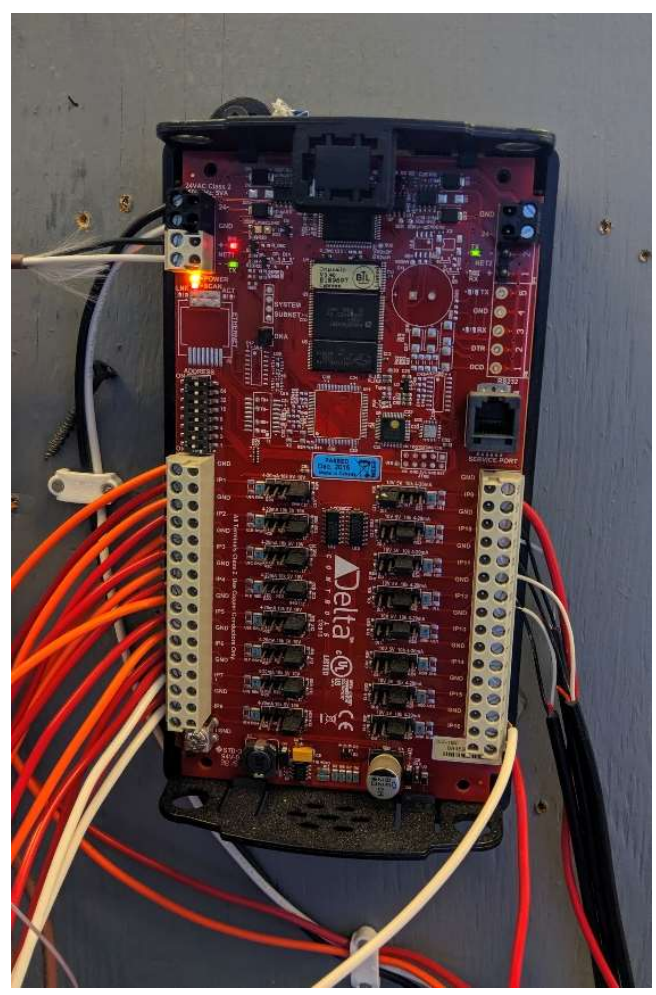

Figure 3.14: Delta DAC-1600

The Delta controller was used to relay the digital output from the LabVIEW program, into the Delta network as a digital input that was then sent through the laboratory's building automation network to control the heat (steam) input control valve.

\subsection{Commissioning}

Once the setup was completed, a series of tests across the performance range of the chiller were performed to establish if the system was performing to manufacturer specifications. These "calibration" test results can be seen in Figure 3.15 to Figure 3.17 and use constant $\mathrm{HW}, \mathrm{HR}, \mathrm{AC}$ of $85^{\circ} \mathrm{C}, 25^{\circ} \mathrm{C}, 16^{\circ} \mathrm{C}$ when they are not specifically set to vary. 


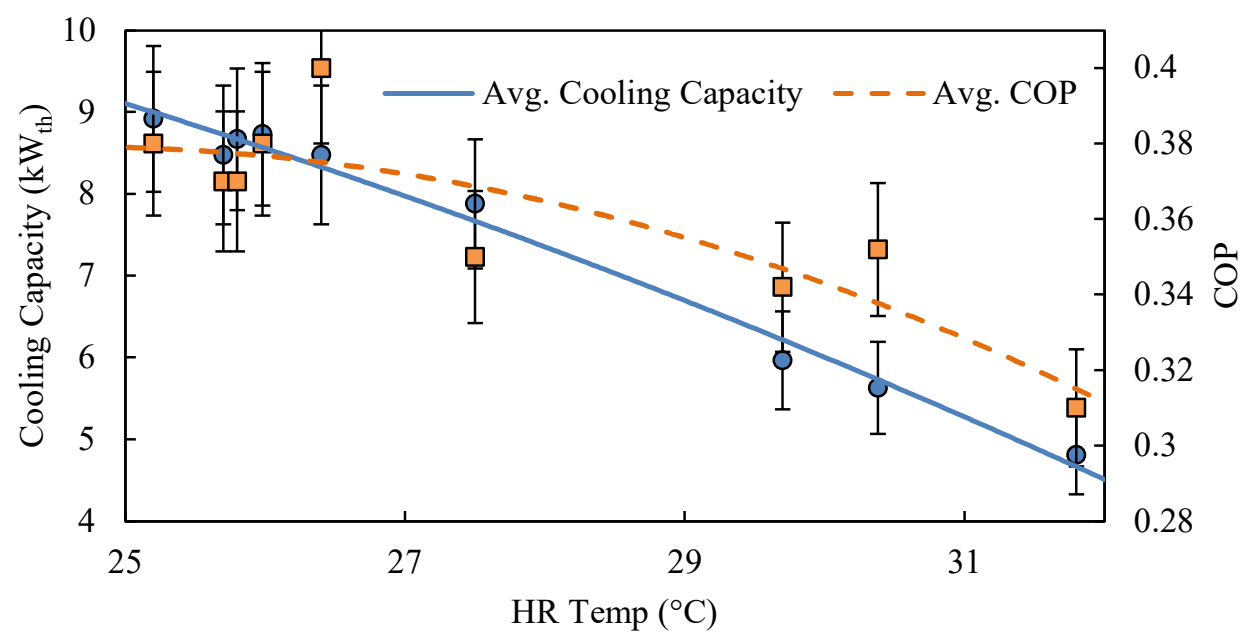

Figure 3.15: Initial commissioning tests varying HR temp

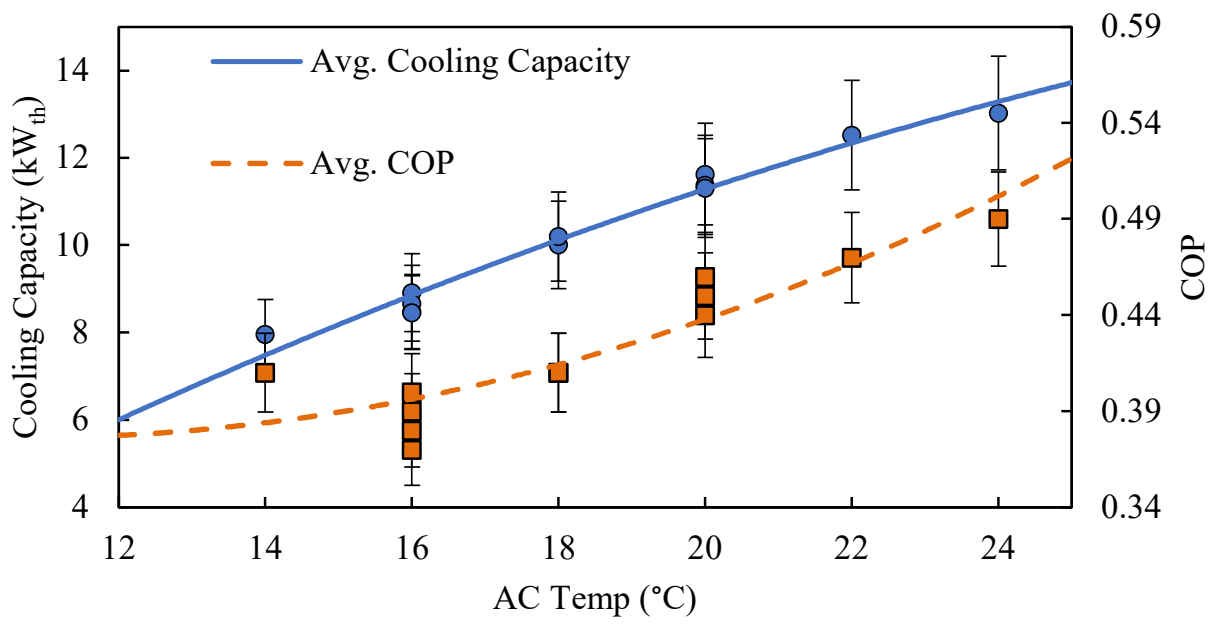

Figure 3.16: Initial commissioning tests varying AC temp

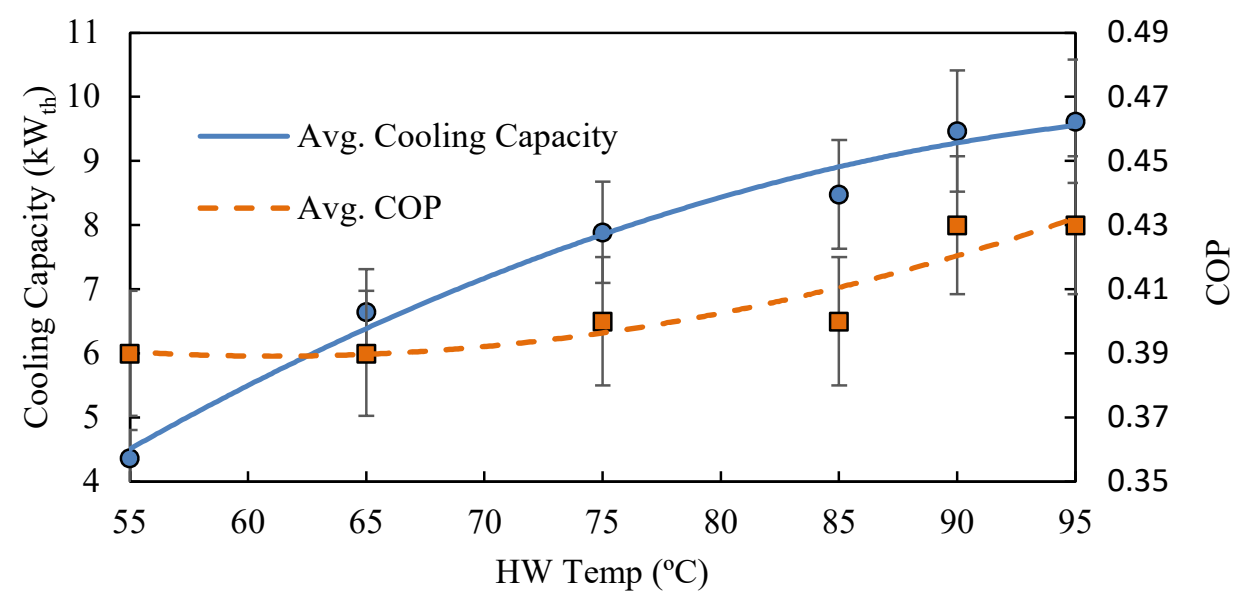

Figure 3.17: Initial commissioning tests varying HW temp 
Each point on the graph represents an entire 4-hour test where the setpoints were held constant and the average value was used. The energy balance across the chiller was calculated and matched with the data to confirm there was no unexpected energy losses. The results are slightly lower than that of the cooling outputs claimed by the manufacturer but are as expected as they likely perform the tests under idealized flow rates and pressures for maximum results.

The next step in the research was to develop a model of the adsorption chiller based off the experimental data in order to perform simulations with a house model. These simulations will compare different system configurations commonly found in houses across Canada, such as electric/gas furnace, heat pump, and air conditioner, to solar adsorption systems. The cooling and economic performance with various system setups will be analyzed over a year period for numerous cities in different regions in Canada. The following chapter discusses the development of a thermodynamic model of an adsorption chiller. 


\section{Chapter 4: Calibration and Uncertainty Analysis}

Chapter 4 discusses the calibration methods used in this study as well as the methodology applied to conduct the uncertainty analysis. The following sections detail the uncertainty from the instrumentation, the heat transfer rates, the COP, and the overall experimental error.

\subsection{Component Calibration and Uncertainty}

The process of calibrating the thermocouples and thermopiles, as previously mentioned were completed by another graduate student, can be found in their thesis [44]. The summary of the calibration and uncertainty for thermocouples, thermopiles, and flow meters from their work are as indicated in the proceeding sections.

\subsubsection{Thermocouples}

Thermocouples determine the temperature of an object by comparing the voltage they read to a standardized temperature table produced by the National Institute of Standards and Technology (N.I.S.T.) [45]. Following these standards an error on temperature readings of $\pm 0.5^{\circ} \mathrm{C}$ can be accepted. However, this error excludes the additional error caused by the cold junction compensation temperature reading by a data acquisition system.

The thermocouples were placed in a constant, uniform temperature bath with a resistant temperature detector (RTD) calibrated to $\pm 0.02^{\circ} \mathrm{C}$. This process was done across a temperature range of 0 to $100^{\circ} \mathrm{C}$. A curve was fit to the data points and the random error was found to be less than the error of the RTD so it could be neglected in the uncertainty analysis. 
The cold junction temperature was measured by a thermistor built in to the NI9214 data card, with an error of $\pm 0.25^{\circ} \mathrm{C}$. A thermocouple from each spool of wire was immersed within a constant temperature bath of $5^{\circ} \mathrm{C}$. Over 3 minutes the bath temperature, cold junction temperature and thermocouple voltage was measured every 5 seconds for a total of 36 readings before the bath was increased $2^{\circ} \mathrm{C}$. This was repeated for a total of 46 different bath temperature set points. This data can be found in Appendix $\mathrm{C}$ of Baldwin [44].

National Instruments (NI) LabVIEW allows for a sixth order polynomial to be used to calculate the temperature difference between the thermocouple and the cold junction compensation. The cold junction temperature and the bath temperature were subtracted and fixed to the voltage value to create a plot of the data. Then a sixth order polynomial was fit to this data to calculate the temperature from the thermocouples. The equations for the 30 gauge and 24-gauge thermocouple wire are found as Equation 4.1 and 4.2.

$$
\begin{gathered}
T=0.00109 * V^{6}+0.00615 * V^{5}-0.0799 * V^{4}+0.212 * V^{3}-0.708 * V^{2}+24.65 * V \\
\quad-0.186+C J C \\
T=0.00258 * V^{6}-0.00374 * V^{5}-0.0633 * V^{4}+0.227 * V^{3}-0.741 * V^{2}+24.68 * V+ \\
0.091+C J C
\end{gathered}
$$

Where $\mathrm{T}$ is temperature in ${ }^{\circ} \mathrm{C}, \mathrm{V}$ is voltage produced by the thermocouple in $\mathrm{mV}$, and CJC is cold junction temperature in ${ }^{\circ} \mathrm{C}$. Looking at the uncertainty of the instruments used during calibration and the reading error on the data acquisition equipment the overall uncertainty can be determined as shown in Table 4.1. 
Table 4.1: Error on thermocouple wire

\begin{tabular}{|c|c|c|}
\hline Source of Error & Error -30 gauge $\left({ }^{\circ} \mathrm{C}\right)$ & Error -24 gauge $\left({ }^{\circ} \mathrm{C}\right)$ \\
\hline $\begin{array}{c}\text { Cold junction temperature - } \\
\text { calibration }\end{array}$ & 0.25 & 0.25 \\
\hline $\begin{array}{c}\text { Cold junction temperature - } \\
\text { experimental }\end{array}$ & 0.25 & 0.25 \\
\hline Regression prediction error & 0.237 & 0.157 \\
\hline Resistance temperature detector & 0.02 & 0.02 \\
\hline Resistance read error - DMM & 0.0397 & 0.0397 \\
\hline Bath uniformity & 0.02 & 0.02 \\
\hline Voltage error - calibration & 0.175 & 0.175 \\
\hline Voltage error - experimental & 0.175 & 0.175 \\
\hline Total Uncertainty & $\mathbf{0 . 4 9}$ & $\mathbf{0 . 4 6}$ \\
\hline
\end{tabular}

It was determined that for the 30 -gauge thermocouple wire the total uncertainty is slightly higher at $\pm 0.49^{\circ} \mathrm{C}$ compared to the 24-gauge wire at $\pm 0.46^{\circ} \mathrm{C}$. This uncertainty would be too high for measuring the systems heat transfer, as it was determined a $\pm 0.49^{\circ} \mathrm{C}$ difference at design conditions would cause an error on the $\mathrm{AC}$ line of around $20 \%$. For this reason, it was necessary to use thermopiles to reduce the uncertainty for the temperature readings and overall compounding system error.

\subsubsection{Thermopiles}

A similar method to the aforementioned was used to calibrate the thermopiles and determine their uncertainty. Two temperature baths outfitted with two separate RTD's were used where one bath was set to a fixed temperature and the other varied from $5^{\circ} \mathrm{C}$ to $95^{\circ} \mathrm{C}$. The voltage from the thermopiles were measured over a 3-minute period of 18 measurements at 10 second intervals. Equations were developed by creating ordered pairs using the data collected for the difference of temperature and voltage between the two baths. The cold bath temperature was varied from 5 to $35^{\circ} \mathrm{C}$ and 60 to $90^{\circ} \mathrm{C}$ at $5^{\circ} \mathrm{C}$ increments. 
Using the uncertainty and error determined as well as the uncertainty of the voltage input for the data acquisition equipment the following table was created to show the total uncertainty for the thermopiles used.

Table 4.2: Error on a thermopile

\begin{tabular}{|c|c|}
\hline Source of Error & Error $\left({ }^{\circ} \mathrm{C}\right)$ \\
\hline Resistance temperature detector - hot & 0.02 \\
\hline Resistance read error - DMM - hot & 0.0397 \\
\hline Bath uniformity - hot & 0.02 \\
\hline Resistance temperature detector - cold & 0.02 \\
\hline Resistance read error - DMM - cold & 0.019 \\
\hline Bath uniformity - cold & 0.02 \\
\hline Voltage error - calibration & 0.051 \\
\hline Voltage error - experimental & 0.051 \\
\hline Regression prediction error & 0.117 \\
\hline Total Uncertainty & $\mathbf{0 . 1 5}$ \\
\hline
\end{tabular}

The resulting uncertainty of the thermopiles were $\pm 0.15^{\circ} \mathrm{C}$ which is much more accurate than a single thermocouple. The high accuracy of the thermopile allows for much lower overall system errors when accounting the uncertainty on the flow meters.

\subsubsection{Flow Meters}

There is a total of three flow meters installed in this system, where there is one flow meter for each hydraulic loop. The uncertainty on the turbine flow meters used is a function of the number of pulses recorded over a period of time rather than the magnitude of the desired data. The flow meters have an error of $1 \%$ and the inherent error of one pulse per time recording, as a fraction of a pulse cannot be displayed by a binary signal. The volumetric flow rate $(\dot{V})$, is a function of the number of pulses, k-factor, and period of measurement $(t)$, represented by Equation 4.3 .

$$
\dot{V}=\frac{p u l s e s}{k * t}
$$


Table 4.3 displays the specifications of the flow meter model, location, K-factor, and the design flow rate.

Table 4.3: Flow meter specification required for uncertainty analysis

\begin{tabular}{|c|c|c|c|}
\hline Fluid Line & Flow Meter Model & K-factor (pulse/L) & Flow Rate Setpoint (L/min) \\
\hline HW & IB39-B110-875 & 305 & 42 \\
\hline HR & IB39-B110-750 & 25 & 80 \\
\hline AC & IB39-B110-875 & 30 & 49 \\
\hline
\end{tabular}

The data acquisition unit counts the pulses generated by the flow meters over the measuring period which is one cycle. The error generated from the cycle potentially ending early and cutting a full pulse of from being recorded must be determined based off various measuring periods. This error can be more significant for flow with low flow rates or relatively low K-factors. The total error is the square root sum of the squares for these two errors and for various measuring times at the design flow rate is shown in Table 4.4.

Table 4.4: Flow meter uncertainty with varying time intervals

\begin{tabular}{|c|c|c|c|c|c|c|}
\hline \multirow{2}{*}{ Fluid Line } & \multirow{2}{*}{ Design Flow Rate (L/min) } & \multicolumn{5}{|c|}{ Error on Flow Rate (L/min) } \\
\cline { 3 - 7 } & & $1 \mathrm{~s}$ & $5 \mathrm{~s}$ & $10 \mathrm{~s}$ & $15 \mathrm{~s}$ & $30 \mathrm{~s}$ \\
\hline $\mathrm{HW}$ & 42 & 0.62 & 0.46 & 0.44 & 0.43 & 0.43 \\
\hline HR & 80 & 3.15 & 1.23 & 0.99 & 0.91 & 0.83 \\
\hline $\mathrm{AC}$ & 49 & 2.49 & 0.89 & 0.69 & 0.62 & 0.56 \\
\hline
\end{tabular}

The total flow rate error over $1,5,10,15$, and 30 seconds was determined, and results show that increasing the measuring period for longer than 10 seconds does not provide a significant decrease in the error. On the AC line a measuring period of 5 seconds provides an error or $0.89 \mathrm{~L} / \mathrm{min}$ which can be reduced by $23 \%$ by doubling the measuring time to 10 seconds. If the measuring time of 10 second was tripled there would only be a $9 \%$ decrease in uncertainty, this impact was less noticeable in the other lines due to higher 
flows or k-factors. For this reason, the 10 second measuring time was selected as it was a short enough time period to adequately capture the cycling of the chiller which takes roughly 15 seconds to occur.

\subsection{Overall System Uncertainty Analysis}

The uncertainty of the instrumentation used in the experimental setup was determined and was used to determine the overall uncertainty of the adsorption system. The overall uncertainty will include the error on heat transfer as well as the COP error.

\subsubsection{Uncertainty on Heat Transfer Calculations}

To determine the uncertainty of the heat transfer calculations, the equation for heat transfer must be transformed into a series of differential sensitivity factors to determine each components' effect on the heat transfer value. Equation 4.4 is equation used for calculating heat transfer $(\dot{Q})$, while Equations 4.5 to 4.8 are the sensitivity factors $(\theta)$ for volumetric flow rate $(\dot{V})$, density $(\rho)$, heat capacity of water $(C p)$, and temperature $(T)$.

$$
\begin{gathered}
\dot{Q}=\dot{V} \rho C_{p} \delta T \\
\theta_{\dot{\mathrm{V}}}=\frac{\partial \dot{Q}}{\partial \dot{V}}=\rho C_{p} \delta T \\
\theta_{\rho}=\frac{\partial \dot{Q}}{\partial \rho}=\dot{V} C_{p} \delta T \\
\theta_{\mathrm{C}_{\mathrm{p}}}=\frac{\partial \dot{Q}}{\partial C_{p}}=\dot{V} \rho \delta T \\
\theta_{\delta \mathrm{T}}=\frac{\partial \dot{Q}}{\partial \delta T}=\dot{V} \rho C_{p}
\end{gathered}
$$

The uncertainty for density is $0.25 \pm \mathrm{kg} / \mathrm{m}^{3}$ and $0.02 \mathrm{~kJ} / \mathrm{kg} \mathrm{K}$ for heat capacity of water at a constant $4.2 \mathrm{~kJ} / \mathrm{kg} \mathrm{K}$. The differentiated equations were solved for a measurement period of 10 seconds and their values can be seen in Table 4.5. 
Table 4.5: Sensitivity factors for each hydraulic line

\begin{tabular}{|c|c|c|c|c|}
\hline Fluid Line & $\begin{array}{c}\theta_{\mathrm{V}}-10 \mathrm{~s} \\
\left(\mathrm{~kW}^{*} \mathrm{~s} / \mathrm{m}^{3}\right)\end{array}$ & $\begin{array}{c}\theta_{\rho} \\
\left(\mathrm{kW}^{*} \mathrm{~m}^{3} / \mathrm{kg}\right)\end{array}$ & $\begin{array}{c}\theta_{\mathrm{Cp}} \\
\left(\mathrm{kg}^{*} \mathrm{~K} / \mathrm{s}\right)\end{array}$ & $\begin{array}{c}\theta_{\delta \mathrm{T}} \\
(\mathrm{kW} / \mathrm{K})\end{array}$ \\
\hline HW & 33440 & 0.023 & 5.60 & 2.93 \\
\hline HR & 29260 & 0.037 & 8.75 & 5.22 \\
\hline $\mathrm{AC}$ & 16720 & 0.0137 & 3.27 & 3.41 \\
\hline
\end{tabular}

The values for the sensitivity factors are multiplied by the values they represent to produce the uncertainty produced by each individual variable. The overall uncertainty is then determined by calculating the squared root sum of the squares for the uncertainty produced for each variable. The overall uncertainty for heat transfer on each fluid loop can be found in Table 4.6.

Table 4.6: Error on system heat transfer

\begin{tabular}{|c|c|c|c|}
\hline Fluid Line & $\begin{array}{c}\text { Heat Transfer }(\mathrm{HT}) \\
\text { Rate }(\mathrm{kW})\end{array}$ & $\begin{array}{c}\text { Uncertainty on } \\
\text { HT }(\mathrm{kW})\end{array}$ & Error (\%) \\
\hline HW & 23.8 & 0.98 & 4.11 \\
\hline HR & 37.4 & 1.45 & 3.88 \\
\hline AC & 13.6 & 0.90 & 6.62 \\
\hline
\end{tabular}

There is an error of $6.62 \%$ on the air conditioning line at design conditions, which was determined to be adequate for this system as the required flow rates are on the higher side for residential applications. A similar process is completed for the uncertainty of the COP in the following section.

After the uncertainty was calculated over the testing range of the chiller it was determined that the relative error was linear, as expected. Equation 4.9 was created using the performance map test points to directly calculate the cooling capacity output error $( \pm \mathrm{kW}$ th $)$.

$$
U_{\text {Cooling Capacity }}=0.019(\text { Cooling Capacity })+0.7169 R^{2}=1
$$




\subsubsection{Uncertainty on the COP of the Adsorption Chiller}

The heat transfer uncertainty determined in the previous section and design heat transfer rates can be used to solve for the COP uncertainty. Similar to before, using Equations 4.11 and 4.12 for the sensitivity factors for the cold and hot input to the system.

$$
\begin{gathered}
C O P_{\text {th }}=\frac{\dot{Q}_{\text {cold }}}{\dot{Q}_{\text {hot }}} \\
\theta_{\dot{Q}_{\text {cold }}}=\frac{\delta C O P_{\mathrm{th}}}{\delta\left(\dot{Q}_{\mathrm{cold}}\right)}=\frac{1}{\dot{Q}_{\mathrm{hot}}} \\
\theta_{\dot{Q}_{\mathrm{hot}}}=\frac{\delta C O P_{\mathrm{th}}}{\delta\left(\dot{Q}_{\mathrm{hot}}\right)}=\frac{\dot{Q}_{\mathrm{cold}}}{\left(\dot{Q}_{\mathrm{hot}}\right)^{2}}
\end{gathered}
$$

Solving the equations as done in the previous sections results in an uncertainty of 0.048 on the design COP of 0.571 which is an $8.4 \%$ error. This value is acceptable as it is expected the COP will be higher than the error on the AC line which is $6.62 \%$.

Similar to the equation produced for the cooling capacity error the $\%$ error for COP was found to have a strong trend as a function of power as expected from the sensitivity formula. Equation 4.13 determines the \% error on COP is as follows.

$$
U_{\mathrm{COP}}=2.2321(C O P)^{-2.558} \quad R^{2}=0.9698
$$

The r-squared value for this equation is high considering the high variability of COP.

The uncertainty of the experimental work allows for the model and simulation results to be compared to experimental data to determine what is "good enough" for the simulation accuracy. 


\section{Chapter 5: Modelling Methodology}

To model a complex system with a cyclic transient nature as seen in adsorption chillers, a powerful simulation tool must be used. Software such as Modelica and Simulink were considered for their advanced heat and mass transfer capabilities, but Transient System Simulation Tool (TRNSYS) was chosen due to its capabilities to add prebuilt components into the modelling environment and building load resources previously acquired. TRNSYS allows for uses to select prebuilt components, "Types", which are a series of mathematical equations that allow for user inputs and specifications to be entered. All the different components can be connected and execute through a predetermined order for each timestep. This program allows for components, such as a house model, to be imported and have various components, such as HVAC, to be altered with relative ease.

\subsection{Adsorption Chiller}

TRNSYS has an extension library called Thermal Energy System Specialists (TESS) which already has an adsorption model (Type-909) built into it based on the SJTU SWAC-10 adsorption chiller, which is about 10 years older than the unit used in this study and has a much smaller range of hot water temperatures $\left(75\right.$ to $\left.95^{\circ} \mathrm{C}\right)$ compared to the unit tested $\left(50\right.$ to $\left.95^{\circ} \mathrm{C}\right)[13]$. The Type-909 component uses a thermodynamic modelling approach which requires a normalized performance map to calculate the cooling capacity and coefficient of performance (COP) of the chiller. The mathematical workflow in the Type-909 component is as follows.

The model first checks to determine how much cooling is possible by taking the lower value between the maximum cooling capacity, $\dot{q}_{\text {capacity, found from linear }}$ interpolation of the performance map for current inlet conditions and the calculated cooling 
power required to reach the temperature setpoint of the chilled water line (AC). The cooling power for the AC line, $\dot{q}_{A C}$, is shown as Equation 5.1.

$$
\dot{q}_{\mathrm{AC}}=\operatorname{MIN}\left(\dot{q}_{\text {capacity }},\left(\dot{m}_{\mathrm{AC}} C p\left(T_{\mathrm{AC}, \text { in }}-T_{\mathrm{AC}, \text { setpoint }}\right)\right)\right)
$$

The cooling power required to reach the setpoint temperature is found by multiplying the mass flow rate, $\dot{m}$, in $\mathrm{kg} / \mathrm{s}$ by the specific heat capacity for water, $C p$, and the temperature different between the $\mathrm{AC}$ inlet and $\mathrm{AC}$ setpoint, $T_{\mathrm{AC} \text {,setpoint. The cooling }}$ power produced, $\dot{q}_{\mathrm{AC}}$, is then used to calculate the power extracted from the hot water line (HW), shown with Equation 5.2.

$$
\dot{q}_{\mathrm{HW}}=\frac{\dot{q}_{\mathrm{AC}}}{C O P}
$$

The coefficient of performance of the chiller (COP) is linearly interpolated from the performance map to solve for the power used from the HW line. The cooling and heating power are then used in an energy balance for the system, as seen in Equation 5.3.

$$
\dot{q}_{\mathrm{HR}}=\dot{q}_{\mathrm{AC}}+\dot{q}_{\mathrm{HW}}+\dot{q}_{\mathrm{aux}},
$$

where the heat rejection (HR) power is the summation of the cooling power, hot waterpower, and the auxiliary power. The auxiliary power is defined as the power required to drive the pump as it has thermal loses into the system. Once all the rates of power for each line are solved, the model determines the outlet temperature for each line, using Equations 5.4 to 5.6 . 


$$
\begin{aligned}
T_{\mathrm{HR}, \text { out }} & =T_{\mathrm{HR}, \text { in }}+\frac{\dot{q}_{\mathrm{HR}}}{\dot{m}_{\mathrm{HR}} C p} \\
T_{\mathrm{HW}, \text { out }} & =T_{\mathrm{HW}, \text { in }}-\frac{\dot{q}_{\mathrm{HW}}}{\dot{m}_{\mathrm{HW}} C p} \\
T_{\mathrm{AC}, \text { out }} & =T_{\mathrm{AC}, \text { in }}-\frac{\dot{q}_{\mathrm{AC}}}{\dot{m}_{\mathrm{AC}} C p}
\end{aligned}
$$

The COP of the adsorption chiller model is determined by solving the ratio of cooling produced to the amount of heat input into the system (Equation 5.7), where the heat input to the system is the sum of the heat extracted from the hot water line and the thermal losses into the system from the AC pump.

$$
C O P_{\text {sim }}=\frac{\dot{q}_{\mathrm{AC}}}{\dot{q}_{\mathrm{HW}}+\dot{q}_{\mathrm{aux}}}
$$

Figure 5.1 displays the performance of the chiller over the testing ranges used for the performance map that drives this model, where the cooling capacity is displayed on the $\mathrm{y}$-axis, the chilled water temperature inlet is on the $\mathrm{x}$-axis, and each graph represents a hot water setpoint. 

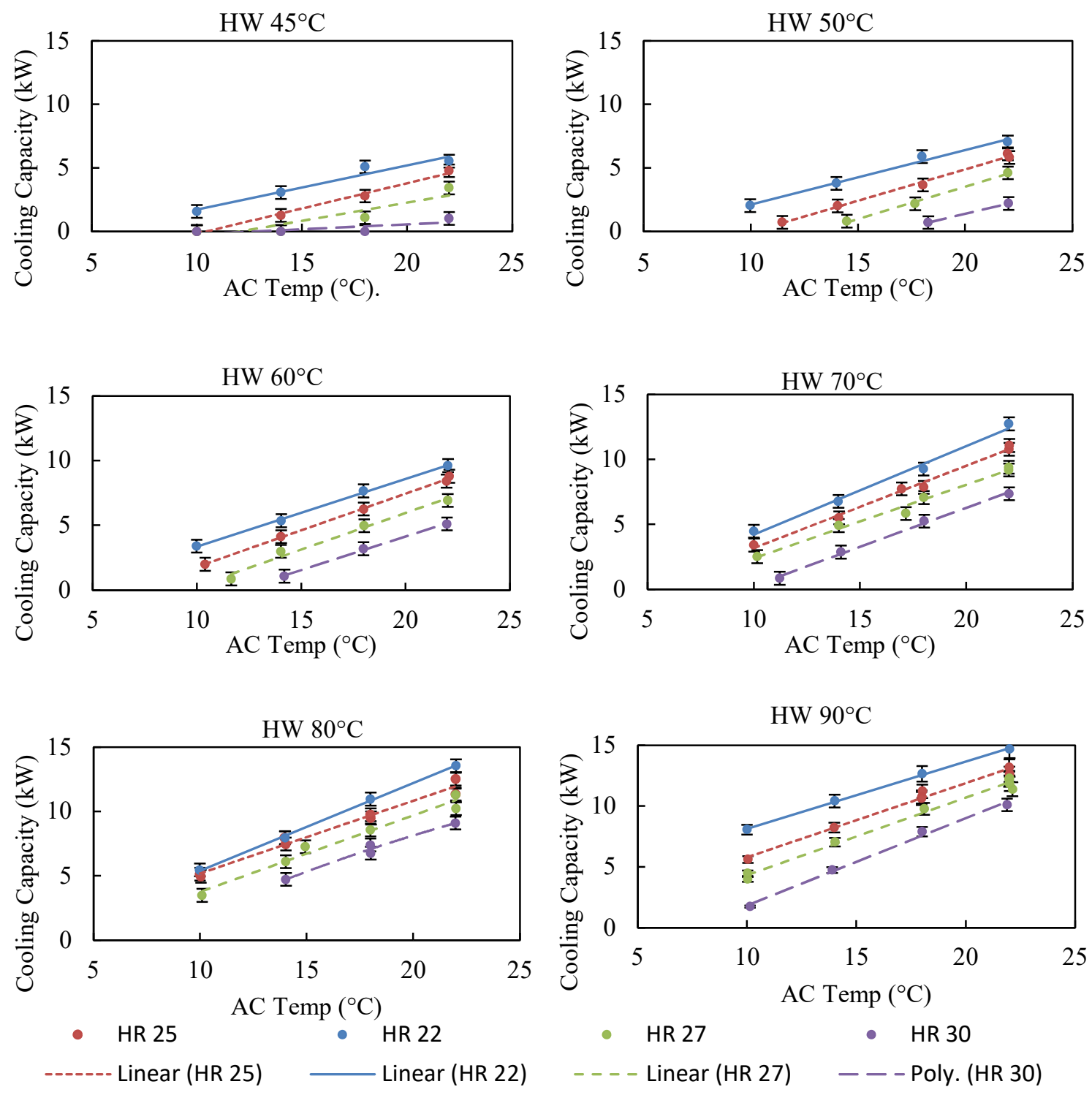

$$
\begin{aligned}
& \text { - HR } 27 \text { HR } 30 \\
& \text { - - - Linear (HR 27) - - - Poly. (HR 30) }
\end{aligned}
$$

Figure 5.1: Experimentally determined performance map for a SorTech Adsorption Chiller

The incremental increase for the HW, heat rejection HR, and chilled water AC flows occurred due to the cooling capacity and COP having a linear relation over shorter ranges of temperatures, as determined experimentally as shown in Figure 5.1. The performance map was normalized to a cooling capacity of $14 \mathrm{~kW}_{\text {th }}$ and $0.5 \mathrm{COP}$ and transformed into a database (.dat) file for TRYNSYS to use found in Appendix B. 
The SorTech model used in this experimental setup is cyclic where approximately every five and a half minutes a new cycle starts. The Type-909 component does not cycle in such a manner and the transients during start up are ignored as most of its run time is steady cyclic operation. The Type-909 model does not fully represent the effect the control valves have when switching between barrels in the chiller, which cause large spikes or drops in the heat rejection and hot water line, respectively. The control valve locations in relation to the hydraulic lines can be seen in Figure 5.2.

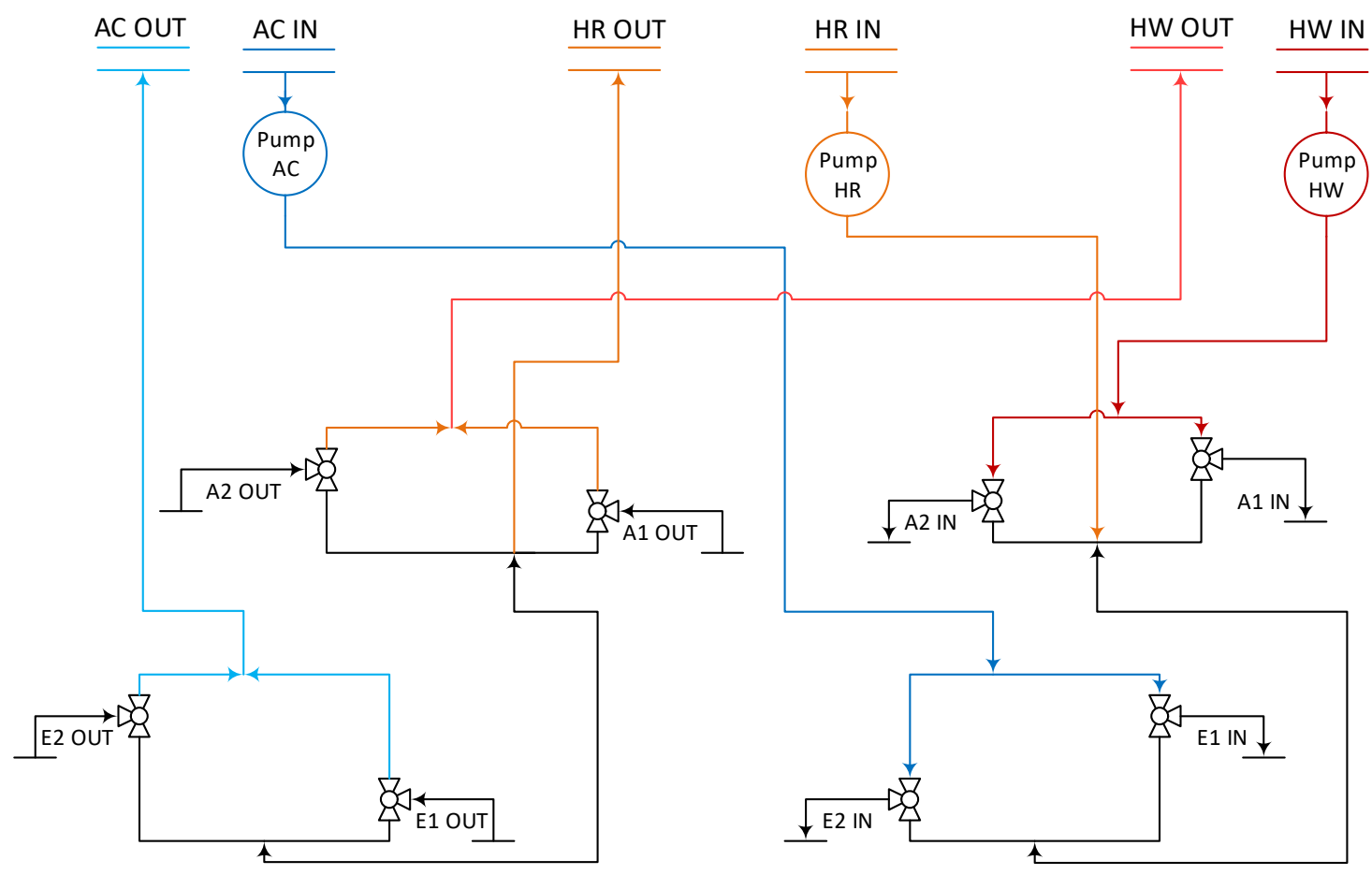

Figure 5.2: Adsorption chiller internal schematic

The schematic for the internal piping of the adsorption chiller is shown in Figure 5.2 where the evaporator/condenser and absorber/desorber are shown as E and A respectively for side 1 and 2 . The red, orange, and blue lines display the HW, HR, and AC lines, where the lighter HW and AC colour show the section of the hydraulic loop with lower temperatures than the inlet (where heat was extracted/cooled). Hot water flows into 
the adsorption chiller at the hot water inlet (HW IN) and is directed into adsorber 1 or 2 depending on the orientation of the control valves and exits the adsorber then the chiller (HW OUT). While adsorber 1 has hot water flowing into it, adsorber 2 does not and has water from the heat rejection inlet (HR IN) flowing into it and out through HR OUT. This demonstrates how the control valves manipulating the flows for the adsorbers/desorbers allow flow to mix as they switch from side 1 to 2 and vice versa, shown by the rapid drops/spikes in temperature shown in Figure 5.3. It was noted that the thermal power of the hot water drops, and the thermal power of the heat rejection drops are equal in magnitude allowing for this correlation, which can be seen in Figure 5.3. The physical phenomenon that causes this is the mixing between the hot water and heat rejection line as the control valve re-directs the flows from one barrel to the other at the end of the cycle.

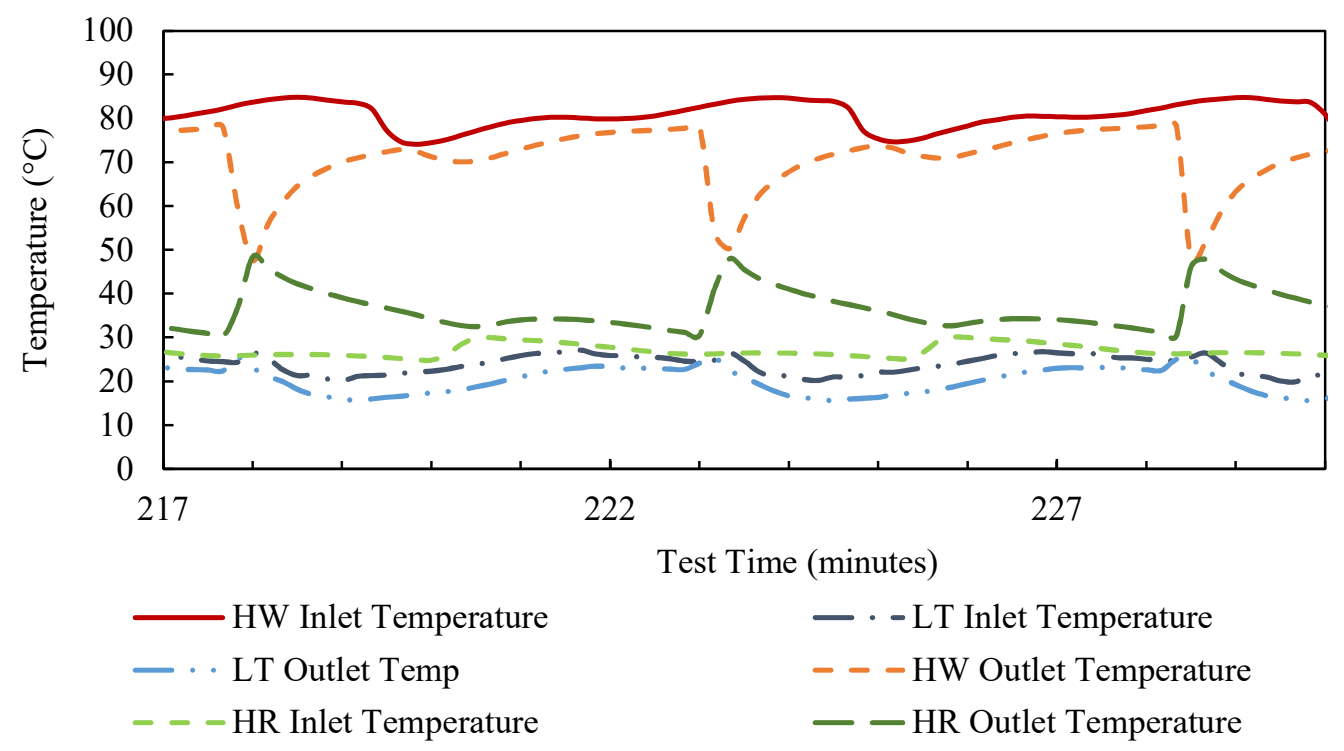

Figure 5.3: Adsorption chiller results displaying cyclic nature

Figure 5.3 shows the cyclic nature of the adsorption chiller, and the peaks where the HW and HR lines decrease and increase, respectively. The beginning and ending of each cycle are made apparent by this phenomenon. 


\subsubsection{Adsorption Model Validation}

To use the Type-909 in simulations the data produced from it must be validated. The validation processes consisted of feeding in inlet temperatures to the Type-909 model and comparing the simulated output results to the experimental output. It should be noted that the inlet temperatures used were not the same ones used for creating the performance map; the model was tested between performance map temperatures and tested using CIT and DIT test types.

A sample of the simulation results for the cooled water line (AC) is shown in Figure 5.4 at average inlet temperatures for $\mathrm{AC}, \mathrm{HR}, \mathrm{HW}$ lines of $22,25,70^{\circ} \mathrm{C}$ respectively.

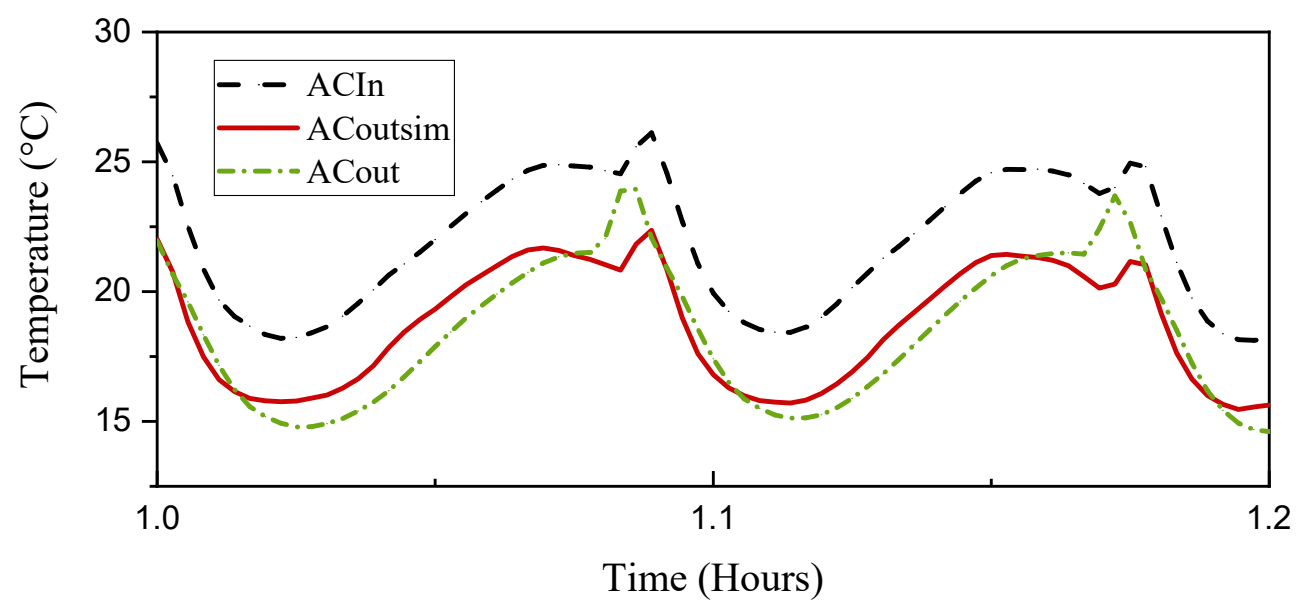

Figure 5.4: Preliminary modelling results for the TRNSYS adsorption chiller model

The model predicts the AC outlet temperatures, ACoutSim, relatively close to the experimental data, ACout, apart from a small-time shift where the simulated results are predicted slightly ahead of the experimental. The time delay between the experimental results can be attributed to the time constant of the system, where there is a thermal delay through the chiller and piping. The delay would be expected due to the time it takes the internal control valves to switch the flow from one barrel to the other. The simulated results 
for the AC temperatures shown in Figure 5.4 is combined with the simulated and measured results for the HR and HW outlet temperatures to create Figure 5.5.

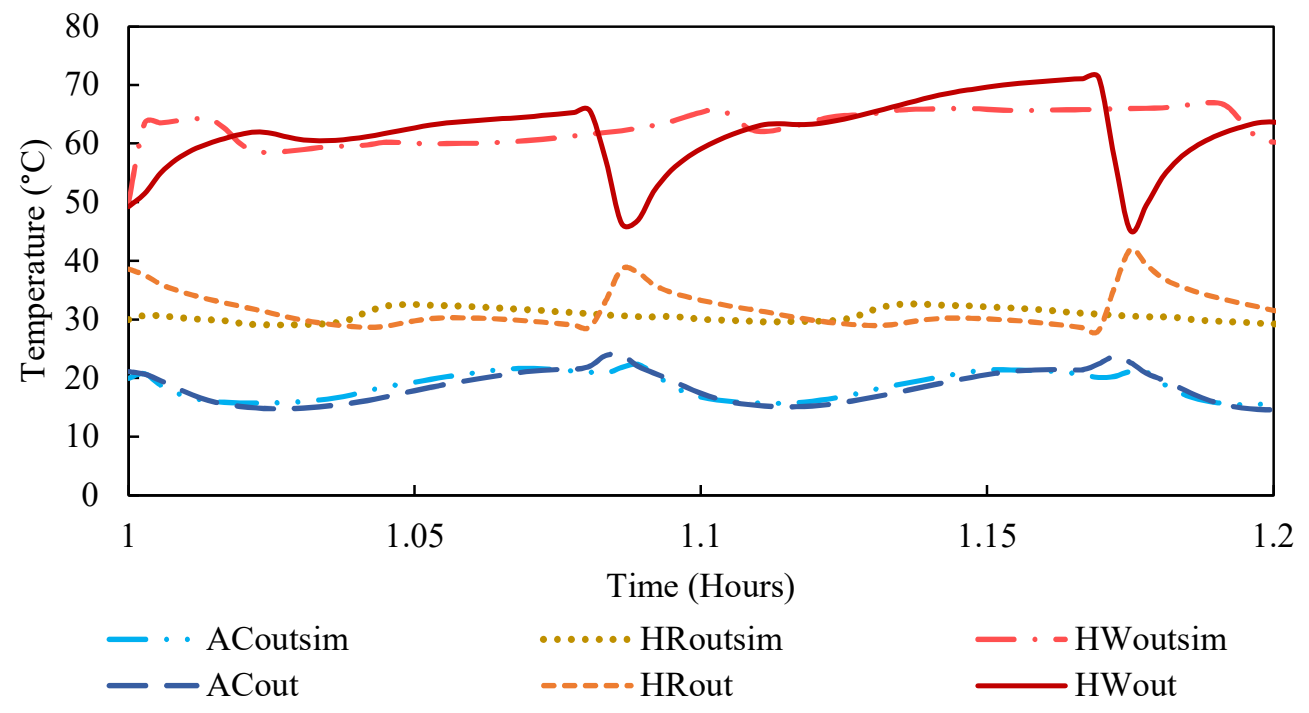

Figure 5.5: Comparison of measured and simulated outlet temperatures

Figure 5.5 shows how the results in Figure 5.4, for the AC temperature, are much more accurate than those of the HR and HW lines. This is due to the previously mentioned impact the control valves have on the HR and HW line, as seem in Figure 5.5. This phenomenon is amplified when calculating the heat transfer for each line, due to the temperature difference between the inlet and the outlet being multiplied by the flow rate and specific heat of water. The sudden spikes/dips in the temperatures are magnified as seen in Figure 5.6. 


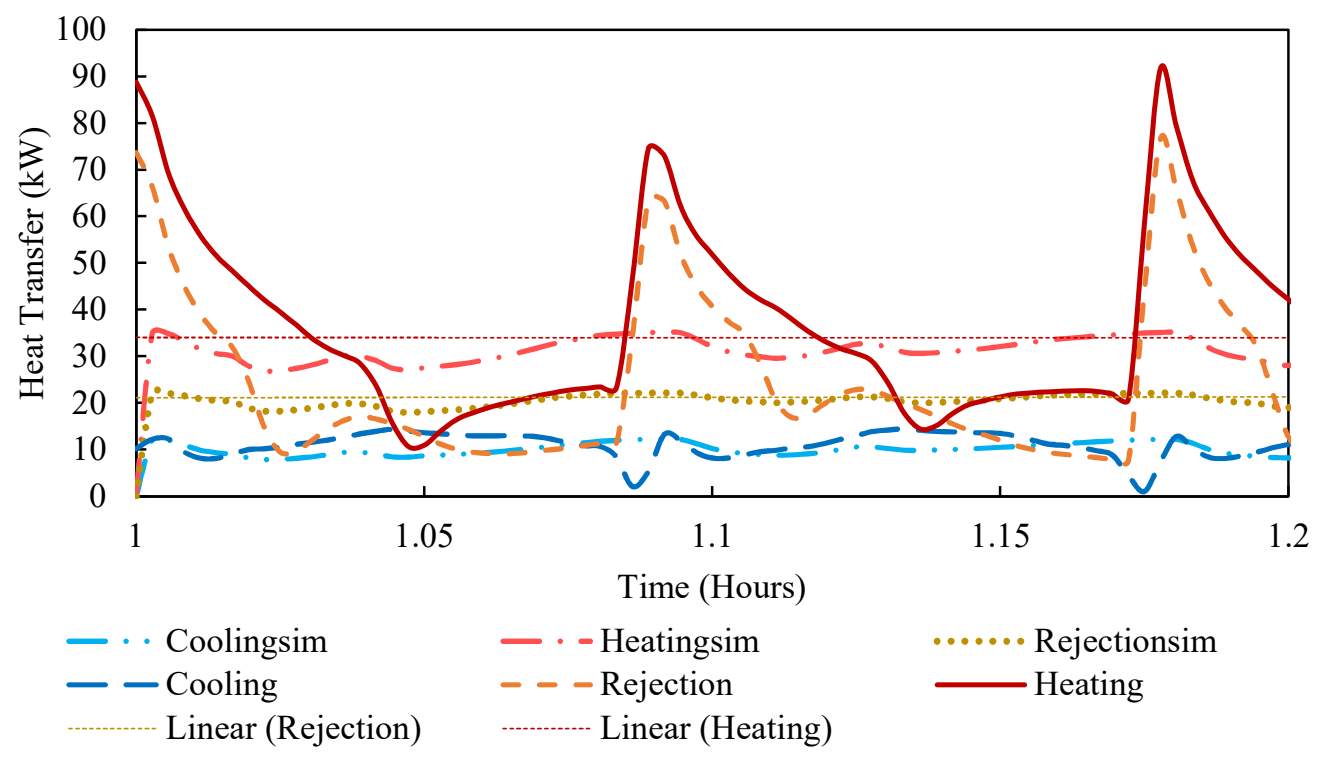

Figure 5.6: Comparison of measured and simulated heat transfers through the chiller

The heat transfer difference between simulated and experimental data for the HW and HR lines noticeably standout in Figure 5.6, where they do not line up as close to the AC line. When the linear trendline for the HR and HW average heat transfer is graphed over the whole test period it appears that the simulated results are within a few degrees of the experimental data. This may be true for the entire average for the duration of the chiller test, but it is not a valid comparison for transient cooling loads in a building. To compare the results more accurately from Figure 5.5 and Figure 5.6 the difference between the respective fluid lines for the measured and simulated results are taken, then averaged. This average difference can be found in Table 5.1 and 5.2 for the average difference in temperature and heat transfer, respectively. The average difference between the experimental and simulated results for each line were normalized by each line's mean measured temperature or mean measured heat transfer to cross compare which line (AC, HR, HW) is further away from their respective measured results. 
Table 5.1: Difference between measured and simulated outlet temperatures

\begin{tabular}{|c|c|c|c|}
\cline { 2 - 4 } \multicolumn{1}{c|}{} & $\begin{array}{c}\text { Avg. AC temp. } \\
\text { difference }\end{array}$ & $\begin{array}{c}\text { Avg. HR temp. } \\
\text { difference }\end{array}$ & $\begin{array}{c}\text { Avg. HW temp. } \\
\text { difference }\end{array}$ \\
\hline${ }^{\circ} \mathrm{C}$ & 1.18 & 2.99 & 4.81 \\
\hline Normalized by Avg. ${ }^{\circ} \mathrm{C}$ & 0.063 & 0.096 & 0.076 \\
\hline
\end{tabular}

Table 5.2: Difference between measured and simulated heat transfer

\begin{tabular}{|c|c|c|c|}
\cline { 2 - 4 } \multicolumn{1}{c|}{} & $\begin{array}{c}\text { Avg. cooling } \\
\text { difference }\end{array}$ & $\begin{array}{c}\text { Avg. heat rejection } \\
\text { difference }\end{array}$ & $\begin{array}{c}\text { Avg. heat input } \\
\text { difference }\end{array}$ \\
\hline $\mathrm{kW}$ & 3.69 & 14.63 & 17.85 \\
\hline $\begin{array}{c}\text { Normalized by } \\
\text { Avg. } \mathrm{kW}\end{array}$ & 0.348 & 0.651 & 0.533 \\
\hline
\end{tabular}

Table 5.1 shows that the normalized heat rejection temperature difference from the model, 0.096, is greater than the measured data of the normalized hot water temperature difference, 0.076, despite the HW line having a larger average temperature difference of $4.81^{\circ} \mathrm{C}$. This finding is also true in Table 5.2 for the average heat transfer difference between heat rejection and heat input (HW line). In comparison, the AC line has the lowest normalized differences for both temperature and heat transfer which indicates this simulated data is the most accurate out of the three lines. Therefore, the model is an adequate representation of an adsorption chiller for its cooling output, as when integrated over the test duration the variance from the experimental data it is within the experimental error, and if the model followed the results closer there would be slightly higher output for less heat input. The trends indicate this model is slightly underestimating the chiller's performance which is better than overestimating it as systems in practical applications tend to have unexpected losses.

\subsection{Description of System}

A previously developed and validated house model for a standard newly built home in urban Ontario by Baldwin and Cruickshank [11] was used and modified for this study. 
The house modelled is a two story, single detached home with a basement. The house has a total floor area of $330 \mathrm{~m}^{2}$ divided evenly between the 3 floors. Each of the floors as well as the attic were divided into their own thermal zones. A single thermostat is located on the main floor with the heating and cooling setpoint of $20^{\circ} \mathrm{C}$ and $23^{\circ} \mathrm{C}$, respectively. The publication by Baldwin and Cruickshank can be referenced for additional details. The model was used for Case 1 and modified for the various heating methods in other cases.

Table 5.3 shows all cases studied.

Table 5.3: Cases explored in this study

\begin{tabular}{|c|c|}
\hline Case \# & Description \\
\hline 1 & Heat pump for heating and cooling \\
\hline 2 & Electrical heater and standard AC \\
\hline 3 & Natural gas ${ }^{\dagger}$ burning furnace and standard $\mathrm{AC}$ \\
\hline 4 & Adsorption chiller and heat pump with constant hot water supply (const. HW) \\
\hline 5 & $\begin{array}{l}\text { Adsorption chiller with } 39.2 \mathrm{~m}^{2} \text { solar collector, } 500 \mathrm{~L} \text { tank and heat pump with } \\
\text { (const. HW) }\end{array}$ \\
\hline 6 & $\begin{array}{l}\text { Adsorption chiller with } 39.2 \mathrm{~m}^{2} \text { solar collector } 500 \mathrm{~L} \text { tank and heat pump with } \\
\text { solar collector }\end{array}$ \\
\hline
\end{tabular}

+Where natural gas is not available furnace oil was used.

These cases were selected based on the HVAC equipment that can typically be found in homes in Canada, both old and new, with the addition of the adsorption chiller cases (Cases 4-6). The electrical or fuel consumption for the constant hot water supply is not considered for any of the cases. It should be noted that on a district heating system hot water supply would be readily available but if this is not the case there would be added electricity consumption and GHG emissions produced for Case 1, Case 4, and Case 5.

\subsection{Overview of Cases}

This section goes into further detail on each case and provides a basic schematic from which the systems were designed. 


\subsubsection{Base Cases}

The base cases were selected based off the most common arrangements seen across Canada, (Case 2 and 3) which are electric or natural gas furnace with a common vapour compression air conditioner, as well as an increasingly common system setup for new builds which is using a heat pump (Case 1).

\subsubsection{Case 1}

Case 1 is a system that is using a $6 \mathrm{~kW}_{\text {th }}$ heat pump, capable of a $\mathrm{COP}_{\text {th }}$ of 3.25 for cooling and 4.25 for heating, which meets the house's summer and winter demands. A schematic for what this system looks like is show in Figure 5.7.

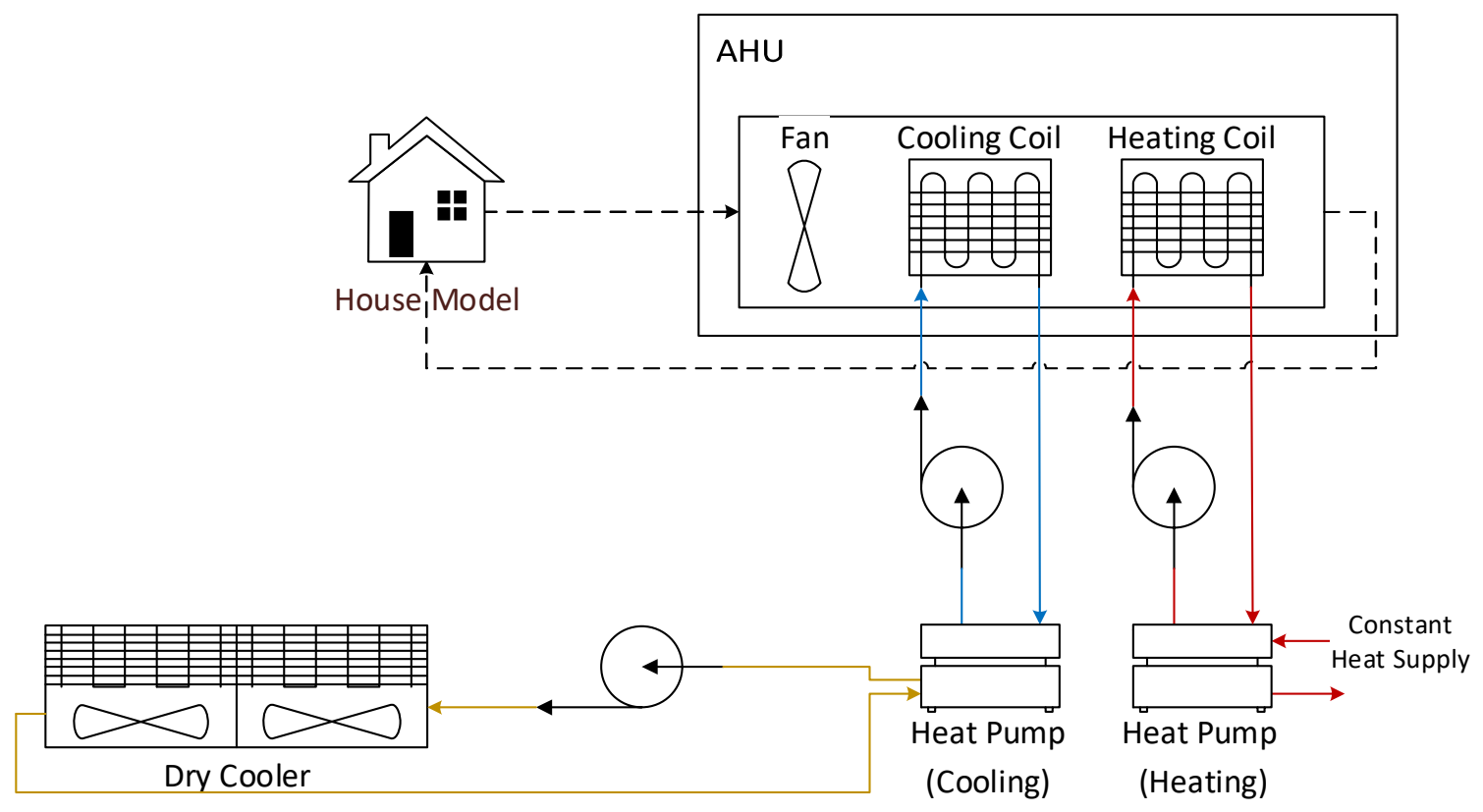

Figure 5.7: Case 1 schematic

The heat pump was supplied with a constant heat supply of $20^{\circ} \mathrm{C}$ at a mass flow rate of $720 \mathrm{~kg} / \mathrm{hr}$. This system does not actually have 2 heat pumps, but for a visual and modelling perspective, 2 heat pumps are shown to distinctively show the cooling and heating mode. More details for this model can be found in works by Baldwin [46]. 


\subsubsection{Case 2}

Case 2 is a system that uses a $6 \mathrm{~kW}_{\text {th }} \mathrm{AC}$ capable of COP of 3.25 that runs on electrical power which houses with central air commonly use. The heating is provided by an electric furnace that heats the air directly and distributed through the building's ducts. The heating capacity of the electric furnace was slightly oversized to $8.33 \mathrm{~kW}$ th so it would provide adequate heating for all cases. The efficiency of the electric furnace was assumed to be $100 \%$ [47]. This schematic is shown in Figure 5.8 .

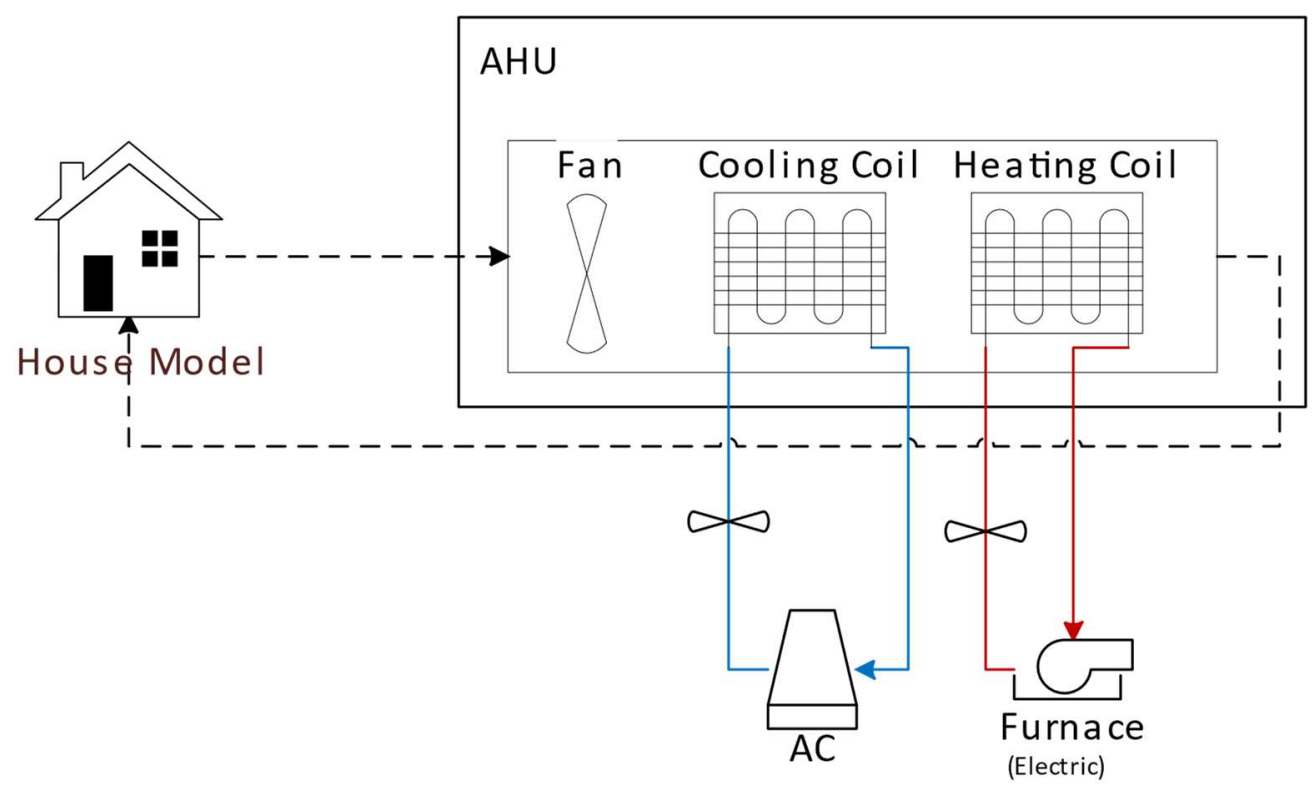

Figure 5.8: Case 2 schematic

\subsubsection{Case 3}

Case 3 is similar to Case 2 with the only difference being the furnace burns natural gas to heat the air. This system configuration is the most common to find across Canada. Similar to Case 2, the heating capacity of the natural gas furnace was slightly oversized so it would provide adequate heating for all cases. The assumed efficiency of the natural gas furnace is $95 \%$ as majority of furnaces installed since 2013 operate at that efficiency due 
to DOE regulations requiring an efficiency of over $90 \%$ in colder climates [48]. Figure 5.9 shows a schematic for this setup.

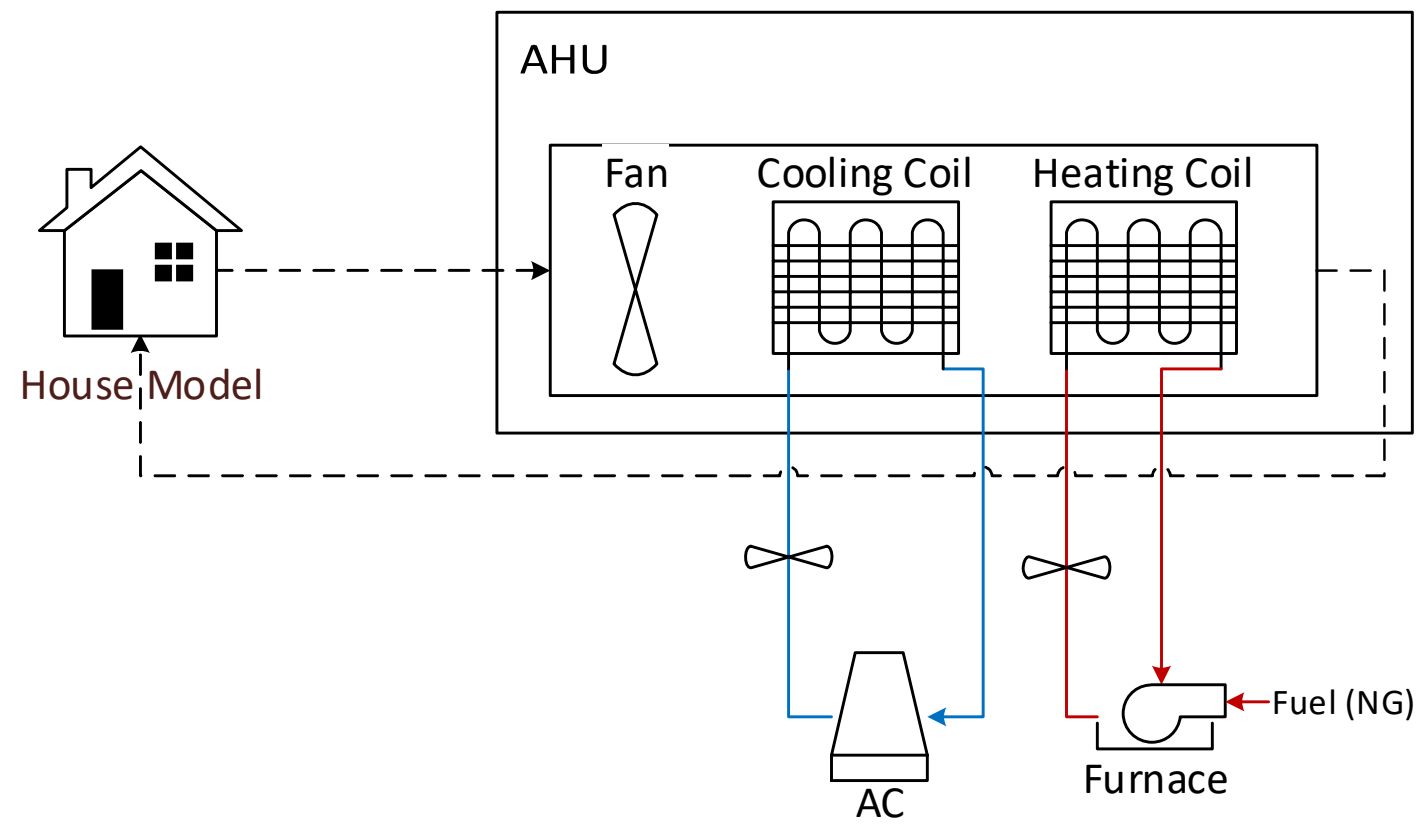

Figure 5.9: Case 3 schematic

Similar to Case 2 this system would require two fans compared to at least three pumps needed for Case 1 .

\subsubsection{Adsorption Cases}

Various configurations of adsorption cooling systems were used to show how the adsorption system is impacted when the driving heat source is switched from a constant unlimited (district) source to a limited solar fed source.

\subsubsection{Case 4}

Case 4 is the simplest of the adsorption cases where the hot fluid source is at a constant rate of $42 \mathrm{~L} / \mathrm{min}$ and temperature of $75^{\circ} \mathrm{C}$ from an unlimited source outside of the systems control volume. This case would be most reflective of a district heating setup where there are distributed steam lines through the buildings or neighborhoods. The 
cooling in this case is provided by the adsorption chiller and heating is provided by the same heat pump used previously in Case 1. This system schematic can be seen in Figure 5.10.

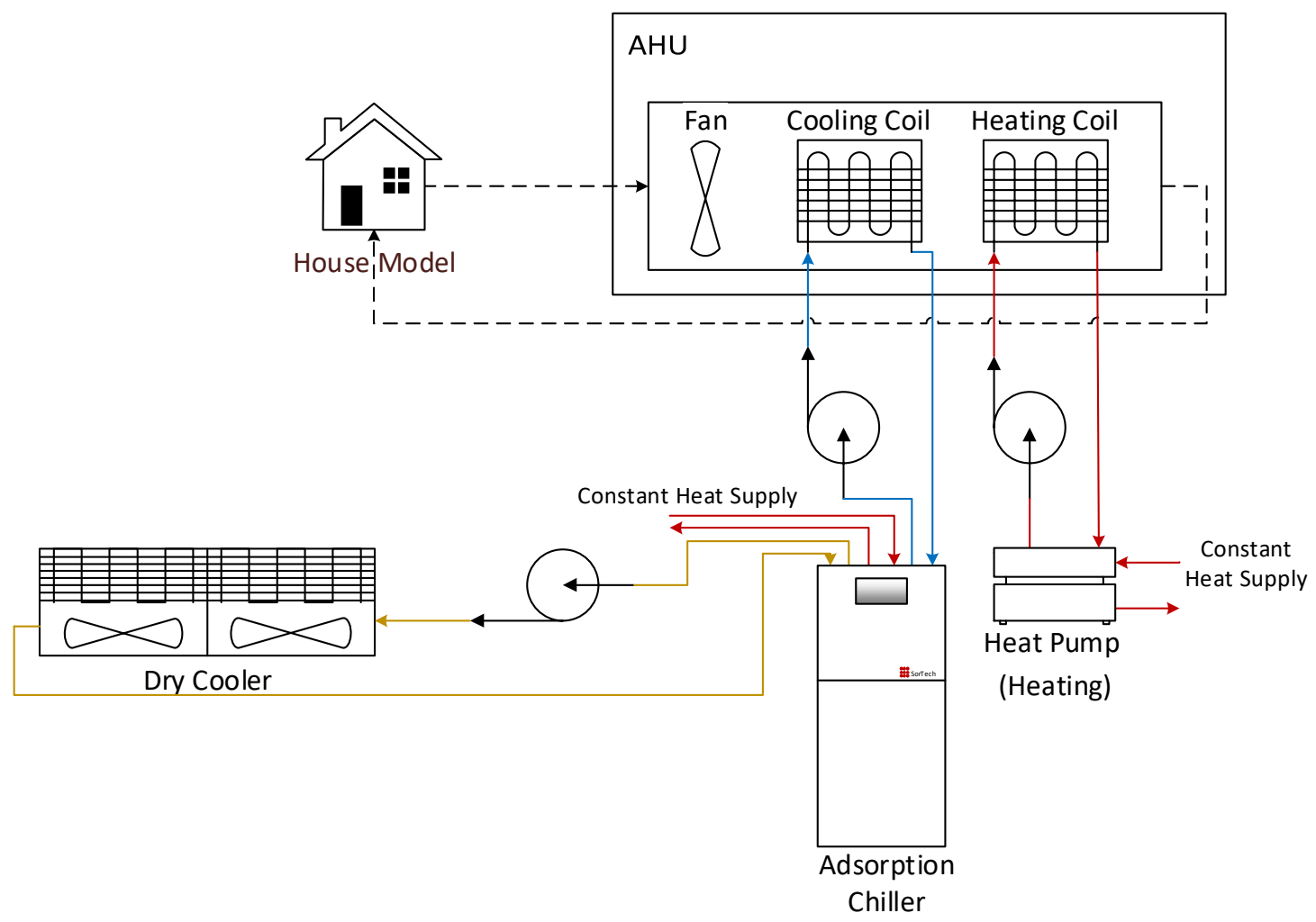

Figure 5.10: Adsorption system layout (Infinite HW supply)

The adsorption chiller can operate in a heating mode, but that was not experimentally tested as the scope of this research is to determine the more limiting factor of cooling.

\subsubsection{Case 5}

Case 5 is similar to Case 4 with the exception that the adsorption chiller's heat source is now provided from a flat plate solar array of $39.2 \mathrm{~m}^{2}$ and a hot water tank of $500 \mathrm{~L}$ with a setpoint of $75^{\circ} \mathrm{C}$. The schematic for this system including the pumps are shown in Figure 5.11 . 


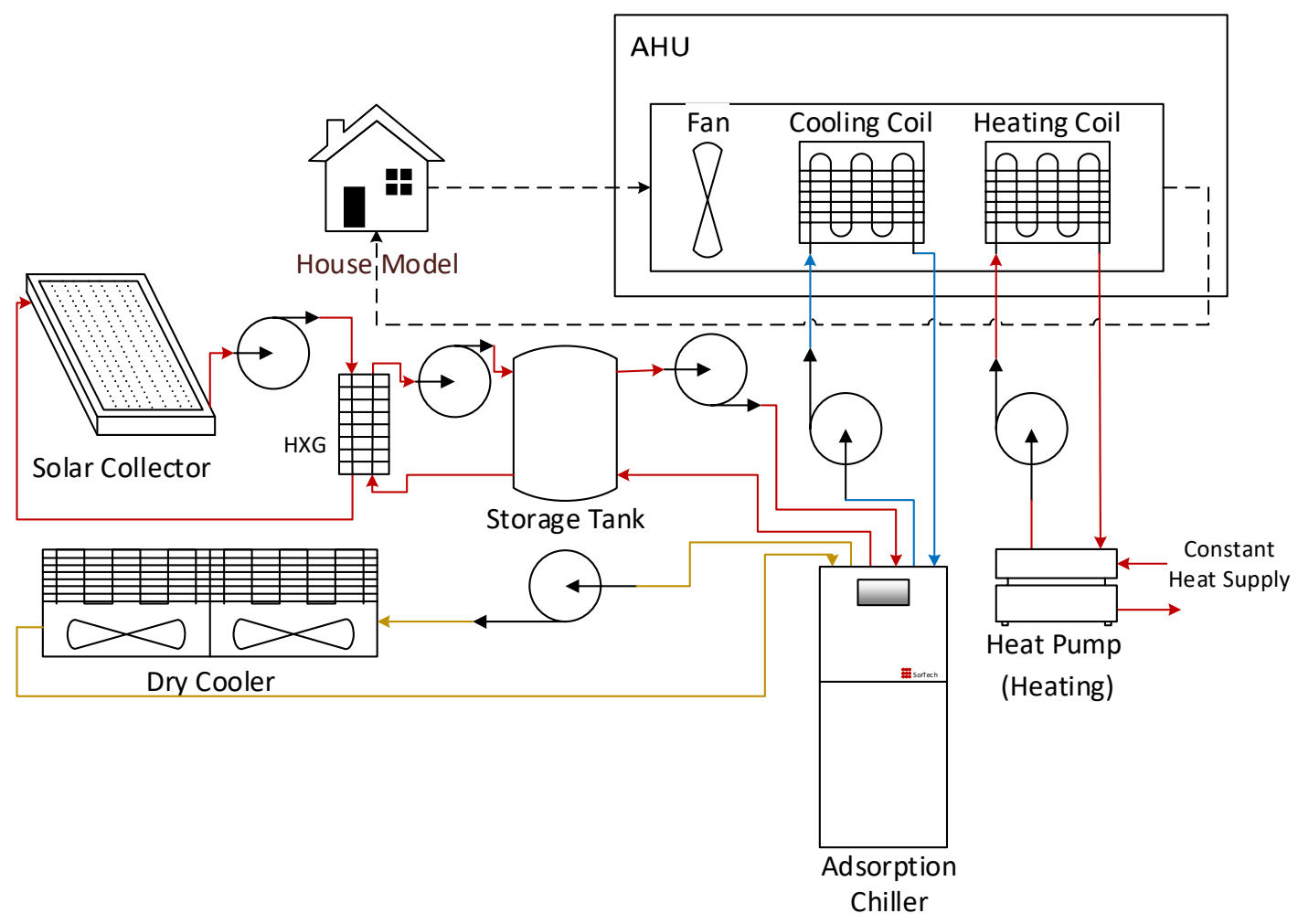

Figure 5.11: Adsorption system layout with solar (HP uses infinite HW supply)

The flat plate collector is connected to the hot water tank through a heat exchanger, and the adsorption chiller draws hot water from the tank. The heat pump is still using the same constant source as in Case 4.

\subsubsection{Case 6}

Case 6 is similar to Case 5 with the exception that the heat pump in Case 6 is also drawing its hot water supply from the hot water tank, which is heated by the same sized solar array as in Case 5 . There is also the addition of a $250 \mathrm{~L}$ cold storage tank with a $16^{\circ} \mathrm{C}$ setpoint to the AC loop. This schematic is as shown as Figure 5.12. 


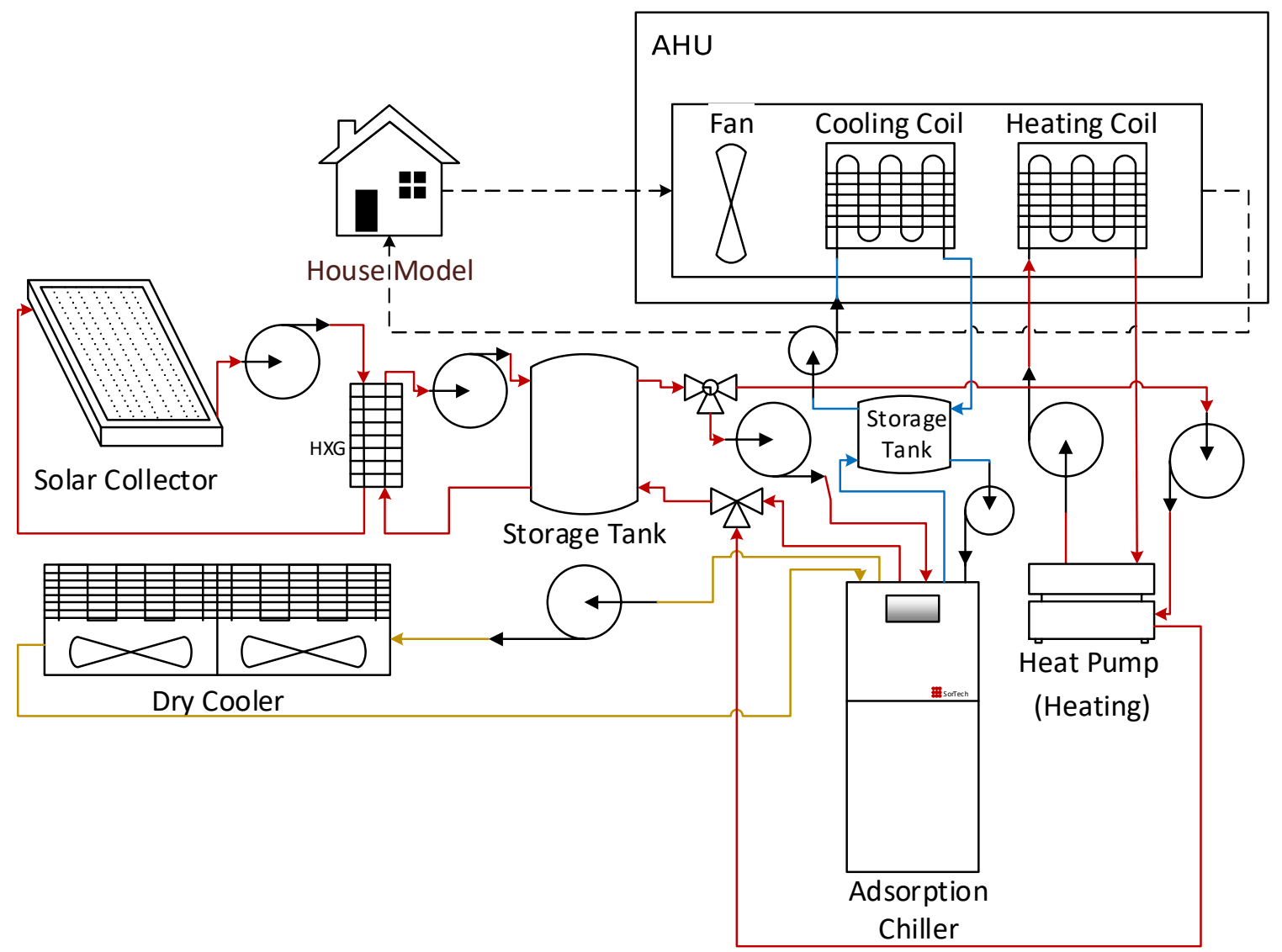

Figure 5.12: Adsorption system layout with solar

This system uses seven pumps between all the lines, where majority of the lines contain water except for the loop from the solar collector to the heat exchanger which is a 50/50\% propylene glycol/water solution.

\subsubsection{Case 7}

Case 7 is the most complex case modelled where the heat pump is removed, and the stored hot water is used to heat the house directly. There is a $500 \mathrm{~L}$ cold storage tank within the chilled water loop to store the chilled water from the chiller to be used at a later time for space cooling. The hot water storage tank size was increased to $1000 \mathrm{~L}$. The schematic for this system can be found in Figure 5.13. 


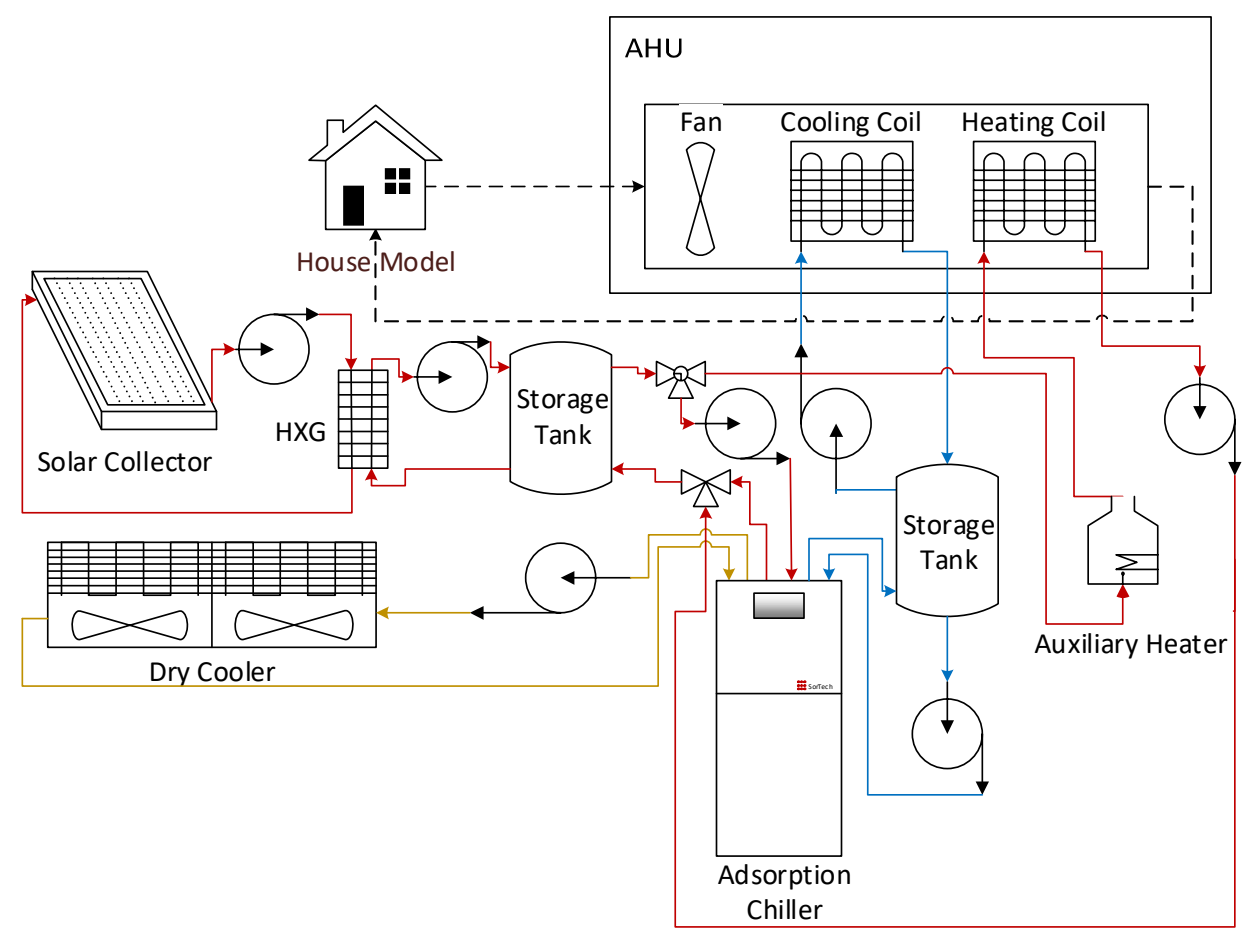

Figure 5.13: Adsorption system utilizing DHW

This system can be scheduled where the adsorption chiller will only operate during off-peak hours, to reduce electrical costs, and still provide cooling when needed. An additional heating source would have to be provided in the event the demand for hot water required for either the chiller, heating, or domestic hot water (DHW) could not be met. There is a $10 \mathrm{~kW}_{\text {th }}$ auxiliary heater with assumed $100 \%$ efficiency installed in the heating line to provide additional heat when the hot water is not enough to heat the system itself.

\subsection{Heat Input}

The heat input is comprised of a flat plate solar collector, pumps, heat exchanger, and a 500L storage tank. There are two main loops to the heat input, one loop circulates glycol through the solar collector and source side of the heat exchanger while water is circulated through the sink side of the heat exchanger and storage tank, where it can be drawn to the adsorption chiller or heat pump. The orientation and specifications of the flat 
plate collector modelled is summarized in Table 5.4 and based of the Apricus FPC-A32 Solar Collector and the efficiency curve of the solar collector is shown in Figure 5.14 [42].

Table 5.4: Simulated solar collector data

\begin{tabular}{c|c}
\hline Variable & Value \\
\hline Aperture Area & $2.8 \mathrm{~m}$ \\
Gross Area & $2.99 \mathrm{~m}$ \\
Number of Panels & 14 \\
$\theta$ & $45^{\circ}$ \\
Fluid Capacity & $1.8 \mathrm{~L}$ \\
Max Flow Rate & $15 \mathrm{~L} / \mathrm{min}$ \\
dir. & Due South \\
Collector Material & 6063 Black Anodized AL \\
\hline
\end{tabular}

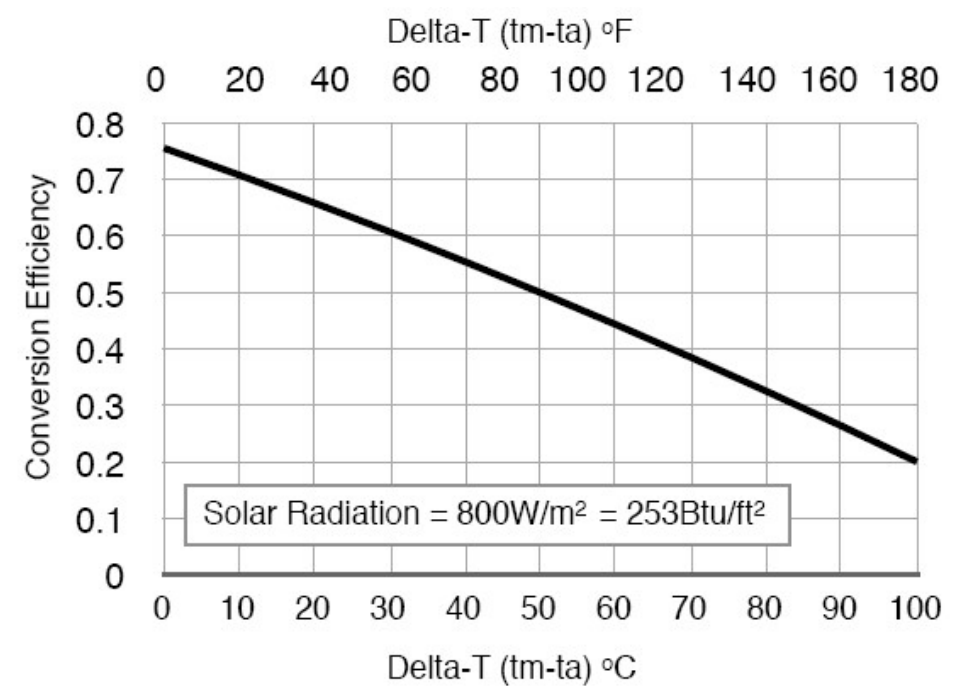

Figure 5.14: Efficiency curve for Apricus solar collector

\subsection{Heat Rejection}

The heat rejection loop was modelled with a dry cooler that was capable of rejecting enough heat to bring the temperature down to $2^{\circ} \mathrm{C}$ warmer than the ambient air [49]. If ambient temperatures were below $22^{\circ} \mathrm{C}$, the dry cooler setpoint would remain at $22^{\circ} \mathrm{C}$. In some cases, a cooling tower may be required due to warmer temperatures as a dry cooler may not be able to provide effective cooling. 


\subsection{Simulation Control}

The TRNSYS simulation was run at a time step of 5 minutes which allows for the adsorption chiller to receive an on or off signal every 5 minutes, simulating the cycling periods it would undergo during operation. The simulation ran from January $1^{\text {st }}$ at 00:00hr to December $31^{\text {st }}$ at $24: 00 \mathrm{hr}$ (total 8760 hours). The convergence and integration limit are relative and were set to 0.001 .

The control systems for this model were configured to only operate during periods when cooling or heating were able to be produced. The solar collection loop only had fluid pumped to the storage tank when the water from the solar collectors were higher than the average tank temperature. Hot water was only drawn from the storage tank when the chiller/heat pump were switched on by the thermostat control. This thermostat control utilized a binary control signal which would call for heating or cooling based off the needs of the house and the time of year. The control signals were sent to the HVAC equipment as well as the pumps in each loop.

The storage tanks also had a temperature setpoint control system. The hot water tank was allowed to keep heating until $90^{\circ} \mathrm{C}$ and if it reached below $45^{\circ} \mathrm{C}$ it would turn the adsorption chiller off. The cold-water storage tank would operate with a $\pm 2^{\circ} \mathrm{C}$ dead band allowing the chiller to charge the tank once it began warming up. Fluid from the tank would be pumped through the house's cooling coil when the house temperature was above the cooling setpoint. A more complex control scheme where the chiller would be limited to operate during off-peak hours to further reduce the peak consumption was not used in this study. 


\subsection{Economics Methodology}

This section discusses the assumptions, rates, and methodology used to determine the utility rates, installation, life cycle and system costs used for the economic analysis. Table 5.5 displays the residential utility rates for electricity and natural gas, where data in alternative units can be found in Appendix C.1. In areas where natural gas was not available the price of furnace oil was used, and the GHG intensity and efficiency of the oil burning furnace (86\%) [50] was also considered during the simulations. For both electricity and natural gas rates, only the variable costs based off usage are considered and not fixed rates.

Table 5.5: Utility rates for each location 2019

\begin{tabular}{|c|c|c|c|c|}
\hline City & Province/Territory & $\begin{array}{c}\text { Electricity Rate } \\
(\$ / \mathrm{kWh})[51]\end{array}$ & $\begin{array}{c}\text { Natural Gas } \\
\text { Rate } \\
(\$ / \mathrm{kWh})\end{array}$ & $\begin{array}{c}\text { Heating Oil } \\
\text { Rate }(\$ / L) \\
{[52]}\end{array}$ \\
\hline Charlottetown & Prince Edward Island & 0.168 & $*$ & 0.61 \\
\hline Edmonton & Alberta & 0.072 & $0.020[53]$ & \\
\hline Fredericton & New Brunswick & 0.112 & $0.083[54]$ & \\
\hline Halifax & Nova Scotia & $\begin{array}{l}\text { Standard: } 0.15603 \\
\text { Off-peak: } 0.0876 \\
\text { On-peak: } 0.19961\end{array}$ & $0.071[55]$ & \\
\hline Montreal & Quebec & $\begin{array}{c}\text { Tier 1: } 0.0608 \text { up to } \\
\text { 40kWh/day } \\
\text { Tier 2: } 0.0938\end{array}$ & $0.018[56]$ & \\
\hline Ottawa & Ontario & $\begin{array}{l}\text { Peak: } 0.134 \\
\text { Mid: } 0.094 \\
\text { Off: } 0.065\end{array}$ & $0.023[57]$ & \\
\hline Saskatoon & Saskatchewan & 0.152 & $0.017[58]$ & \\
\hline St. John's & Newfoundland & 0.122 & $*$ & 0.61 \\
\hline Toronto & Ontario & $\begin{array}{l}\text { Peak: } 0.134 \\
\text { Mid: } 0.094 \\
\text { Off: } 0.065\end{array}$ & $0.023[57]$ & \\
\hline Vancouver & British Colombia & $\begin{array}{l}\text { Tier 1: } 0.0945 \text { up to } \\
\text { 22.2kWh/day } \\
\text { Tier 2: } 0.1417\end{array}$ & $0.032[59]$ & \\
\hline Winnipeg & Manitoba & 0.0874 & $0.041[60]$ & \\
\hline Yellowknife & Northwest Territories & 0.301 & 1 & 1 \\
\hline
\end{tabular}


The annual operating cost of each system was calculated using Equation 5.8,

$$
X=W+C_{\text {fuel }},
$$

where $X$ is the operating cost, $W$ is the cost of electricity, and $\mathrm{C}_{\text {fuel }}$ is the cost of fuel.

Adsorption systems especially ones utilizing solar as the heat input requires the payback period as well as life cycle costs to be determined for an adequate comparison. These systems inherently have lower operating costs but at a much higher capital cost. The PBP is determined using Equation 5.9,

$$
P B P=\frac{C_{\mathrm{ads}}-C_{\mathrm{sys}}}{\left(X_{\mathrm{sys}}+M_{\mathrm{sys}}\right)-\left(X_{\mathrm{ads}}+M_{\mathrm{ads}}\right)},
$$

where $C_{\text {ads }}$ and $M_{\text {sys }}$ is the capital costs and maintenance costs of the adsorption system and its components such as solar collectors, etc. $C_{\text {sys }}$ and $M_{\text {ads }}$ is the system cost and maintenance costs the adsorption system is being compared with. Common components can be neglected in the capital costs such as the cost of ducting and common pumps. The capital costs, installation, and annual maintenance cost of Case 4 and Case 6 are shown in Canadian dollars in Table 5.6. The cost of the solar collector array is not included for Case 4 as it represents a district heating setup while Case 6 does include these costs.

Table 5.6: Costs associated with installing an adsorption system

\begin{tabular}{|c|c|c|}
\hline & $\begin{array}{c}\text { Case 4: Adsorption } \\
\text { System (no solar } \\
\text { collectors) }\end{array}$ & $\begin{array}{c}\text { Case 6: Adsorption } \\
\text { System (with solar } \\
\text { collectors) }\end{array}$ \\
\hline Chiller Cost (\$) & 20,000 & 20,000 \\
\hline $\begin{array}{c}\text { Installation Cost (\$) } \\
\text { Solar Collector System (panels, } \\
\text { piping, insulation, etc.) \& Design } \\
\text { Costs \& Installation (\$) }\end{array}$ & 5,000 & 5,000 \\
\hline Capital Cost (\$) & 0 & 69,000 \\
\hline $\begin{array}{c}\text { Annual Maintenance Cost } \\
\text { (\$year) }\end{array}$ & 100 & 94,000 \\
\hline
\end{tabular}


The cost of the chiller and installation cost is based off the experimental chiller used within this project. The solar collector system and installation cost comes from a publication from National Renewable Energy Laboratories (NREL) [61] where a solar collector system has costs ranging from $\$ 292 \mathrm{USD} / \mathrm{m}^{2}$ to $\$ 3439 \mathrm{USD} / \mathrm{m}^{2}$ with the average being $\$ 1538 \mathrm{USD} / \mathrm{m}^{2}$. This cost is determined based off the average breakdown of $22 \%$ of the cost being the solar collectors themselves, $40 \%$ is plumbing costs, and the remaining $38 \%$ is the engineering, designing, and permitting costs. The costs for the required amount of Apricus solar collectors were determined and the total cost was scaled based on the $22 \%$ value. The annual maintenance costs are based off values companies provide for annual routine maintenance checks [62]. The capital costs with installation cost, and maintenance cost for the comparison systems, Cases 1 to 3 are shown in Table 5.7 [63] with all costs in Canadian dollars.

Table 5.7: Costs associated with installing Cases 1 to 3

\begin{tabular}{|c|c|c|c|}
\hline & Case 1 (Heat pump) & $\begin{array}{c}\text { Case } 2 \text { (Electric } \\
\text { Furnace) }\end{array}$ & $\begin{array}{c}\text { Case } 3 \text { (Natural } \\
\text { Gas Furnace) }\end{array}$ \\
\hline $\mathrm{AC}(\$)$ & - & 3500 & 3500 \\
\hline Electric Furnace (\$) & - & 3600 & - \\
\hline NG Furnace (\$) & - & - & 4600 \\
\hline HP $(\$)$ & 7600 & - & - \\
\hline $\begin{array}{l}\text { Installation Cost } \\
(20 \%)(\$)\end{array}$ & 1520 & 1420 & 1620 \\
\hline Capital Cost (\$) & 9120 & 8520 & 9720 \\
\hline $\begin{array}{c}\text { AC }(\$ / \text { year }) \\
\text { Electric Furnace } \\
(\$ / \text { year }) \\
\text { NG Furnace }(\$ / \text { year }) \\
\text { HP }(\$ / \text { year })\end{array}$ & $\begin{array}{c}- \\
- \\
- \\
130\end{array}$ & $\begin{array}{c}125 \\
130 \\
- \\
-\end{array}$ & $\begin{array}{c}125 \\
- \\
130 \\
-\end{array}$ \\
\hline $\begin{array}{c}\text { Annual Maintenance } \\
\text { Cost (\$/year) }\end{array}$ & 130 & 255 & 255 \\
\hline
\end{tabular}


An adsorption system has significantly higher capital costs, but lower maintenance costs due to the lack of moving parts in the adsorption chiller. Each of these systems have a similar predicted lifespan so their life cycle costs (LCC) for a 25-year period is analyzed using Equation 5.10:

$$
L C C=C+X_{\mathrm{p}}+M_{\mathrm{p}}
$$

where $\mathrm{C}$ is the capital costs, $X_{\mathrm{p}}$ is the present value of the operation costs, and $M_{\mathrm{p}}$ is the present value of the annual maintenance cost. Equation 5.11 can be used to determine the present value,

$$
X_{\mathrm{p}}=X *\left(\frac{1-\left(\frac{1}{1+r}\right)^{n}}{r}\right)
$$

where $n$ is lifespan, $r$ is percent interest rate. The interest rate is determined using a $2 \%$ inflation rate, $i$ [64], discount rate, $d$, of 3\% [65], and using Equation 5.12.

$$
r=(1+d) *(1+i)-1
$$

The breakeven cost (BE) analysis was also done in order to see what the capital costs needed to be to cause this system to become more economically viable than standard systems and what subsidy rate, $S$, can help achieve this. The breakeven and subsidy cost are determined by Equations 5.13 and 5.14 respectively.

$$
\begin{gathered}
C_{\mathrm{BE}}=C_{\mathrm{sys}}+\left(M_{\mathrm{p}, \mathrm{sys}}-M_{\mathrm{p}, \mathrm{ads}}\right)+\left(X_{\mathrm{p}, \mathrm{sys}}-X_{\mathrm{p}, \mathrm{ads}}\right) \\
S=C_{\mathrm{ads}}-C_{\mathrm{BE}, \mathrm{ads}}
\end{gathered}
$$

The cost of the environmental impact is also an important factor to consider. Putting a price on carbon allows for a better comparison of how the reduction of carbon also impacts the systems feasibility. Using a $\$ 50$ per metric ton of carbon dioxide equivalent 
for the carbon price (CP) [66] a new breakeven point is determined using the carbon price and total carbon offset from the standard system using Equation 5.15,

$$
C_{\mathrm{BE}, \mathrm{ads}, \mathrm{CP}}=C_{\mathrm{BE}, \mathrm{ads}}+G H G_{\mathrm{offset}} * C P \text {, }
$$

where the GHG offset is simply the amount of GHG reduced over the lifespan. A new subsidy will also be applied based off the breakeven point with carbon pricing.

\subsection{Limitations and Assumptions}

The simulation analysis and modelling approach were subjected to several assumptions which result in some limitations of the model. Some assumptions made during modelling and simulations are as follows:

- Transients at startup and end of operation for the adsorption chiller model have minimal impact on the overall heat transfer during the period of operation;

- Each node of the storage tank used a one-dimensional heat transfer process;

- The dry cooler was adequately sized to allow for the heat rejection temperature to be within $2^{\circ} \mathrm{C}$ of the ambient temperature;

- Equipment used for the base cases had efficiencies meeting the standards instated within the past decade;

- The initial conditions for the simulation were at the setpoints for each component;

- Cooling from the adsorption chiller did not exceed the maximum values on the performance map;

- The construction of the house model was comparable for each location and equipment/system sizing did not vary between locations; 
- There are no substantial variance in internal gains, due to additional equipment such as pumps, chillers, and storage tanks, in the house model between the six cases studied;

- Heat transfer from the solar collectors into the building envelope of the house model are negligible;

- GHG emissions are constant over the summer (cooling) and winter (heating) months and can be represented by an average value as instead of varying monthly;

- Costs for initial design, installation, and equipment for solar collection must be considered as they are not commonly installed;

- The cost of ducts and storage tanks were similar between all cases and therefore not needed to be considered as they are installed regardless of system; and

- The cost of water to fill or operate some of the cases were negligible.

The main limitations from some of these assumptions are that in practicality the building envelope would vary in construction based on location, the system sizing would also vary based on locations needs, and the effects from the solar collectors on the heat transfer through the building envelope would affect system performance. The assumptions were necessary in order to maintain direct comparability of results between locations. 


\section{Chapter 6: Results and Discussion}

In Chapter 3 and 5 some base results were given for context and will be presented again in this section with additional details and discussions. The experimental results section will review the CIT and DIT test results over the range of the chiller with the common test parameters and will further discuss the mock solar heat input used within the laboratory. The modelling results of the adsorption model and various residential systems across Canada will be discussed. The results from the various residential systems across Canada will be broken down into separate sections for the thermal energy analysis, greenhouse gas analysis, cost basis, and overall systems economic analysis.

\subsection{Experimental Results}

The following section reviews results from the CIT and DIT tests. Tests were shown to be repeatable where some tests were repeated numerous times resulting in very small variances well within the experimental error for the cooling capacity and slightly larger variation in the COP.

\subsubsection{Constant Inlet Temperature}

A CIT is when the inlet temperature to the adsorption chiller are set and controlled by PID loops to maintain a continuous temperature and flow rate. Some CIT test results, shown in Figure 6.1-Figure 6.3, illustrate the variance in cooling performance for changing one temperature value at a time. This allows for the impact of the difference in temperature from the optimal value for each hydraulic line to be visualized for both cooling power and COP. The temperature and flow rate ranges that were tested, along with the range of results is in Table 6.1. 
Table 6.1: Parameter ranges for tests

\begin{tabular}{c|c|c}
\hline Parameter & Range & Unit \\
\hline Cooling capacity & $4.4-14$ & $\mathrm{~kW}_{\text {th }}$ \\
\hline COP & $0.30-0.60$ & - \\
\hline HW inlet & $48-94$ & ${ }^{\circ} \mathrm{C}$ \\
\hline HW FR & 42 & $\mathrm{~L} / \mathrm{min}$ \\
\hline HR inlet & $23-32$ & ${ }^{\circ} \mathrm{C}$ \\
\hline HR FR & 80 & $\mathrm{~L} / \mathrm{min}$ \\
\hline AC inlet & $14-24$ & ${ }^{\circ} \mathrm{C}$ \\
\hline AC FR & 49 & $\mathrm{~L} / \mathrm{min}$ \\
\hline
\end{tabular}

The adsorption chiller performed as expected during the CIT tests, meeting manufacturer specifications. The results can be seen over the testing envelope in the following figures, starting with varying the HR temperature while the other fluid lines were held at a constant temperature, shown in Figure 6.1.

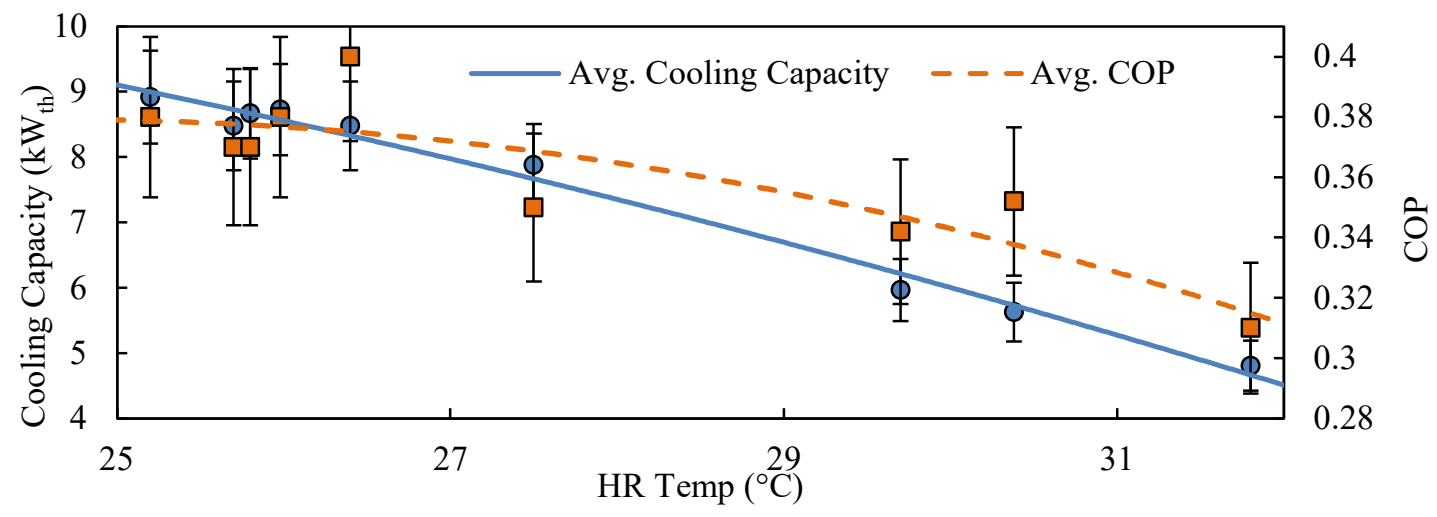

Figure 6.1: Relationship between cooling capacity and varying HR inlet

The AC and $\mathrm{HW}$ temperatures for these tests were held constant at $16^{\circ} \mathrm{C}$ and $85^{\circ} \mathrm{C}$, respectively. It can be seen from Figure 6.1 that the highest performance for the heat rejection temperature is when the temperature is around $25^{\circ} \mathrm{C}$ which is also where the COP is highest. The unit was not tested at heat rejection temperatures below $25^{\circ} \mathrm{C}$ because in those cases, the heat rejection water could have potential to be used directly for space 
cooling. The performance of the chiller while varying the $\mathrm{AC}$ inlet temperature from 14 to $24^{\circ} \mathrm{C}$ is shown in Figure 6.2

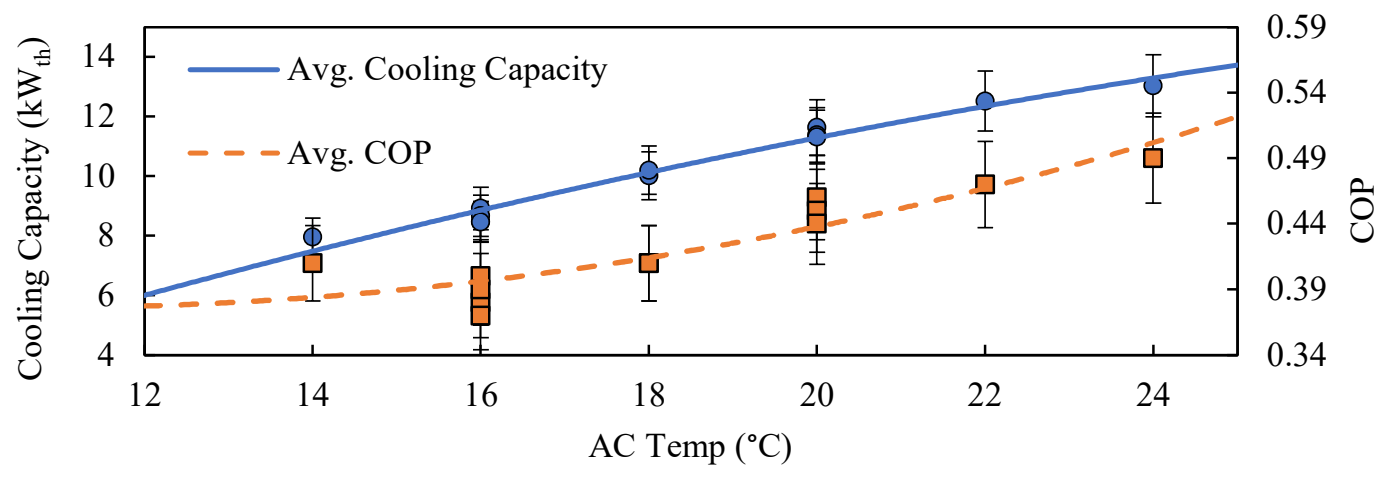

Figure 6.2: Relationship between cooling capacity and varying AC inlet

When the cooling inlet temperature is varied test by test, shown in Figure 6.2, the results show that temperatures between 22 to $24^{\circ} \mathrm{C}$ provide better cooling performance. This is because the return temperature is between 18 to $20^{\circ} \mathrm{C}$ and inlet supply temperatures below this could directly be used for cooling. The HR and HW inlet temperature were held constant at $25^{\circ} \mathrm{C}$ and $85^{\circ} \mathrm{C}$, respectively for these tests. The variation of chiller performance with the HW temperature is shown in Figure 6.3.

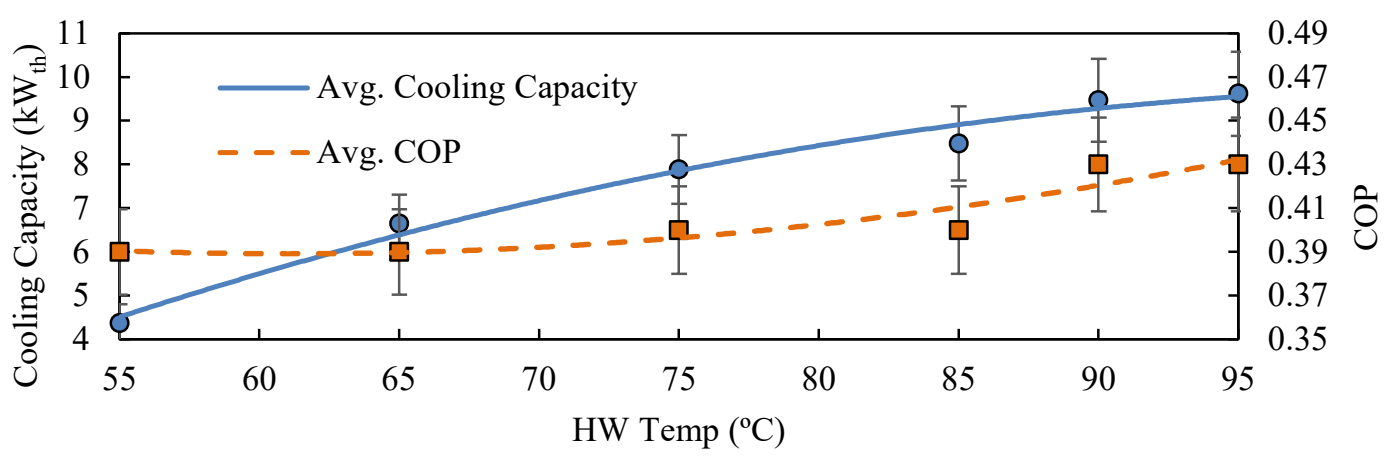

Figure 6.3: Relationship between Cooling capacity and varying HW inlet

The heat input to the chiller, via the hot water line, is the most significant factor in determining the chillers cooling performance. The AC and HR temperatures were held constant around $16^{\circ} \mathrm{C}$ and $25^{\circ} \mathrm{C}$, respectively. The cooling performance increases steadily 
until the hot water temperature reaches 85 to $90^{\circ} \mathrm{C}$ where the increase becomes less significant. As the HW temperature increases, the $\mathrm{COP}$ also increases due to the increase of cooling capacity and begins to taper into a plateau as it approaches $85^{\circ} \mathrm{C}$.

Additional tests were run where the flow rate was varied, and the temperatures were held constant and it was found that in general, varying the flow rates by 15 to $20 \%$ had a smaller effect on the thermal performance than the temperatures. When the flow rates were varied by $15 \%$, the thermal performance varied by about $3 \%$, while when the temperatures were varied by $15 \%$, the thermal performance varied by $11 \%$. The flows were left at the manufacturer specified rates, shown in Table 6.1, as these results produced no reason to alter them.

The parameters for a test yielding an average cooling output of $13 \mathrm{~kW}_{\text {th }}$ are displayed in Table 6.2. The results showing the relationship between the HW inlet temperature and cooling produced are shown in Figure 6.4. While the inlet and outlet temperatures for each hydraulic line are shown in Figure 6.5.

Table 6.2: CIT Test Conditions

\begin{tabular}{|c|c|c|c|c|c|c|c|}
\hline $\begin{array}{c}\text { Cooling } \\
\text { Capacity }\left(\mathrm{kW}_{\text {th }}\right)\end{array}$ & COP & $\begin{array}{c}\text { HW inlet } \\
\left({ }^{\circ} \mathrm{C}\right)\end{array}$ & $\begin{array}{c}\text { HW FR } \\
(\mathrm{L} / \mathrm{min})\end{array}$ & $\begin{array}{c}\text { HR inlet } \\
\left({ }^{\circ} \mathrm{C}\right)\end{array}$ & $\begin{array}{c}\text { HR FR } \\
(\mathrm{L} / \mathrm{min})\end{array}$ & $\begin{array}{c}\text { AC inlet } \\
\left({ }^{\circ} \mathrm{C}\right)\end{array}$ & $\begin{array}{c}\text { AC FR } \\
(\mathrm{L} / \mathrm{min})\end{array}$ \\
\hline 13 & 0.49 & 81 & 42 & 27 & 75 & 24 & 48 \\
\hline
\end{tabular}




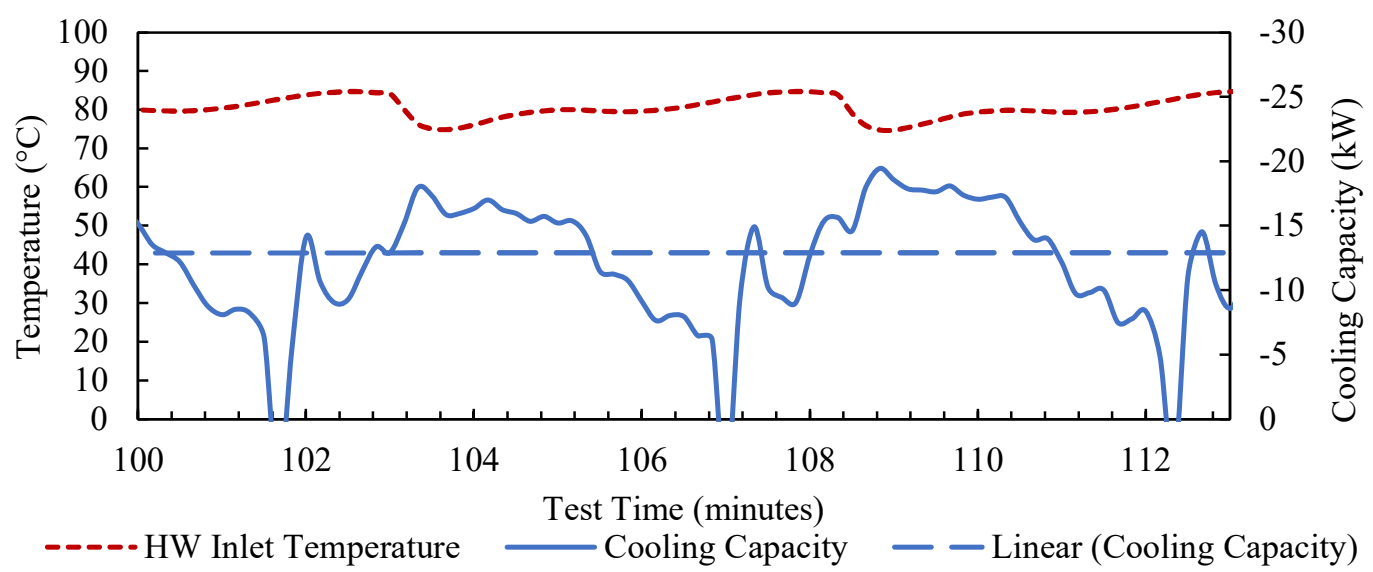

Figure 6.4: HW inlet and cooling capacity for two cycles of a constant inlet temperature test

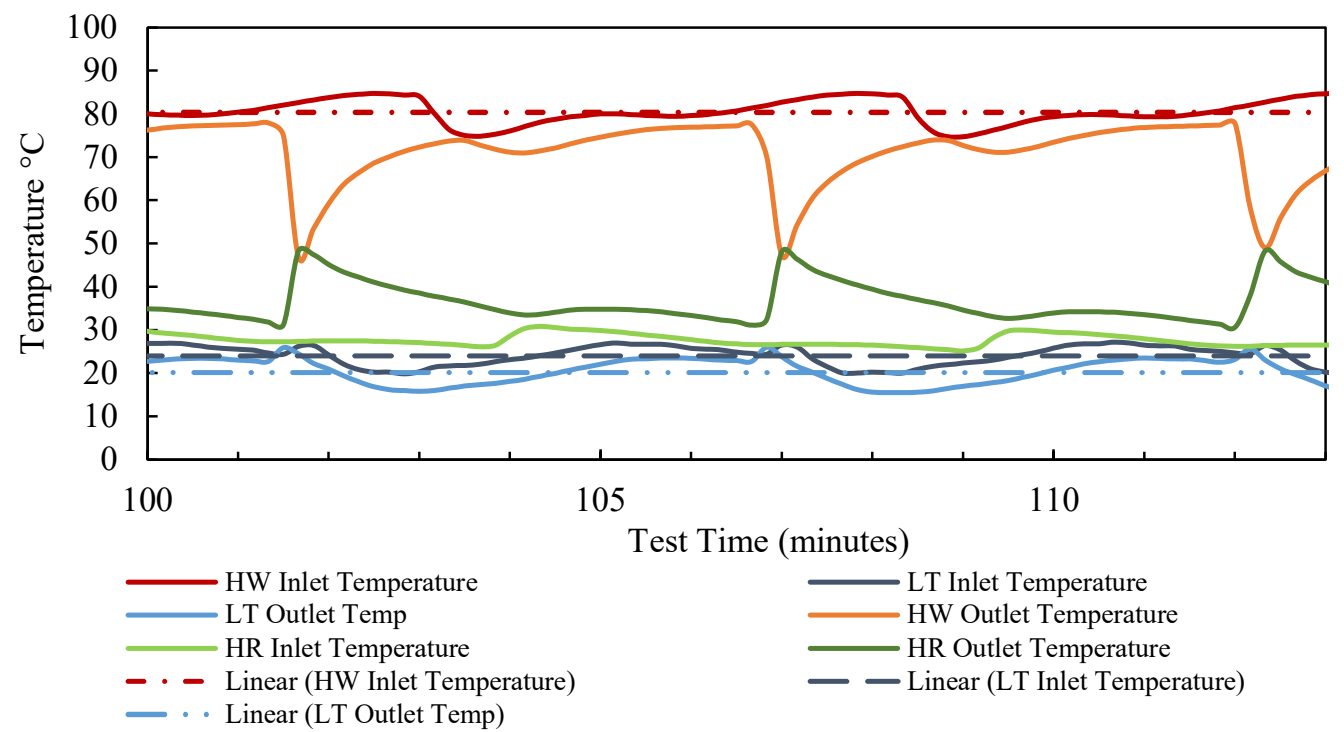

Figure 6.5: Chiller inlet and outlet temperatures for two cycles of a constant inlet temperature test

To effectively display the cyclic nature of the adsorption chiller the above figures show the duration of two full cycles. A cycle start/end is shown in Figure 6.4 when the cooling power rapidly drops to zero and when the HW and HR outlet spike towards each other in Figure 6.5. The cooling power from the adsorption chiller is cyclic due to the unit switching from adsorbing in Barrel A and desorbing in Barrel B to adsorbing in Barrel B and desorbing in Barrel A. The moment of the switching, when the control valves are moving positions, cause temperature fluctuations in the lines due to the remaining high temperature or low temperature water in the circuit during switching. The fluctuations in 
temperature is causing the fluctuations in the cooling capacity as it is calculated from the temperatures and flow rate. The cycles look similar over the duration of the test except for the first startup cycles and the last shutdown cycle.

\subsubsection{Dynamic Inlet Temperature}

The dynamic inlet temperature results are reflective of being connected to a solar collector array as the hot water inlet temperature can vary based off the calculated solar gains from the dynamic heat input program created.

Using the data from thirty CIT tests, the ideal operating temperatures for HR and AC were determined based off the performance graphs shown as Figure 6.1 to 6.3. These ideal operating temperatures were determined to be $22^{\circ} \mathrm{C}$ and $25^{\circ} \mathrm{C}$ for the $\mathrm{AC}$ and $\mathrm{HR}$ lines, respectively, due to their higher performance and COP. The control system varies

the HW constantly, and new weather data is read in every 15 minutes to increase or decrease the temperature setpoint. Operating conditions for the test are shown in Table 6.3, and the radiation and HW inlet temperature are shown in Figure 6.6, using 2016 CWEC data for August $1^{\text {st }}$ (shown in Figure 3.2).

Table 6.3: DIT Test Conditions

\begin{tabular}{|c|c|c|c|c|c|c|c|}
\hline $\begin{array}{c}\text { Cooling Capacity } \\
\left(\mathrm{kW}_{\text {th }}\right)\end{array}$ & COP & $\begin{array}{c}\text { HW inlet } \\
\left({ }^{\circ} \mathrm{C}\right)\end{array}$ & $\begin{array}{c}\text { HW FR } \\
(\mathrm{L} / \mathrm{min})\end{array}$ & $\begin{array}{c}\text { HR inlet } \\
\left({ }^{\circ} \mathrm{C}\right)\end{array}$ & $\begin{array}{c}\text { HR FR } \\
(\mathrm{L} / \mathrm{min})\end{array}$ & $\begin{array}{c}\text { AC inlet } \\
\left({ }^{\circ} \mathrm{C}\right)\end{array}$ & $\begin{array}{c}\text { AC FR } \\
(\mathrm{L} / \mathrm{min})\end{array}$ \\
\hline 8.5 & 0.51 & 62 & 36 & 25 & 72 & 22 & 47 \\
\hline
\end{tabular}




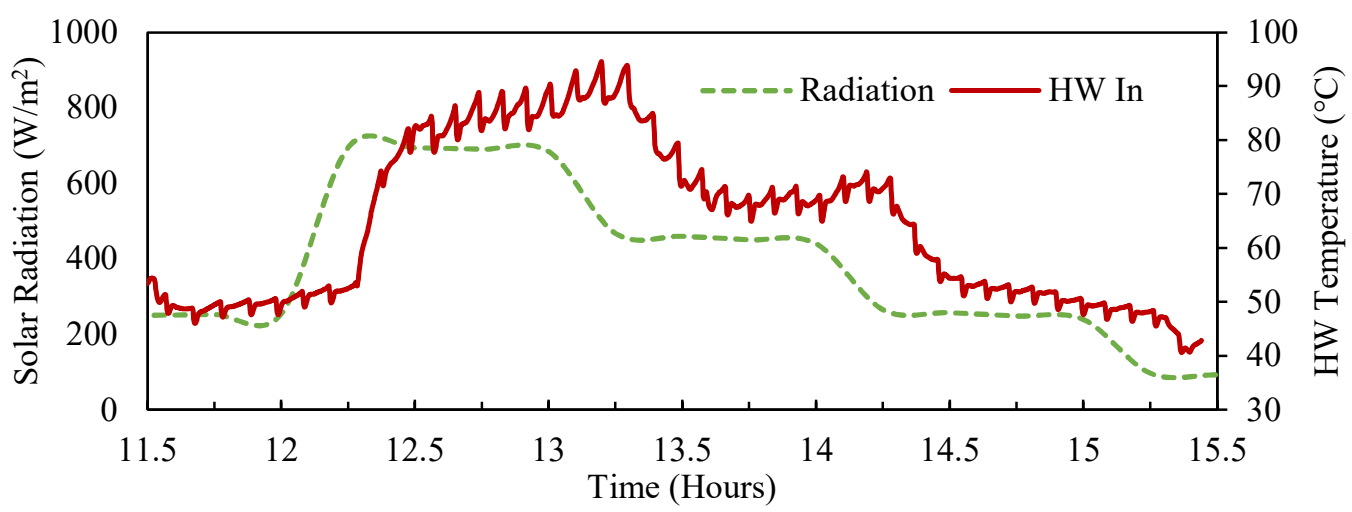

Figure 6.6: Hot water vs solar radiation over test duration

The hot water inlet temperature increases based off the radiation available. There is some time delay because it is a thermal system and heat transfer is not instantaneous. The trends of each line match, whereas if the radiation steps up or down the hot water temperature will also step up or down, respectively. The cooling capacity throughout the test is a function of the hot water available, because in adsorption systems, the hot water is the driving force. This allows for a strong correlation between the cooling power (capacity) and the HW inlet temperature, shown in Figure 6.7.

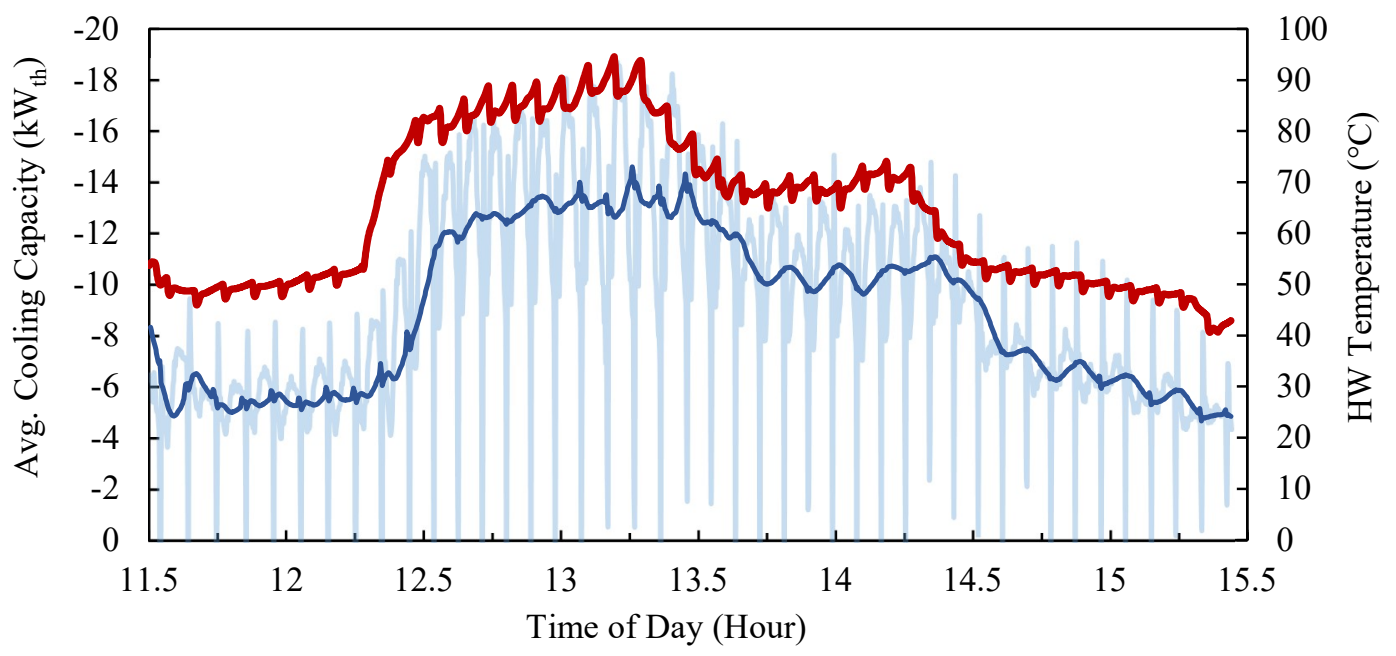

Cooling Power — HW In $\quad 32$ per. Mov. Avg. (Cooling Power)

Figure 6.7: Cooling capacity vs hot water inlet over test duration 
The trendline of 32 per moving average was used to reduce the large spiking of the cooling power due to the cyclic parts of the tests, when the AC inlet and outlet would be almost the same temperature during switching points. There are approximately 32 data points recorded every cycle, so using this period allows for the trendline to be developed as a per cycle average. The HW temperature is a function of radiation available, and because the cooling capacity is a function of the HW temperature, it allows for the cooling capacity to be correlated to the amount of solar radiation available, shown in Figure 6.8.

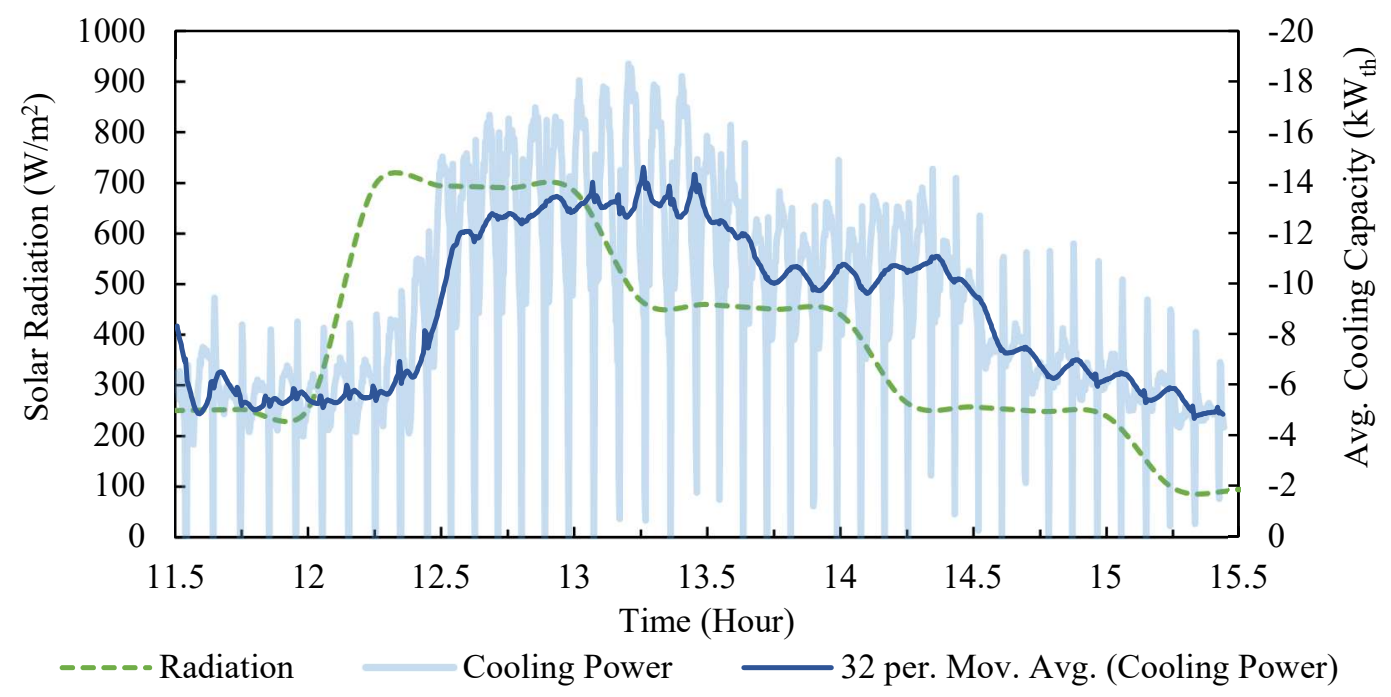

Figure 6.8: Cooling capacity vs solar radiation over test duration

Similar to the trends for the cooling power and heat input to the adsorption chiller, as the radiation increases or decreases, after a slightly delay the cooling power also follows suit.

\subsubsection{CIT Compared to DIT}

Comparing the CIT and DIT results allows for observation of any thermal advantages or implications for either operating style. These findings are important as a CIT test represents how the chiller would operate on a district heating system and a DIT test represents to how the chiller would operate with a solar collector. 
After completing a broad range of tests to cover the operating envelope of the chiller, trends could be created to represent the overall testing method, shown in Figure 6.9. The constant inlet temperature tests were performed over eight HW inlet temperature setpoints while the remaining condition were held steady. To vary the average dynamic inlet temperature from test-to-test numerous solar profiles were used to allow for varying rates and amounts of solar heat input.

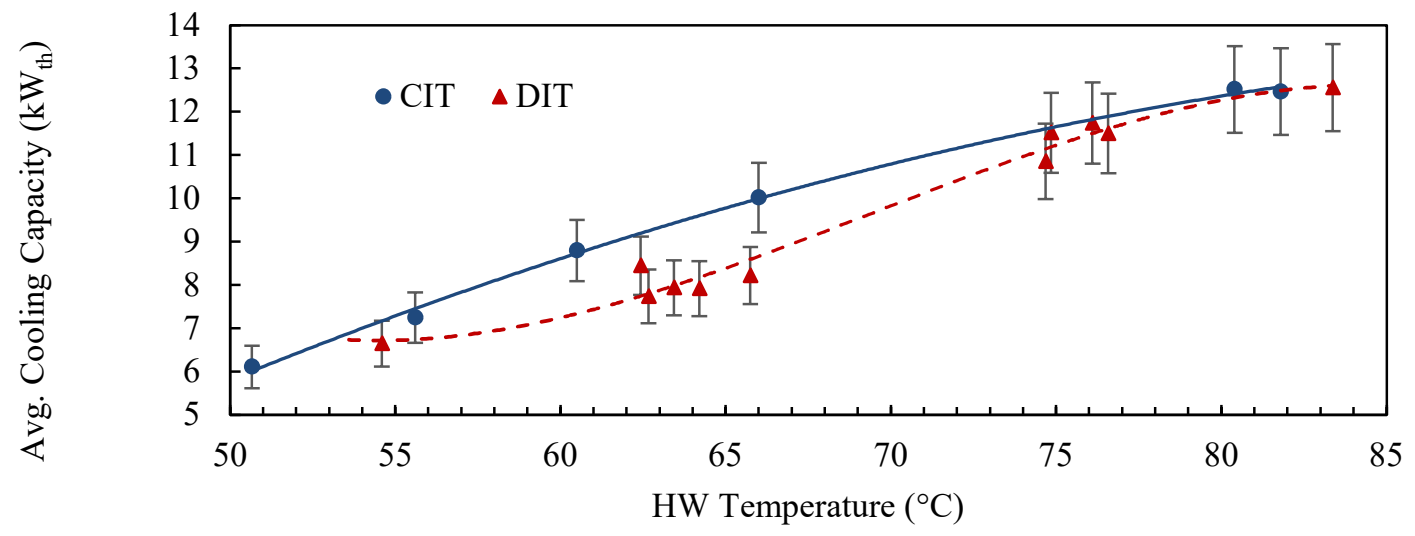

Figure 6.9: Comparison of CIT and DIT test results

The DIT and CIT tests show similar performance at high average HW temperature, but in the mid-range, approximately 58 to $68^{\circ} \mathrm{C}$, the performance for DIT tests is lower, and when the $\mathrm{HW}$ temperature is below approximately $55^{\circ} \mathrm{C}$ DIT results are higher. This is because during the DIT tests, the HW temperature has a higher variation which causes the average to incorporate results at lower and higher HW temperatures which either reduces or increases performance, respectively. During a test with an average HW inlet of $55^{\circ} \mathrm{C}$, a portion is run at temperatures between 45 to $50^{\circ} \mathrm{C}$ where the cooling performance drops off significantly, to only about $4 \mathrm{~kW}$ th. Performance varies more linearly during other portions of the test, around $65^{\circ} \mathrm{C}$, where the cooling capacity is around $10 \mathrm{~kW}$ th. Averaging these two parts of the DIT tests produces a higher average performance in the lower range 
of the HW temperature. In summary, the DIT tests showed that adsorption cooling systems with a flat plate solar collector would be feasible within the residential sector in Canada with district heating or when the solar collector can provide an adequate amount of average heat input above $50^{\circ} \mathrm{C}$.

\subsection{Modelling Results}

This section provides an analysis of the adsorption chiller component and its validation with experimental results. Then the simulation results of the solar cooling system are shown, and results from different cities and configurations are compared.

\subsubsection{Adsorption Model}

The adsorption model Type-909 in TRNSYS was used with the normalized data performance map for the adsorption chiller seen in Figure 5.1. Experimental input conditions were fed into the model and the instantaneous results matched typically within 3 to $12 \%$. It appears that the adsorption model reacts slower to the spiking HW and HR temperatures causing some additional variance from the experimental results when compared instantaneously, as discussed in the model validation section. However, the cumulative results match with reasonable error. Using this method by integrating the total cooling, heat rejection, and heating thermal power over the test period allows for a more accurate analysis of the model outputs. Numerous CIT and DIT tests were run and compared to experimentally validate the model. An example of the integrated thermal power for a CIT test can be seen in Figure 6.10. 


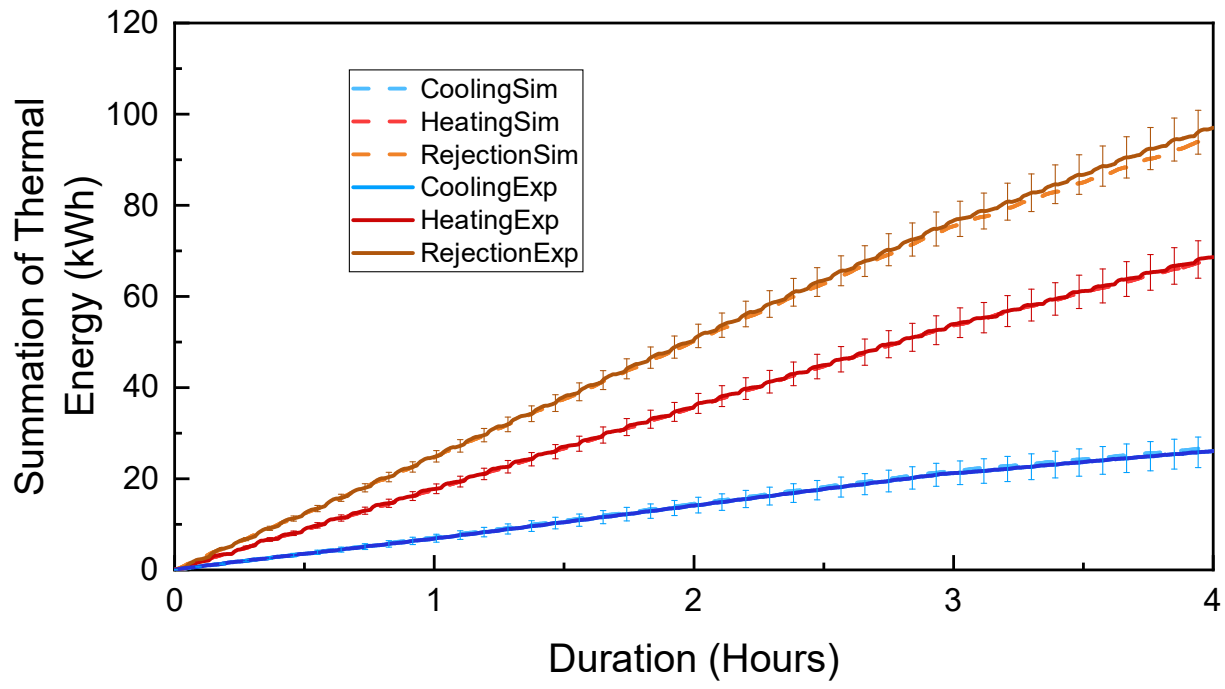

Figure 6.10: Integrated simulated thermal power values for a continuous inlet temperature test (CIT)

Figure 6.10 shows that each respective line falls within the error bars for the experimental data. The dotted lines are the simulation results, and the solid lines are the experimental. The difference between the simulated and experimental results is shown in Table 6.4. It was found that there was a difference of less than $3 \%$ for the cumulative cooling power produced over the test's duration where the chiller model overpredicts cooling produced, while the cumulative experimental error was $9.8 \%\left( \pm 2.58 \mathrm{kWh}_{\text {th }}\right)$. From the tests average $\mathrm{HW}$ inlet temperature $\left(71^{\circ} \mathrm{C}\right)$ and average cooling capacity $(7.05 \mathrm{~kW})$ the average experimental error was $12.1 \%( \pm 0.85 \mathrm{~kW})$.

Table 6.4: Comparison of integrated thermal power between the CIT simulation and test

\begin{tabular}{|c|c|c|c|}
\cline { 2 - 4 } \multicolumn{1}{c|}{} & $\begin{array}{c}\text { Cooling } \\
\left(\mathrm{kWh}_{\text {th }}\right)\end{array}$ & $\begin{array}{c}\text { Heat Rejection } \\
\left(\mathrm{kWh}_{\text {th }}\right)\end{array}$ & $\begin{array}{c}\text { Heating } \\
(\mathrm{kWh}\end{array}$ \\
\hline Experimental & 26.09 & 97.01 & 68.63 \\
\hline Simulation & 26.80 & 94.89 & 68.09 \\
\hline Difference & 0.71 & 2.12 & 0.54 \\
\hline \% Difference & 2.71 & 2.18 & 0.79 \\
\hline
\end{tabular}


The model was also tested using data from the dynamic inlet temperature tests which simulate a solar collector's heat input, and the results are shown in Figure 6.11.

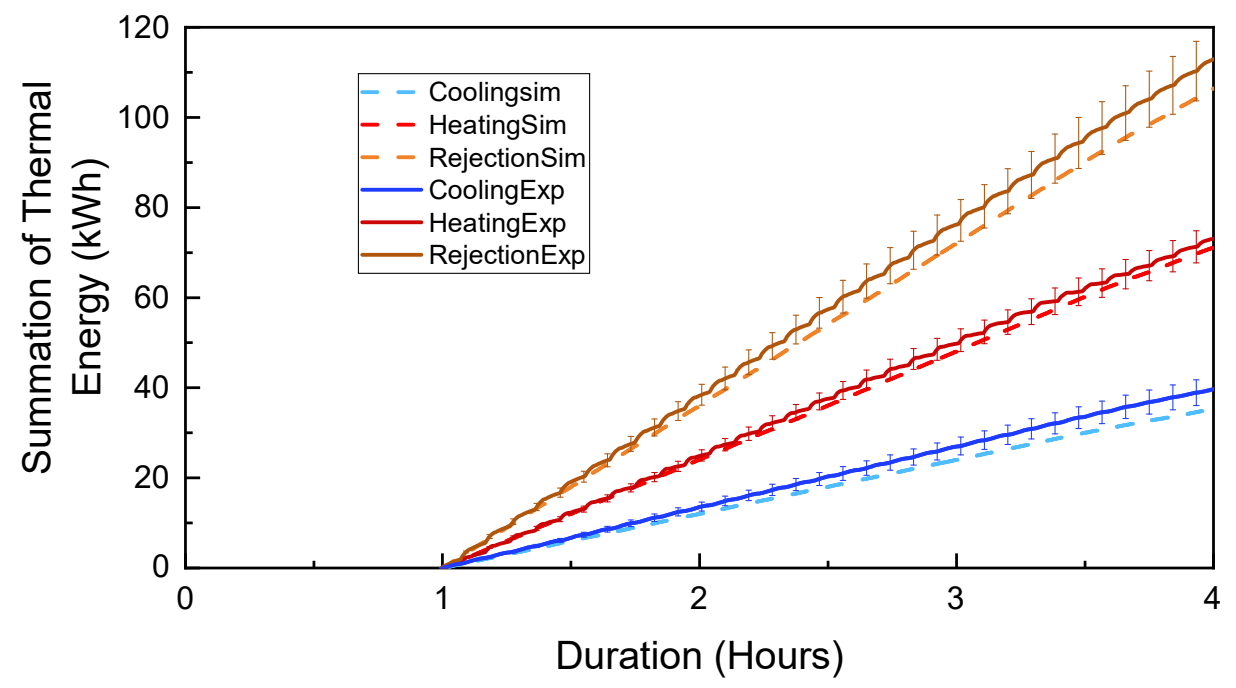

Figure 6.11: Integrated thermal power for a dynamic inlet temperature test (DIT)

The integrated results for the DIT fall just outside the error bars of the experimental results but are still within $12 \%$ of the experimental results. The cumulative cooling produced over the tests duration was predicted approximately $11 \%$ lower than the experimental results, while cumulative experimental error was $7.6 \%( \pm 3.0 \mathrm{~kW}$ th $)$. Table 6.5 shows the numerical details on the accuracy for Figure 6.11.

Table 6.5: Comparison of integrated thermal power between DIT simulation and test

\begin{tabular}{|c|c|c|c|}
\cline { 2 - 4 } \multicolumn{1}{c|}{} & $\begin{array}{c}\text { Cooling } \\
(\mathrm{kWh}\end{array}$ & $\begin{array}{c}\text { Heat Rejection } \\
\left(\mathrm{kWh}_{\text {th }}\right)\end{array}$ & $\begin{array}{c}\text { Heating } \\
\left(\mathrm{kWh}_{\text {th }}\right)\end{array}$ \\
\hline Experimental & 39.70 & 112.90 & 73.08 \\
\hline Simulation & 35.25 & 106.41 & 71.16 \\
\hline Difference & 4.44 & 6.49 & 1.92 \\
\hline \% Difference & 11.20 & 5.75 & 2.63 \\
\hline
\end{tabular}

A difference of $11.2 \%$ from the experimental results for cooling provided was deemed to be suitable during this DIT simulation as there was almost $13 \mathrm{kWh}_{\text {th }}$ more 
cooling produced than the CIT simulation, which would result in higher cumulative error. The tests average $\mathrm{HW}$ inlet temperature was $87^{\circ} \mathrm{C}$ with an average cooling capacity of $13.2 \mathrm{~kW}_{\text {th }}$ with an average experimental error was $7.3 \%\left( \pm 0.97 \mathrm{~kW}_{\text {th }}\right)$. When the average cooling capacity is over $13 \mathrm{~kW}_{\text {th }}$ it would be expected some of the cycles may produce cooling close to $16 \mathrm{~kW}_{\text {th }}$, which cannot be accounted for as the highest cooling capacity on the performance map is $14.7 \mathrm{~kW}_{\text {th }}$. Over a period of 4 hours this could cause a lower-thanexpected value for the cumulative cooling provided. This is assumed to not have an effect on the simulation results of the house model because it is unlikely the hot water storage tank has an average temperature near $90^{\circ} \mathrm{C}$ to allow the chiller to exceed the performance map.

\subsubsection{Toronto Case Comparison}

As mentioned in Section 5.2, a validated house model for urban Ontario was used for this study. This section shows the results for Case 1 to 6 for the city of Toronto and Section 6.2.3 shows the results for Case 1 to 4 and 6 for each of the cities tested. A description of each case can be found in Table 5.3, and the system diagrams for these cases can be seen in Figure 5.7 to Figure 5.12. The annual heating and cooling produced and electrical consumption in Toronto are shown in Figure 6.12.

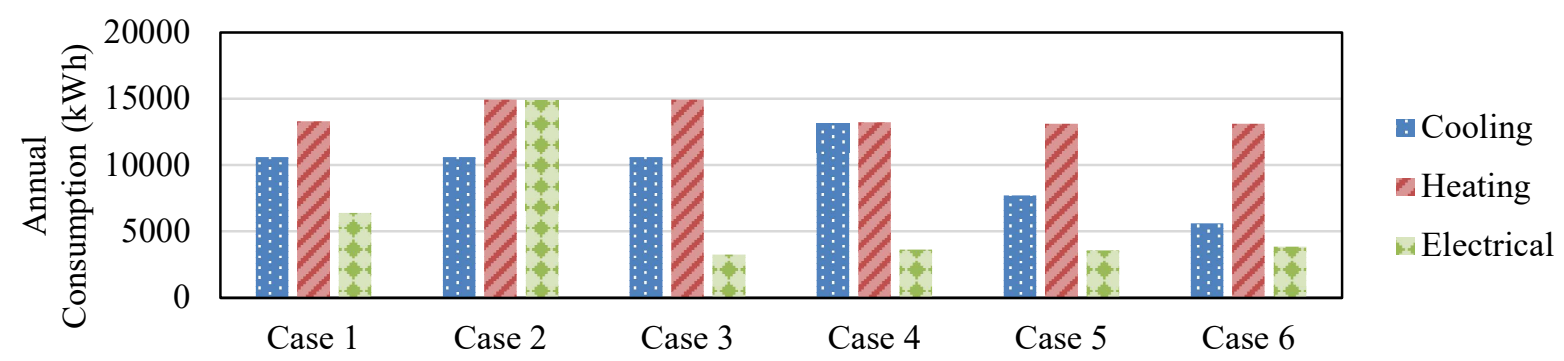

Figure 6.12: Simulated annual thermal and electrical consumption for house model in Toronto 
The cooling load produced from the adsorption chiller in Case 5 and Case 6 are slightly lower than that of Cases 1 to 3 and could be seen as undersized, however the temperatures in the house are still conditioned within ASHRAE standard 55-2013b [67] with the maximum temperature in the summer under $27^{\circ} \mathrm{C}$ [68]. The average main floor temperature during the cooling season are $22.4^{\circ} \mathrm{C}$ for Case $1,22.5^{\circ} \mathrm{C}$ for Case 2 and Case $3,22.1^{\circ} \mathrm{C}$ for Case $4,23.2^{\circ} \mathrm{C}$ for Case 6 . Case 4 shows how much cooling the chiller system in Case 6 could provide given a higher hot water temperature, where the electrical consumption between Case 4 and 6 is largely unaffected. Figure 6.13 shows the electrical consumption for each peak rate for the TOU billing for each case.

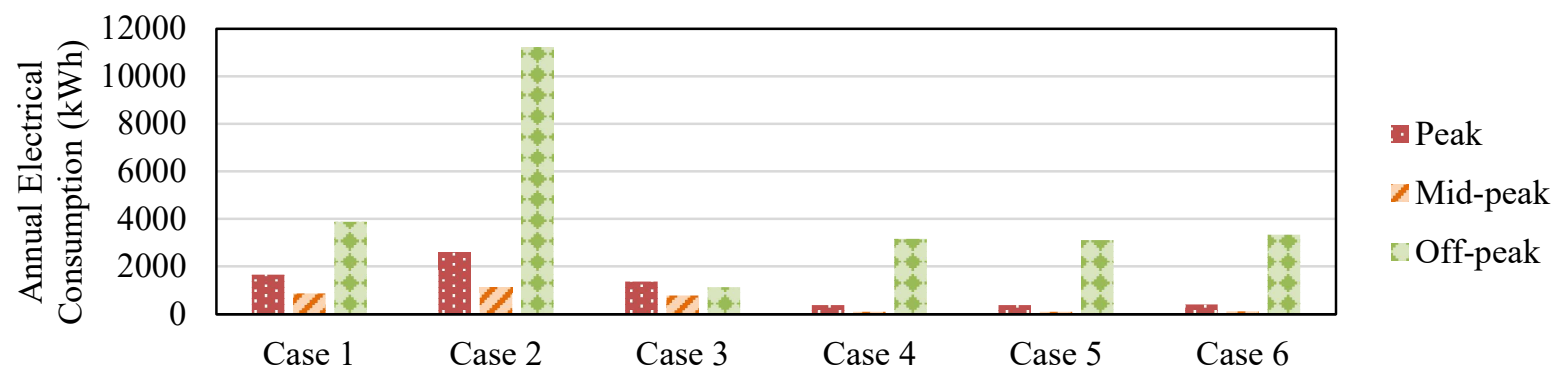

Figure 6.13: Simulated annual electrical consumption breakdown by time-of-use rate

The adsorption systems significantly reduce the peak electrical consumption where most of the peak electrical demand can be attributed to the cooling load. Additionally, electric heating in Case 2 adds a significant increase to the off-peak consumption and slight increase to the peak consumption. The off-peak consumption between Cases 1, 4, 5, and 6 are similar due to the heating being provided by the same heat pump. In comparison to a standard $\mathrm{AC}$ and electric heating, Case 2, the adsorption, and heat pump system require significantly less energy to provide similar heating and cooling. The greenhouse gas emissions in terms of equivalent $\mathrm{CO}_{2}$ and cost of each case is shown in Figure 6.14. 


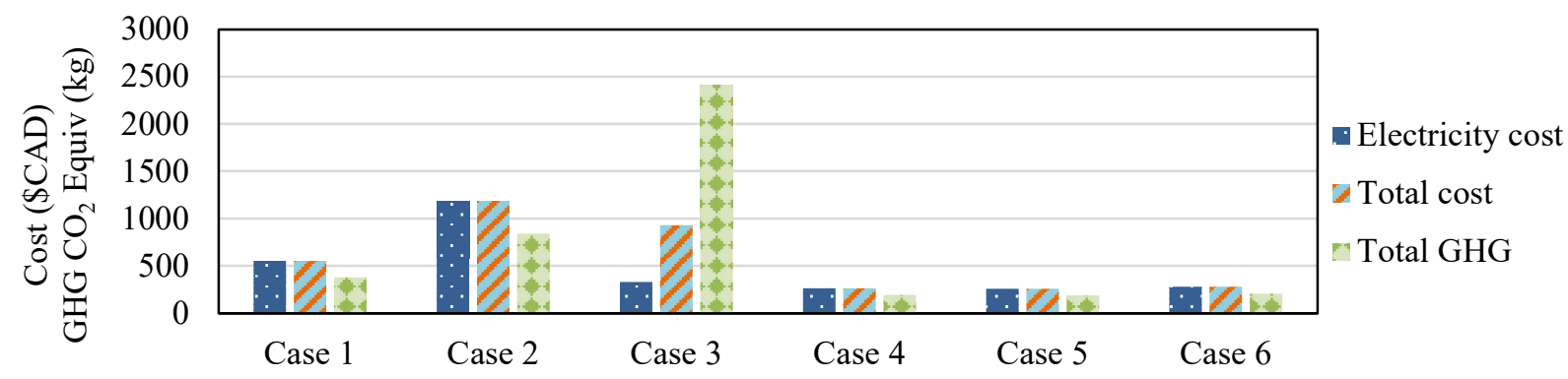

Figure 6.14: Economic and environmental costs/impacts for each experimental case in Toronto

Natural gas heating is cheaper than that of an electric heater but produces significantly more greenhouse gases in Ontario as is illustrated in Figure 6.14. The cost of electricity between adsorption cases and the first three cases is significantly reduced. This is due to the reduction power required to cool the house, which then reduces the greenhouse gas emissions due to the systems energy consumption. The electricity cost of Cases 4 to 6 would not increase greatly if the cooling provided was increased as that would require a higher water temperature, which can be achieved by a larger solar array or an evacuated tube collector.

\subsubsection{Canada-wide Modelling Results}

In this study, there was a total of 12 cities selected because they have different climate, solar potential, and utility rates. There was at least one city per province with two in Ontario as well as one city in the territories. The results look across Canada to compare the feasibility of a solar adsorption chiller as a replacement for the typical natural gas or electric furnace and air conditioner with which most residential homes are equipped. Cases 1 to 4 and 6 are analyzed in Toronto, Ottawa, Montreal, Vancouver, Halifax, Saskatoon, Edmonton, Winnipeg, St. John's, Fredericton, Charlottetown, and Yellowknife. Case 5 is neglected in this section as it is a simplified version of Case 6 as shown by the analysis in Section 6.2.2.1. For the GHG analysis, Figure 6.15 to Figure 6.21 , Case 4 is 
omitted as it is values would be almost identical to Case 6 which had approximately $250 \mathrm{kWh}(6 \%)$ more electrical consumption in Toronto. The annual electrical consumption for the cases and cities is shown in Figure 6.15.

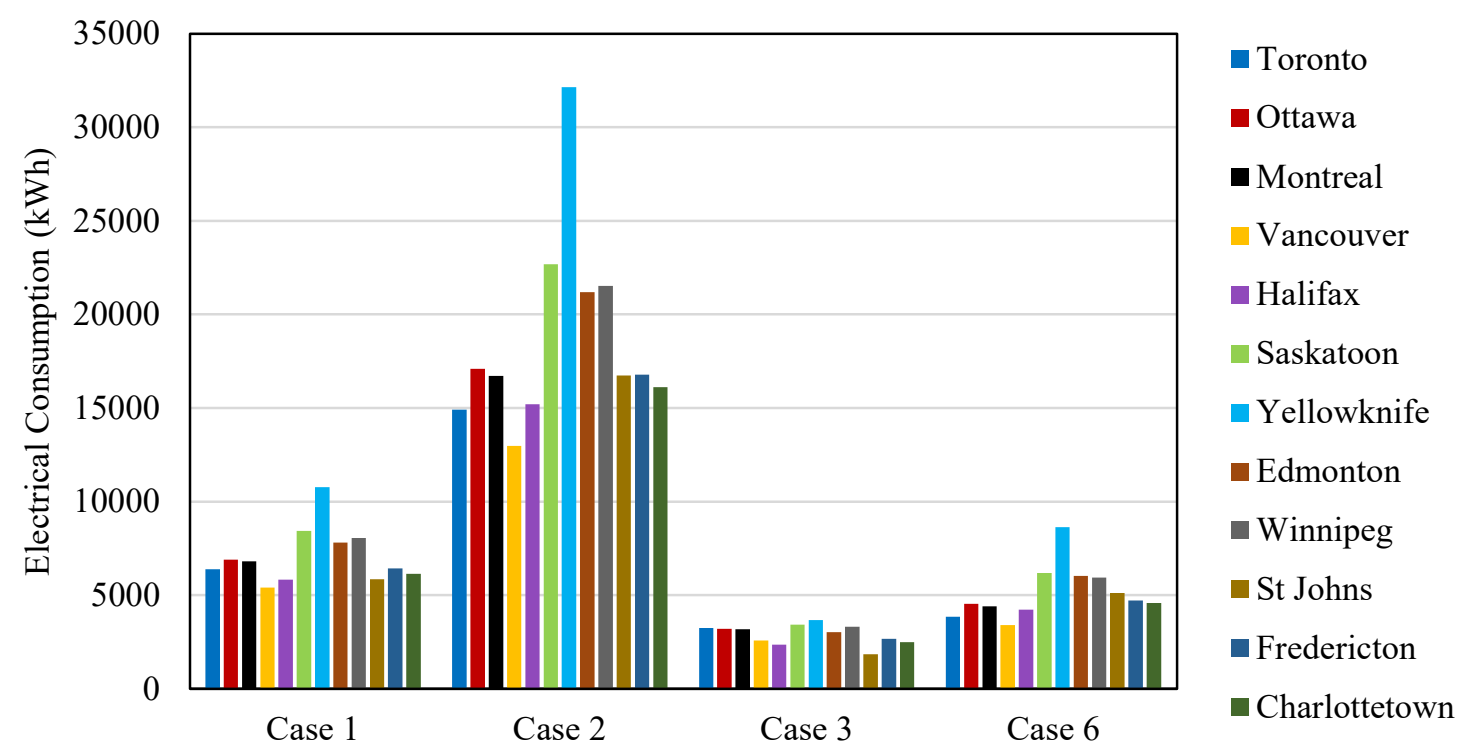

Figure 6.15: Electrical consumption for each city

It can be seen that across all cities, the electrical consumption was reduced significantly in Case 6 where the adsorption chiller was used to cool in the summer and a heat pump supplied heating in the winter. Compared to Case 2 with the electric furnace, there is nearly a threefold reduction in the electricity consumed. When compared to a system with a heat pump, there is nearly a $30 \%$ reduction of electrical consumption across all cities. The largest improvement was seen in Yellowknife where the electrical consumption was reduced by nearly $23000 \mathrm{kWh}$. Not only does this reduce a significant amount of electrical production in an area where electricity is very expensive, but it also shows the application for remote communities where diesel generators are the prominent supplier for electricity. The version of this chart with Case 7 is in Appendix C.2. Case 7 is omitted from the remainder of figures presented due to its high electrical consumption from 
the auxiliary heater being required more frequently than expected, causing electrical consumption similar to Case 2. With an auxiliary heater operating in such a manner the performance benefit of the system is entirely neglected. Complex systems such as Case 7 must be carefully sized with an optimized control scheme to prevent the system from operating in detrimental conditions, reducing the positive appeals to an adsorption system.

\subsection{Thermal Energy Analysis}

The thermal energy implications of this type of system are important because it can be heavily dependent on occupant behavior. Variance from the heating and cooling setpoints used in this study of $20^{\circ} \mathrm{C}$ and $23^{\circ} \mathrm{C}$ can cause large performance gains/losses if the system size is not adjusted to accommodate the difference. The overall amount of cooling power produced could be a lot lower if the setpoint is placed even $1{ }^{\circ} \mathrm{C}$ higher on average. Figure 6.16 and Figure 6.17 display the cooling and heating power results, respectively.

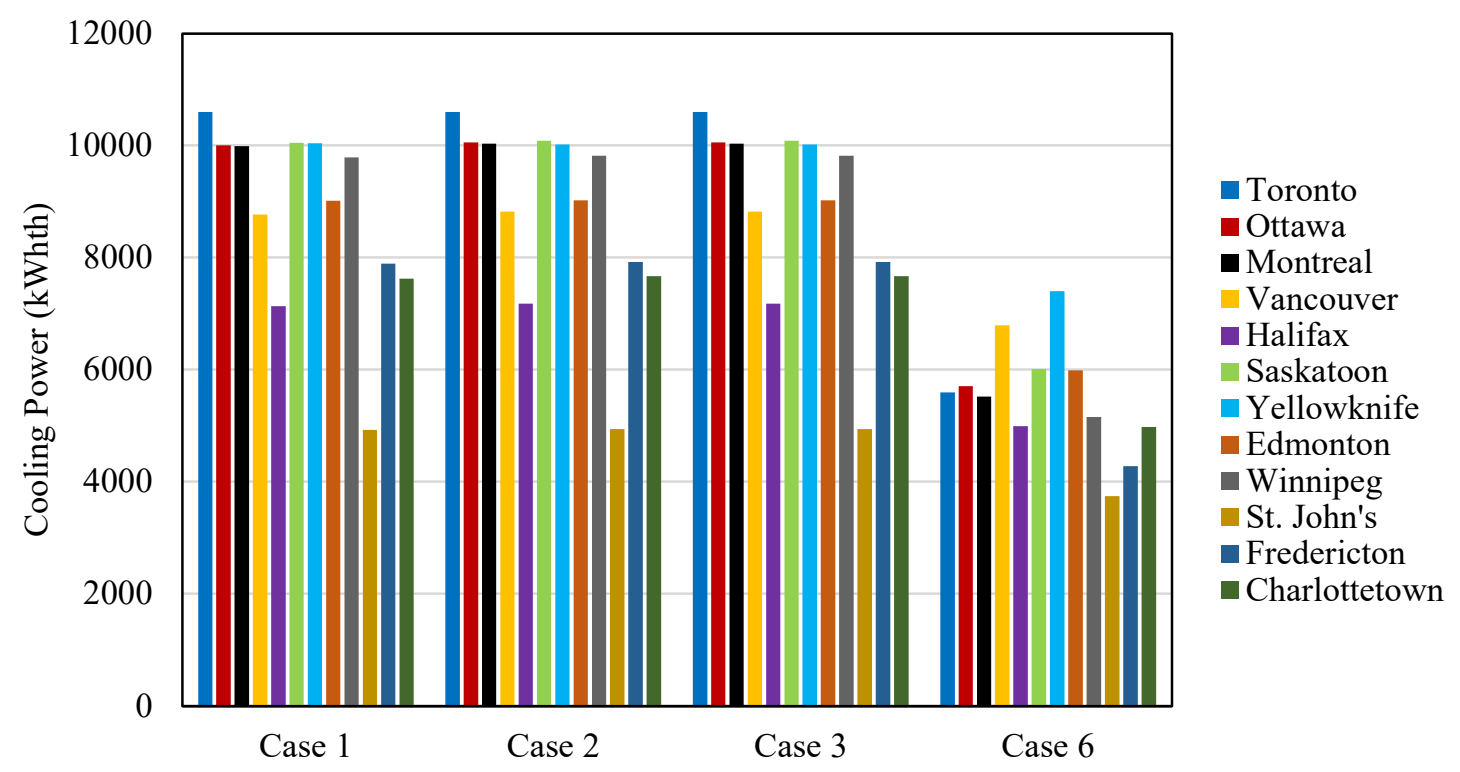

Figure 6.16: Cooling power provided to each city 


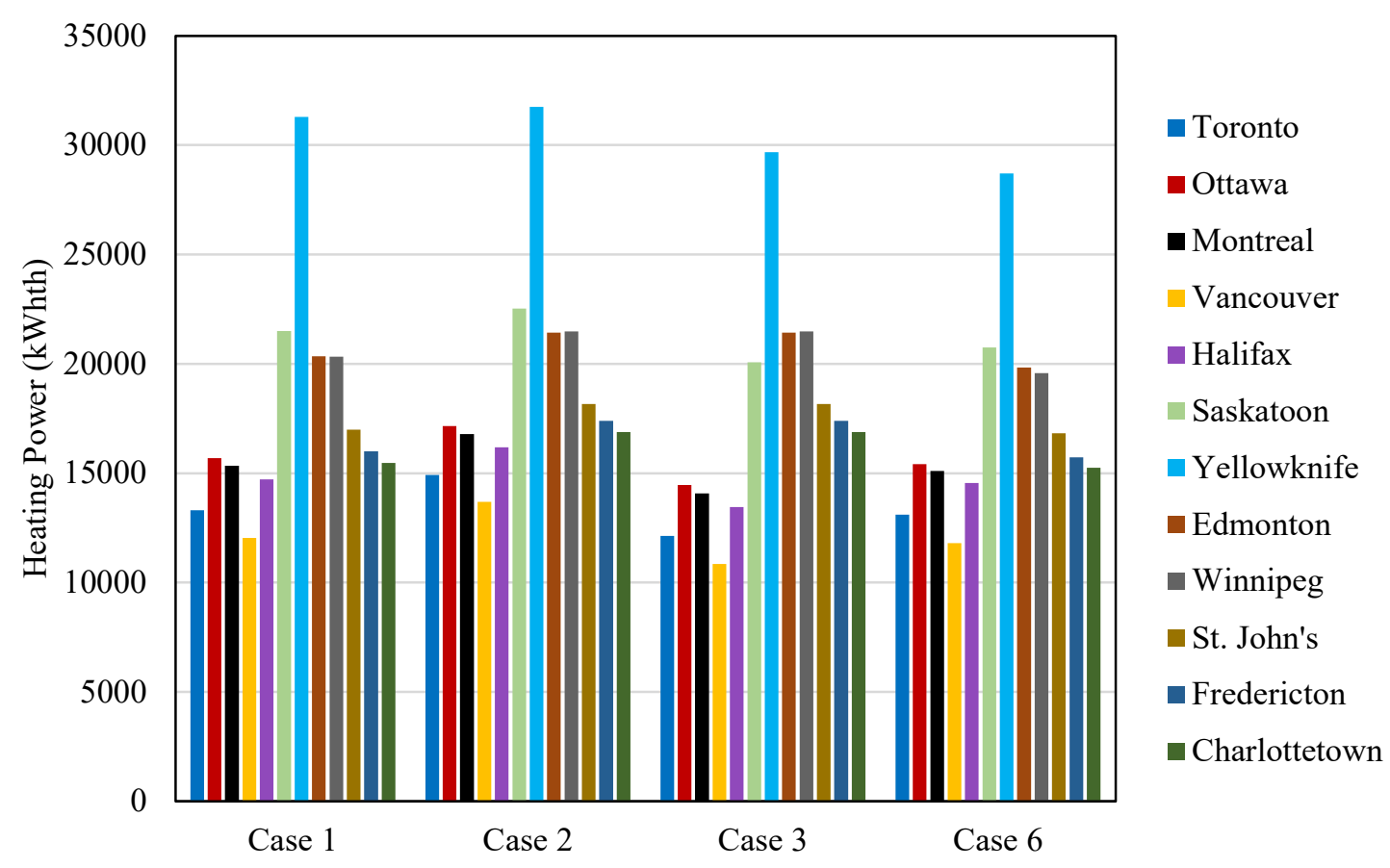

Figure 6.17: Heating power provided to each city

These results show how various ambient temperatures, precipitation, and solar irradiance affect the solar cooling system. These results show that an adsorption chiller paired with a flat plate collector and a heat pump with its heat source connected to the flat plate collector, Case 6 , allows the heating/cooling system to reduce the total electrical consumption in every city it was applied in. Although the cooling provided in Case 6 was less than Cases 1 to 3, it was still enough to provide a comfortable living environment, showing the capability of adsorption cooling in Canada. Figure 6.18 displays the average main floor temperature during the cooling season for Cases 1 to 3 and Case 6 . 


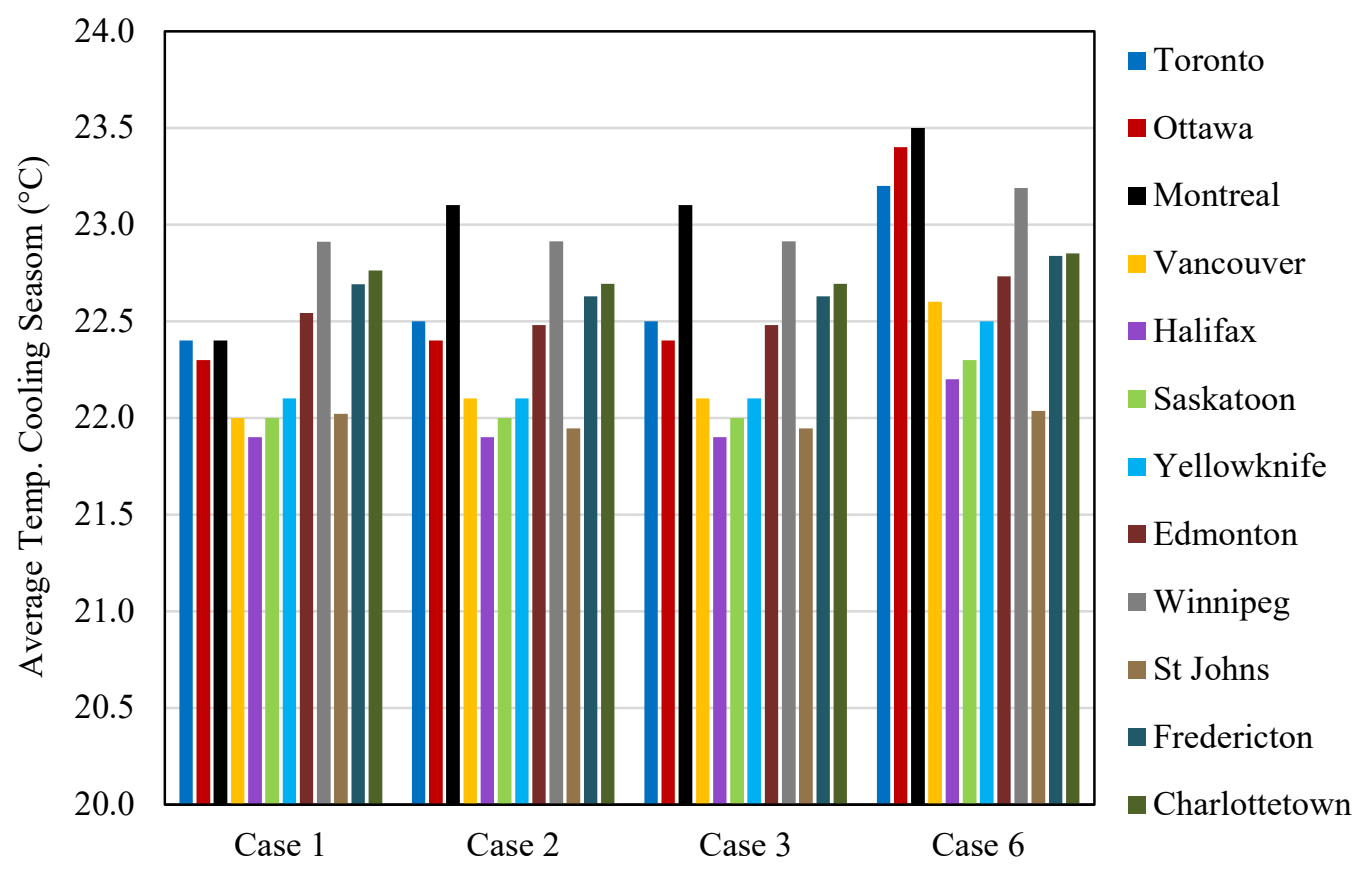

Figure 6.18: Cooling season temperature for Canadian cities

On average across all the cities there was approximately $0.5^{\circ} \mathrm{C}$ increase across the cooling season, with a maximum of $0.78^{\circ} \mathrm{C}$ in Toronto and $0.1^{\circ} \mathrm{C}$ increase for St. John's. In order to compare the short-term performance of the Case 6 to Cases 1 to 3 the percentage of time spent outside the thermal comfort zone of 20 to $27^{\circ} \mathrm{C}$ was analyzed for the cities [68]. This metric evaluates how effective a system is at handling extreme weather highs and lows, and its ability to meet the set point. Majority of the cities had comparable values to those of Case 1 to 3 at $5 \%$ or less of the time outside of the comfort range. Slight improvements were seen in the coastal regions but were not significant enough to suggest a performance increase as variances in the model could have attributed to the increase. The largest impacted region was the prairies where for Case 6 approximately $10 \%$ of the time steps were outside the thermal comfort region, compared to $6.4 \%$ for Case 1 . Similarly, for Yellowknife Case 6 and Case 1 were 19\% and 12\% respectively. The main reason these locations were outside the comfort zones more often than other locations is due to the 
heating system inability to quickly react to the extreme lows of the climate. This shows the link for an adsorption chillers performance to moderate temperatures and relatively high solar gains. In regions that suffered based on this systems configuration, some optimizations to the solar collection system could be done. Additionally, the substitution of vacuum-tube solar collectors for the flat plate collectors could be made to increase average HW temperature.

There is a small heating power performance decrease while using the flat plate collector as the heat source for the heat pump in Case 6 due to slightly lower inlet temperatures than required from an infinite source. This heating performance loss is minimal, but it should be noted that as mentioned above, there was an increase in temperatures below $18^{\circ} \mathrm{C}$ where the temperatures are colder. Regions such as Toronto have no visible decrease for heating performance in Figure 6.17.

\subsection{Greenhouse Gas Analysis}

Adsorption chillers can greatly reduce the electrical load placed on the grid which directly saves consumers cost from a reduction in electrical consumption. Another direct benefit is that they can also reduce GHG intensive power production methods from ramping up during the hottest portions of the day to meet the electrical cooling demand. The greenhouse gas production from each Case was analyzed as the mass of carbon dioxide equivalent for both the electricity consumed and the fuel burned. Each location studied except for two in Ontario have a different GHG intensity based on the embodied and produced carbon from the power generation sources attached to their electrical grid. An analysis for each provinces grid tied GHG was performed to determine annual GHG 
emissions in $\mathrm{gCO}_{2} \mathrm{e} / \mathrm{kWh}$. The GHG intensity data for each power production method was collected from an IPCC report using the $50^{\text {th }}$ percentile values [69] shown in Table 6.6.

Table 6.6: Greenhouse Gas intensity by source

\begin{tabular}{c|c} 
Fuel Source & GHG Intensity $\left(\mathrm{gCO}_{2} \mathrm{e} / \mathrm{kWh}\right)$ \\
\hline Hydro & 4 \\
\hline Wind & 12 \\
\hline Nuclear & 16 \\
\hline Biomass & 18 \\
\hline Solar & 46 \\
\hline Natural Gas & 469 \\
\hline Oil & 840 \\
\hline Coal & 1001
\end{tabular}

Provinces that use hydroelectricity have some of the lowest GHG emission rates due to the low embodied carbon dioxide output. The values from the emission sources were used to determine the GHG intensity for each province based on their respective grid mix of various fuel sources, shown in Table 6.7. The 2018 annual grid mix was used as reported by the Canada Energy Regulator in their Provincial and Territorial Energy Profiles Database [70]. The summer and winter GHG intensities were also determined for each province based on their sources of electrical generation during different seasons and the data in Table 6.6. 
Table 6.7: Provincial greenhouse gas emissions by grid mix

\begin{tabular}{|c|c|c|c|}
\hline \multirow{2}{*}{ Province } & $\begin{array}{c}\text { Annual GHG } \\
\text { Intensity } \\
\left(\mathrm{gCO}_{2} \mathrm{e} / \mathrm{kWh}\right)\end{array}$ & $\begin{array}{c}\text { Summer GHG } \\
\text { Intensity } \\
\left(\mathrm{gCO}_{2} \mathrm{e} / \mathrm{kWh}\right)\end{array}$ & $\begin{array}{c}\text { Winter GHG } \\
\text { Intensity } \\
\left(\mathrm{gCO}_{2} \mathrm{e} / \mathrm{kWh}\right)\end{array}$ \\
\hline Alberta & 663.34 & 666.3144 & 660.3719 \\
\hline British Colombia & 17.91 & 15.61904 & 20.21862 \\
\hline Manitoba & 55.22 & 48.62505 & 61.79531 \\
\hline New Brunswick & 281.03 & 255.011 & 306.6404 \\
\hline Newfoundland & 40.25 & 32.13682 & 47.93607 \\
\hline Northwest Territories & 463.04 & 511.2791 & 415.9012 \\
\hline Nova Scotia & 696.15 & 677.4139 & 714.5407 \\
\hline Ontario & 40.22 & 38.81369 & 41.64222 \\
\hline Prince Edward Island & 18.56 & 9.022268 & 27.92992 \\
\hline Quebec & 5.79 & 5.848726 & 5.732889 \\
\hline Saskatchewan & 628.72 & 634.7474 & 622.7426 \\
\hline
\end{tabular}

The "cleanliness" of the electrical grid varies widely across Canada, where some provinces use predominantly "clean" sustainable energy sources with low GHG emission rates. The regions with the highest GHG intensity are Nova Scotia, Alberta, Saskatchewan, and the Northwest Territories. New Brunswick is in the middle, and the remainder of the provinces have sustainable electrical grids. Using this data, the annual GHG emissions where determined for Case 1 to 3 and Case 6, shown in Figure 6.19. 


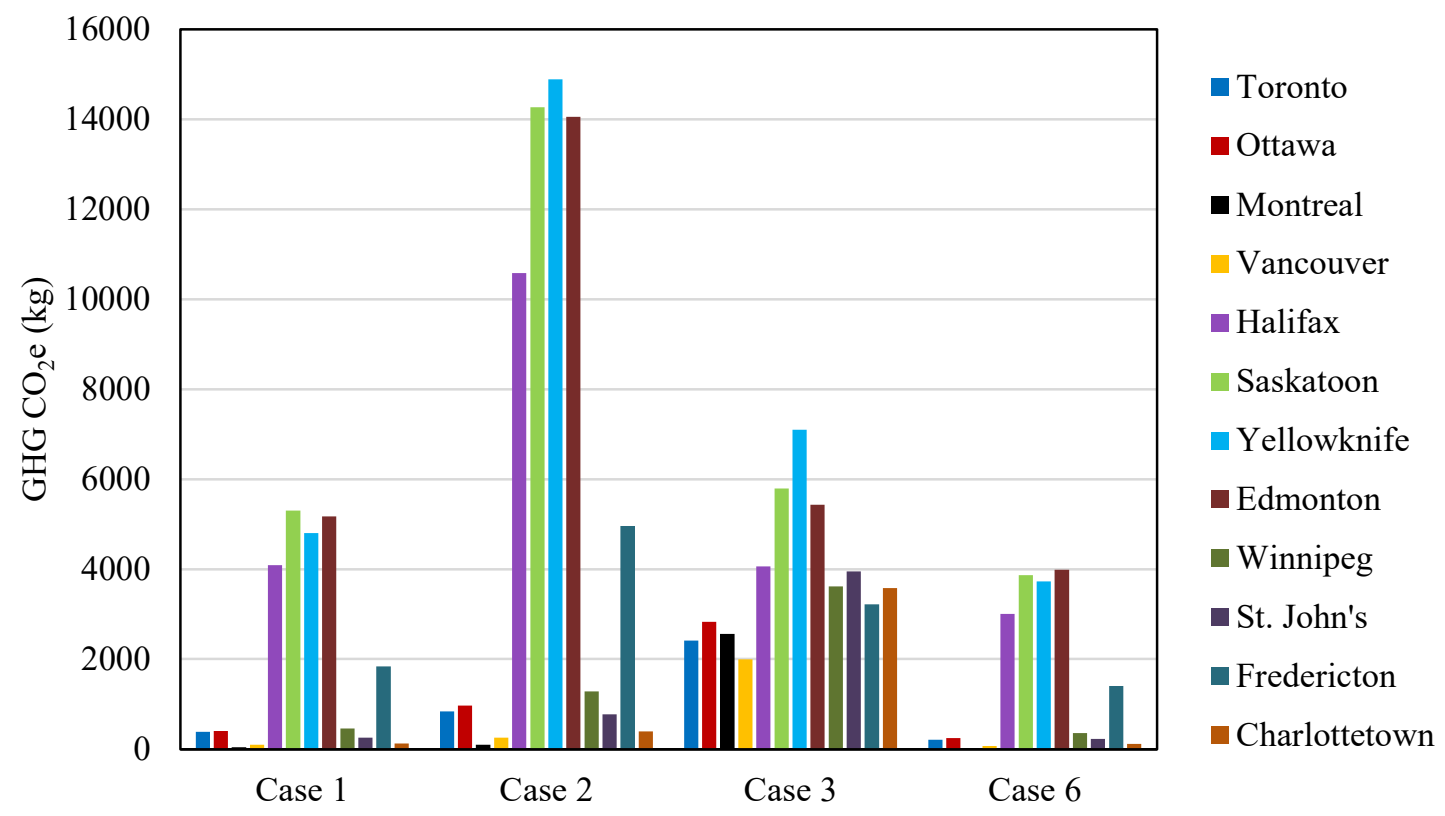

Figure 6.19: GHG emissions across Canada

Overall, Case 6 has the lowest GHG emissions due to its low electrical consumption, while Case 3 has the highest for regions with sustainable grids, including New Brunswick, due to the use of burning natural gas for heating. Case 2 has the highest GHG emissions overall in the provinces with the highest GHG intensity, due to the use of oil and coal with emissions at or over $14000 \mathrm{~kg} \mathrm{CO}_{2}$ e for Yellowknife, Saskatoon, and Edmonton. Halifax is not far behind with over $10000 \mathrm{~kg}$ of $\mathrm{CO}_{2} \mathrm{e}$ emissions. These high emissions are due to having a higher GHG intensity grid and colder temperatures which cause a larger demand of energy for heating. Small improvements in GHG emissions in Edmonton would be more effective at reducing GHG then in Toronto per household. The percent reducing by using a solar adsorption cooling system, such as Case 6 , is shown in Figure 6.20. 


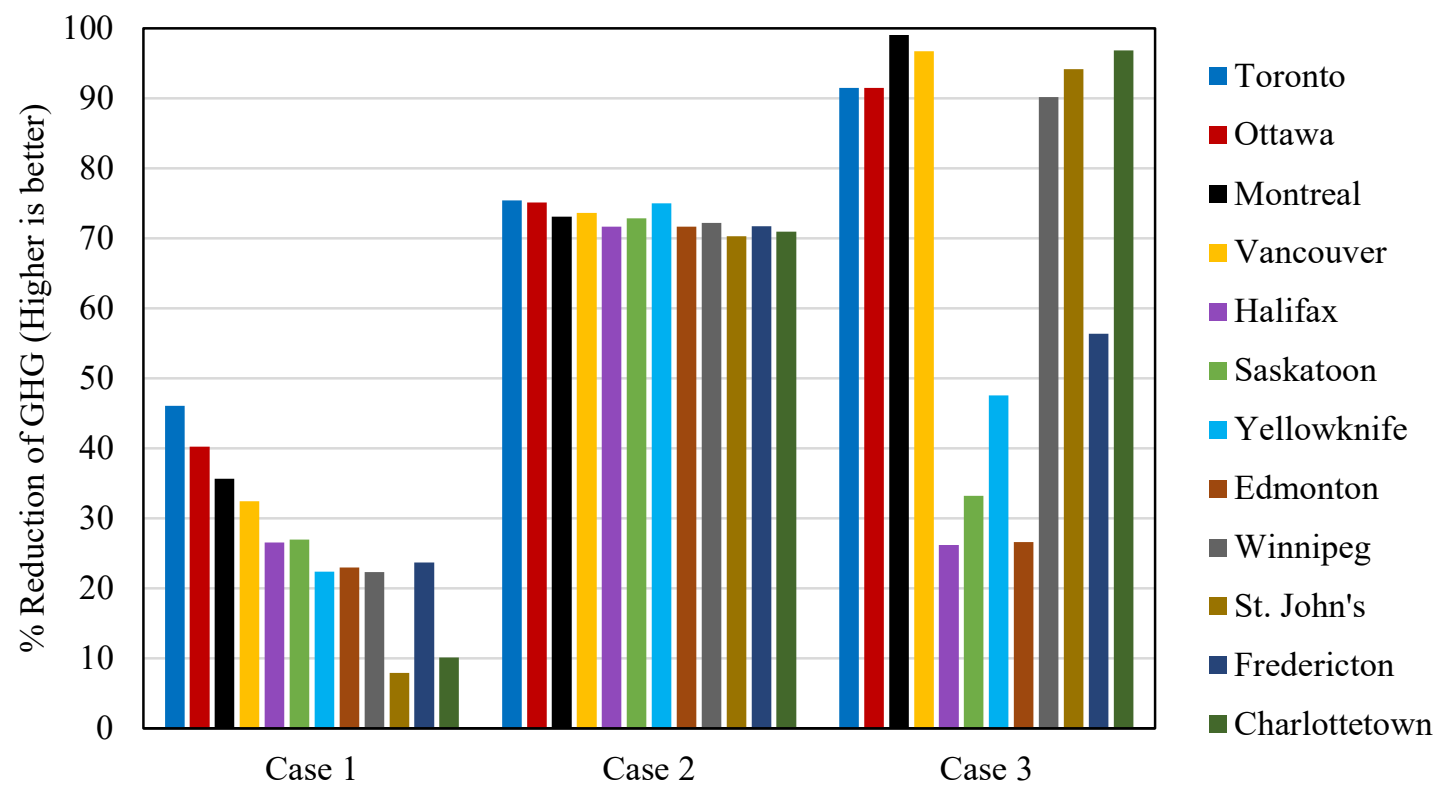

Figure 6.20: Percent reduction in GHG emissions by switching to a solar adsorption system

The percent reduction of GHG emissions is higher in Case 3 due to the reduction of natural gas used by the furnace. However, in the cities with the highest GHG intensity, the largest reductions by mass of $\mathrm{CO}_{2} \mathrm{e}$ are in Case 2 which uses electric heating, as their electrical grid produces more GHG per kilowatt than burning natural gas. Across all the cities, roughly a 70\% reduction in GHG produced from Case 2 occurs, due to the low electrical consumption of an adsorption chiller.

Overall, the largest benefit of switching to a solar adsorption chiller system is the reduction of GHG from Case 3 for sustainable grid locations and Case 2 in areas with nonsustainable electrical grids. The following section analyzes the cost implications for each city and impact of carbon pricing.

\subsection{System Economic Analysis}

The capital cost of a newer and better system is often what prevents people from making a switch to a greener and more sustainable product. For this reason, economics must be considered when determining feasibility of a new system. There must be a benefit 
to the consumer either economic, where the new system is cheaper or within a price, they can justify the reasonable extra cost for the environmental benefits. This section analyzes where in Canada an adsorption system would be justified currently and what it would take to make it more widely feasible.

\subsubsection{Operating Costs}

The operating costs of heating and cooling systems vary greatly across Canada based off diverse climates and the different utility prices. The annual operating cost for each city studied is shown in Figure 6.21, which the expection of Yellowknife due its very high operating costs of nearly $\$ 10,000$ for Case 2 .

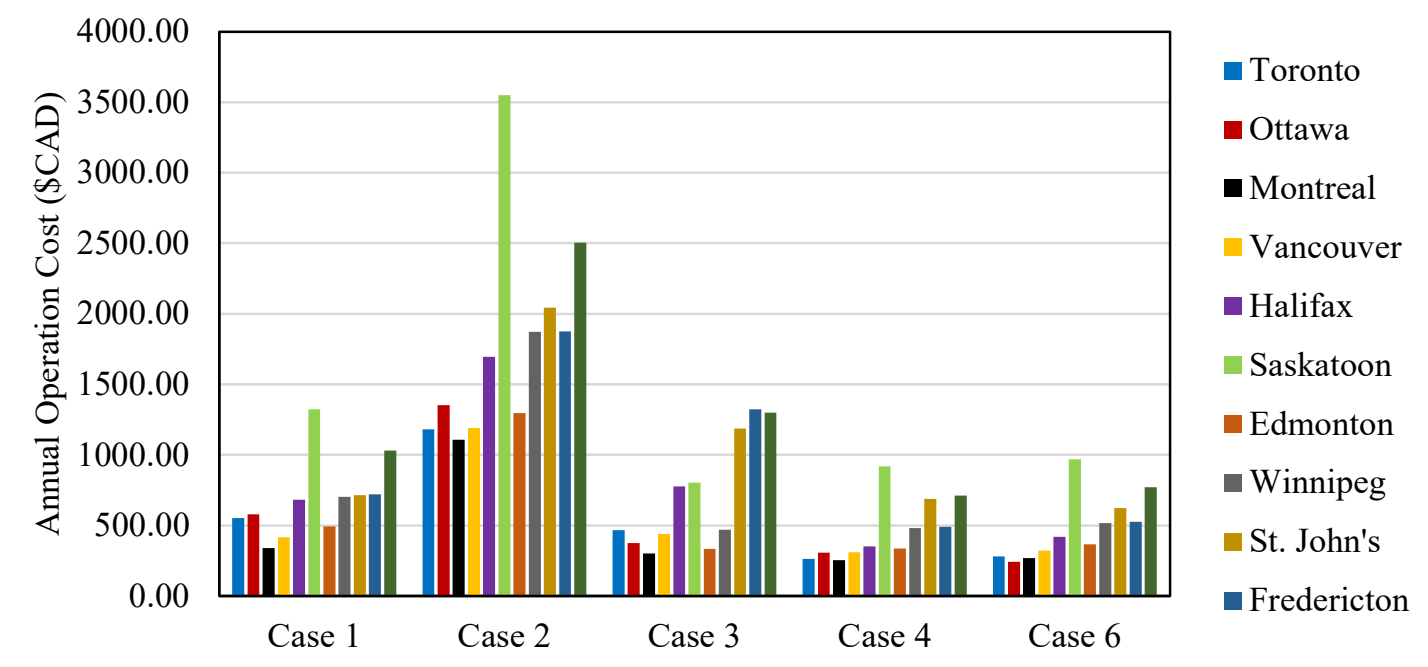

Figure 6.21: Annual operation costs across Canada

The adsorption chiller systems, Cases 4 and 6, primarily have lower operating costs in every city except in Saskachewan due to their low natural gas rates, Case 3 has a slightly lower cost. In most cities, the system with the natural gas furnace (Case 3) has slightly lower operating costs compared to a heat pump (Case 1), and significantly lower costs compared to the electric furnace (Case 2). 


\subsubsection{Payback Period}

The PBP is an effective way of comparing the amount of years it would take the total cumulative cost of a system to equal its cost savings. After the length of the PBP is met the system would be only saving money. Generally, it would be ideal for a system to have a PBP much less than its lifespan but is rarely the case for newer and emerging technology, whereas the technology becomes widely adopted the costs and PBP will drop significantly. The PBP for Case 4 and Case 6 when compared to Case 1 is shown in Figure 6.22.

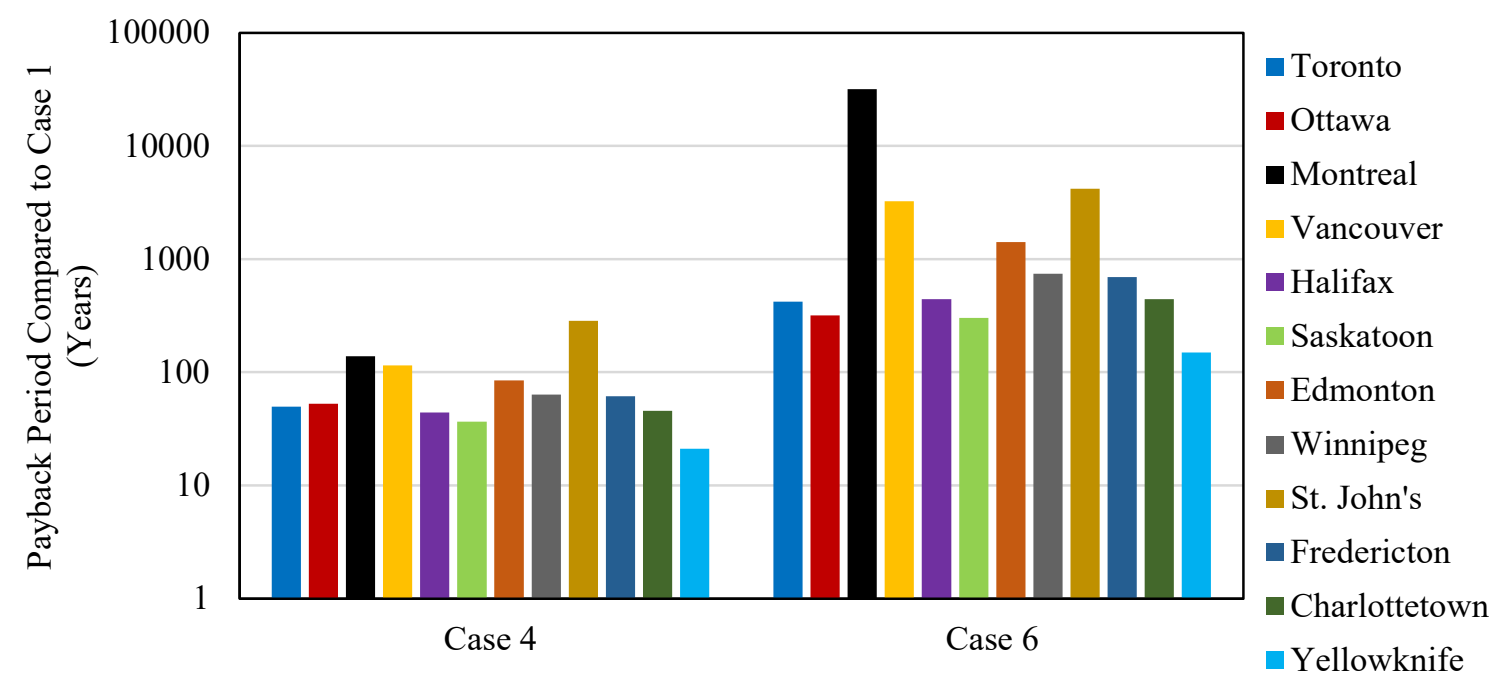

Figure 6.22: Payback period for an adsorption system compared to a heat pump system

As expected, Case 6 has a much longer PBP then that of Case 4 due to its higher capital costs and similar cost savings. Compared to Case 1, a solar adsorption system does not offer enough of a cost savings for the current costs to be economically viable. When a district heating system is considered for Yellowknife, PBP it becomes close to the products lifespan. Montreal, Vancouver, and St. John's benefit the least from switching to an adsorption chiller where for Case 4 the PBP is above 100 years and for Case 6 is well over 
1000 years. When compared to a system with some of the highest operating costs such as Case 2, the PBP is greatly reduced, as shown in Figure 6.23.

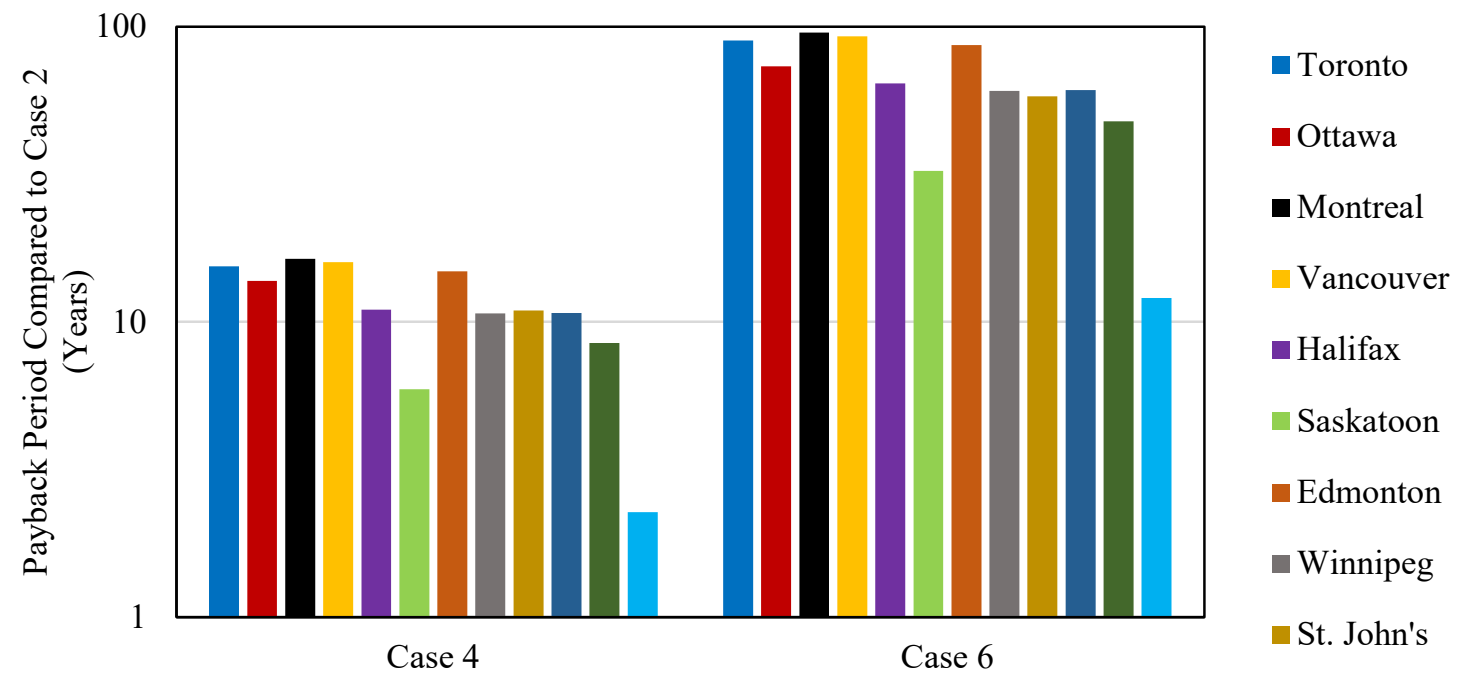

Figure 6.23: Payback period for an adsorption system compared to an electric system

Comparing Case 2 with Case 6, Montreal has a PBP of almost 100 years which is a very large improvement from 50,000 years when compared to Case 1. Compared to electrical furnace and standard air conditioner, all the cities have a PBP under 100 years for Case 6 and near 10 to 25 years for Case 4 . This is significant as district heating with an adsorption chiller would be cost effective in all cities. Saskatoon, where the electricity rates are higher, shows the most benefit (second to Yellowknife) by switching to adsorption chillers at 8-year PBP for Case 4 and 50 years for Case 6. Figure 6.24 displays the PBP for the adsorption systems compared to Case 3 . 


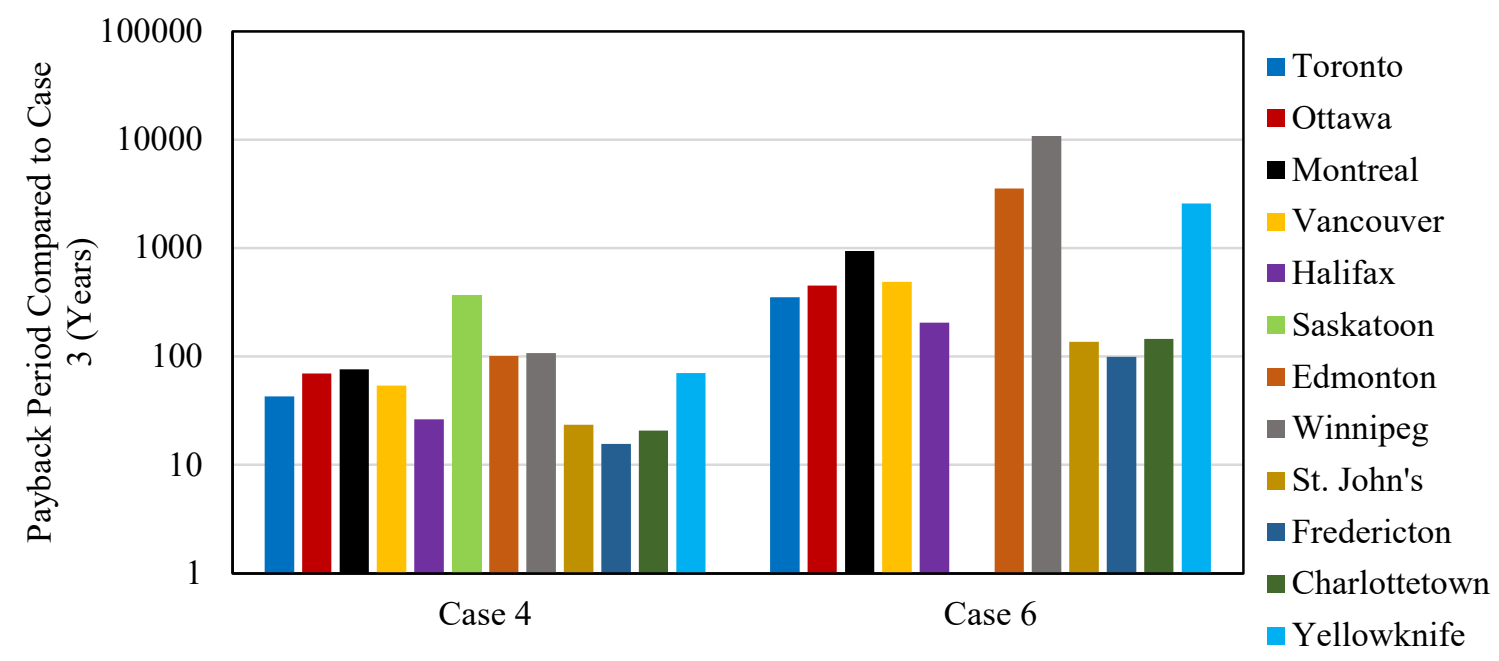

Figure 6.24: Payback period for an adsorption system compared to a natural gas system

Overall, the adsorption system has a lower PBP for the natural gas furnace, Case 3, compared to the heat pump system, Case 1 . The benefit from the adsorption systems do not compare as well to natural gas heating as it did for electric heating. Saskatoon has the highest PBP due to its low cost of natural gas and high electrical rates. For Case 6 Saskatoon will never have a PBP as its value is negative and appears as a blank space in the graph. The adsorption systems would only be economically viable for Charlottetown, Fredericton, and St. John's for Case 4 as their PBP is under 25 years, due to their higher natural gas/heating oil rates. Looking at the costs over the entire lifespan including interest and inflation is also important for systems that can last for over $25+$ years, which is discussed in the following section.

\subsubsection{Life Cycle Cost}

Life cycle cost consider the entire operating costs, maintenance, and capital costs of the system in present day dollars. The LCC of the systems are compared for each of the cities and shown in Figure 6.25. 


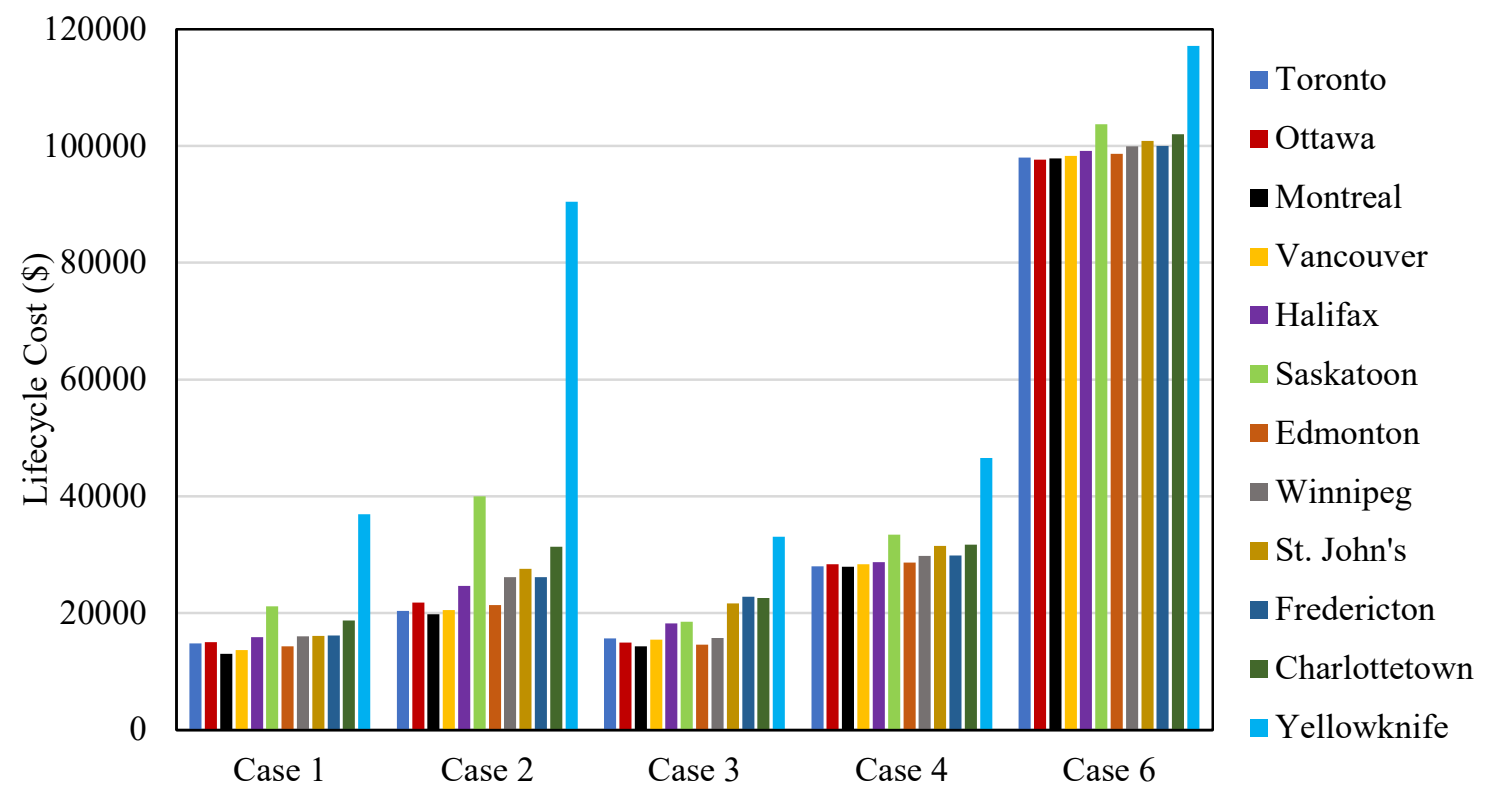

Figure 6.25: Lifecycle costs across Canada

Cases 1 to 3 are shown to be overall the most cost-effective systems with Cases 2 to 4 depending on location. In Saskatoon, the LCC for an adsorption system on district heating would be lower than that of an electric furnace, but not a natural gas furnace. Areas with lower utility rates such as Toronto, Ottawa, Montreal, and Vancouver all have similar LCC trends and magnitude. Where Case 1 and Case 3 are very close to the lowest LCC, Case 2 is slightly higher, and Case 4 is slightly higher than Case 2 . The full solar adsorption system LCC is hovering around $\$ 100,000$ for all cities except Yellowknife where it is closer to $\$ 120,000$. Yellowknife sees only about $20 \%$ increase of LCC compared to the other cities for Case 6 compared to the other Cases where the increase is anywhere from 30 to $300 \%$. Now the LCC can be used to determine what capital costs are required for an adsorption system to meet the same LCC or better as Cases 1 to 3, shown in the following section. 


\subsubsection{Breakeven Cost}

The breakeven cost compares the LCC between two systems to show what the capital costs must be to match the same LCC as the base cases. A subsidy was also calculated, which is the discount needed to reduce the capital costs to the breakeven capital cost. For a district heating adsorption system such as Case 4, the breakeven costs are shown in Figure 6.26.

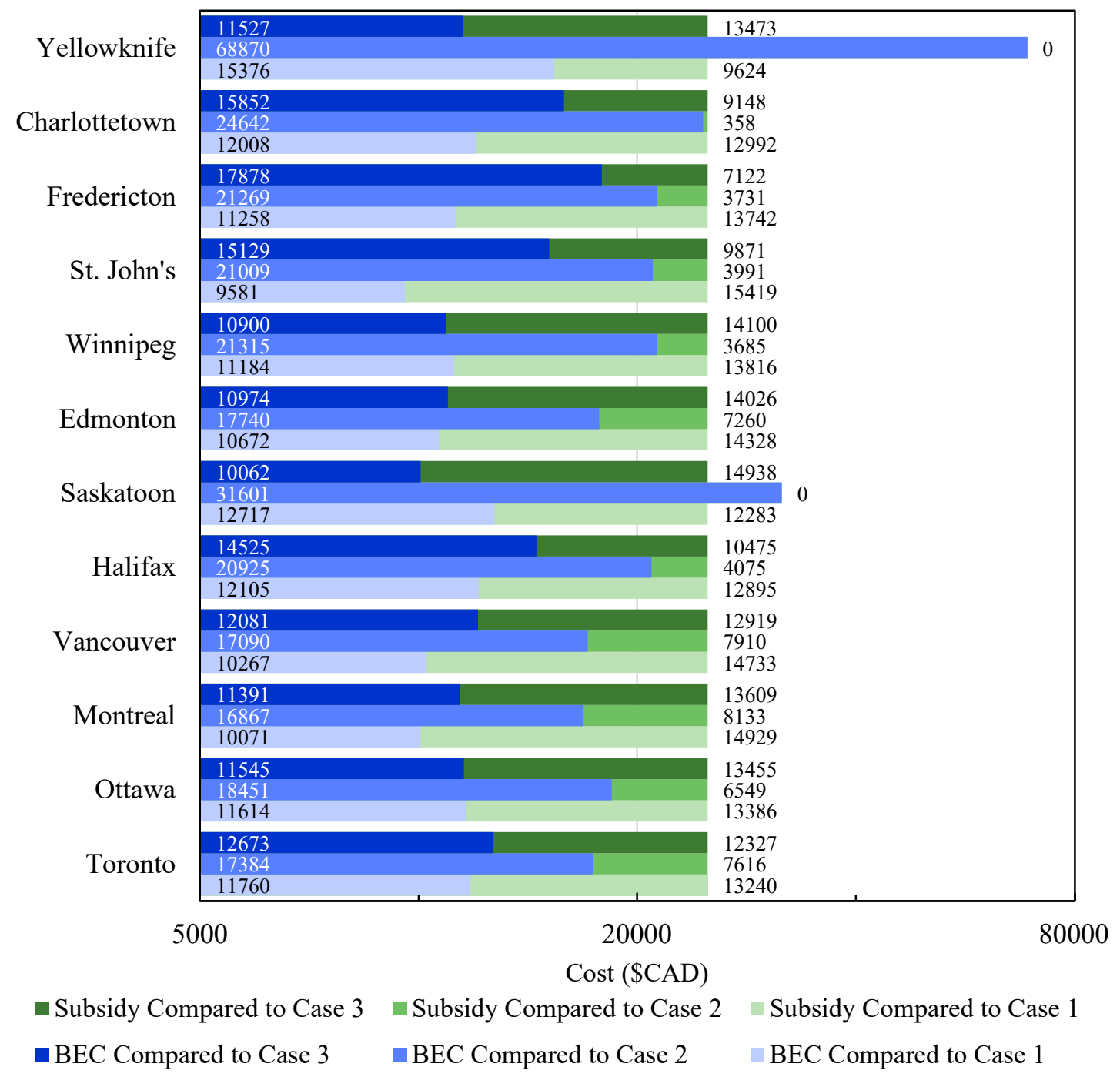

Figure 6.26: Breakeven costs for an adsorption system without solar 
Yellowknife and Saskatoon both require no subsidy when compared to Case 2 as they already have a better LCC for Case 4 then Case 2. The subsidy range is from $\$ 358$ in Charlottetown compared to Case 2 to $\$ 15,500$ in St. John's compared to Case 1 . This subsidy range is reasonable as the price for adsorption chillers are quite high due to low demand/production and relatively new to consumer markets. In the future if the cost of an adsorption chiller reduces by $25 \%$, it will become competitive for district heating systems.

Figure 6.27 shows the breakeven subsidy value for Case 6 .

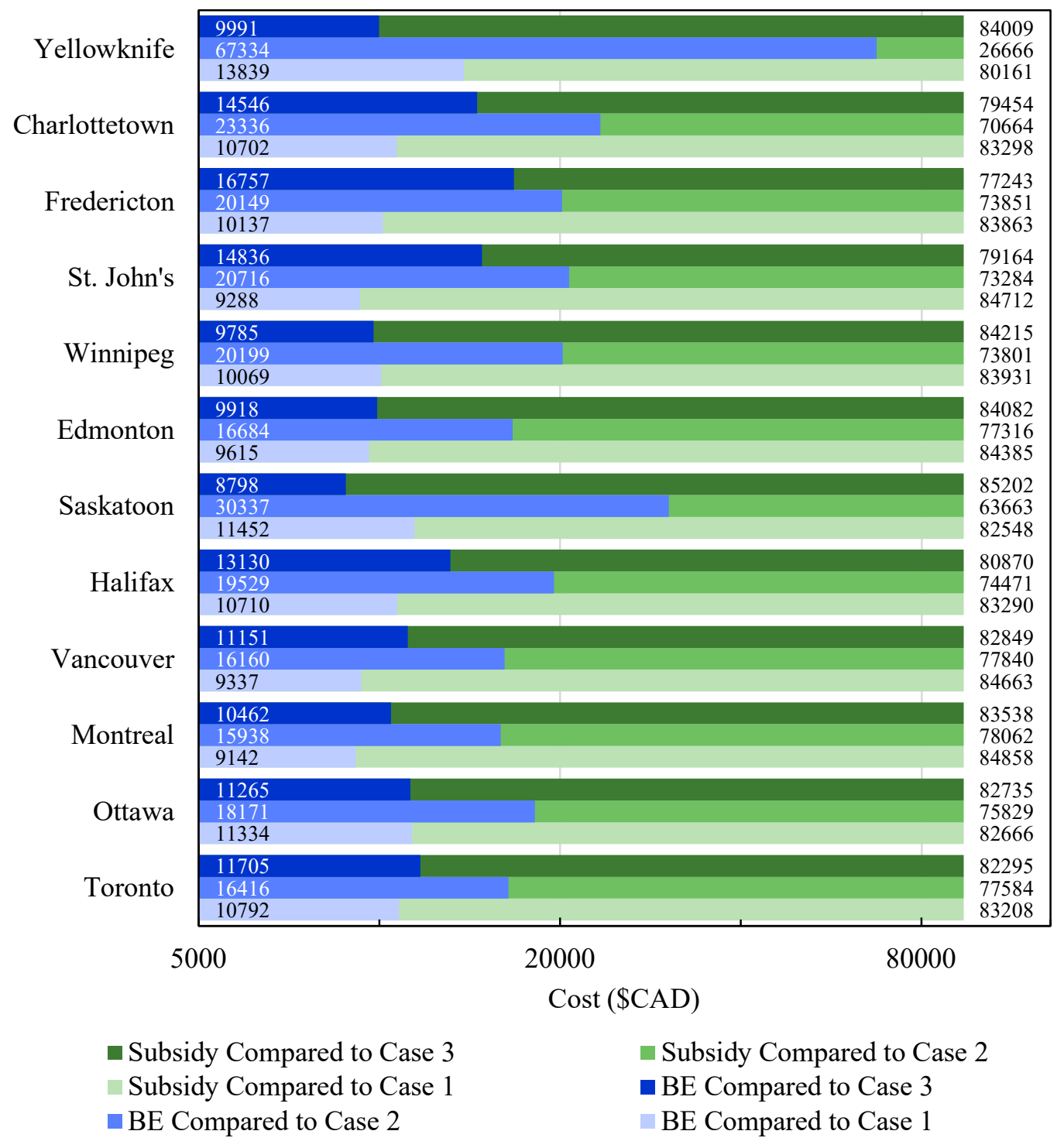

Figure 6.27: Breakeven costs for an adsorption system with solar 
The subsidy price for Case 6 is much higher at about $60 \%$ of the capital costs. Yellowknife has the lowest subsidy price of $\$ 26,700$. A limitation to these rates are that the cost savings due to the hot water supply are not considered, where Case 6 would have some additional cost savings, but not at a magnitude that would justify the $\$ 77,584$ price difference in Toronto for a solar adsorption system compared to Case 2. The impacts of this data when carbon pricing is applied is discussed in the following section.

\subsubsection{Carbon Pricing Impacts}

It is estimated that the current social impact of GHG emissions are over the widely accepted value of $\$ 50$ per metric ton [71]. In the future there may be a higher tax on carbon passed on to consumers to transition to more sustainable products, but the social impact of $\$ 50 /$ ton was used to analyze the impact this has on the breakeven cost and subsidy price. Recently in Canada the federal government announced a new carbon tax plan which will increase the current $\$ 30$ per metric ton rate by $\$ 10$ per year until 2023 , where it will then increase by $\$ 15$ per ton per year until 2030 where it will then be $\$ 170$ per ton [72]. Only Case 2 will be compared with Case 6, shown in Figure 6.28, as it had the largest GHG emissions by almost double Case 3 due to the use of natural gas. All the other cases will have a much smaller carbon impact. 


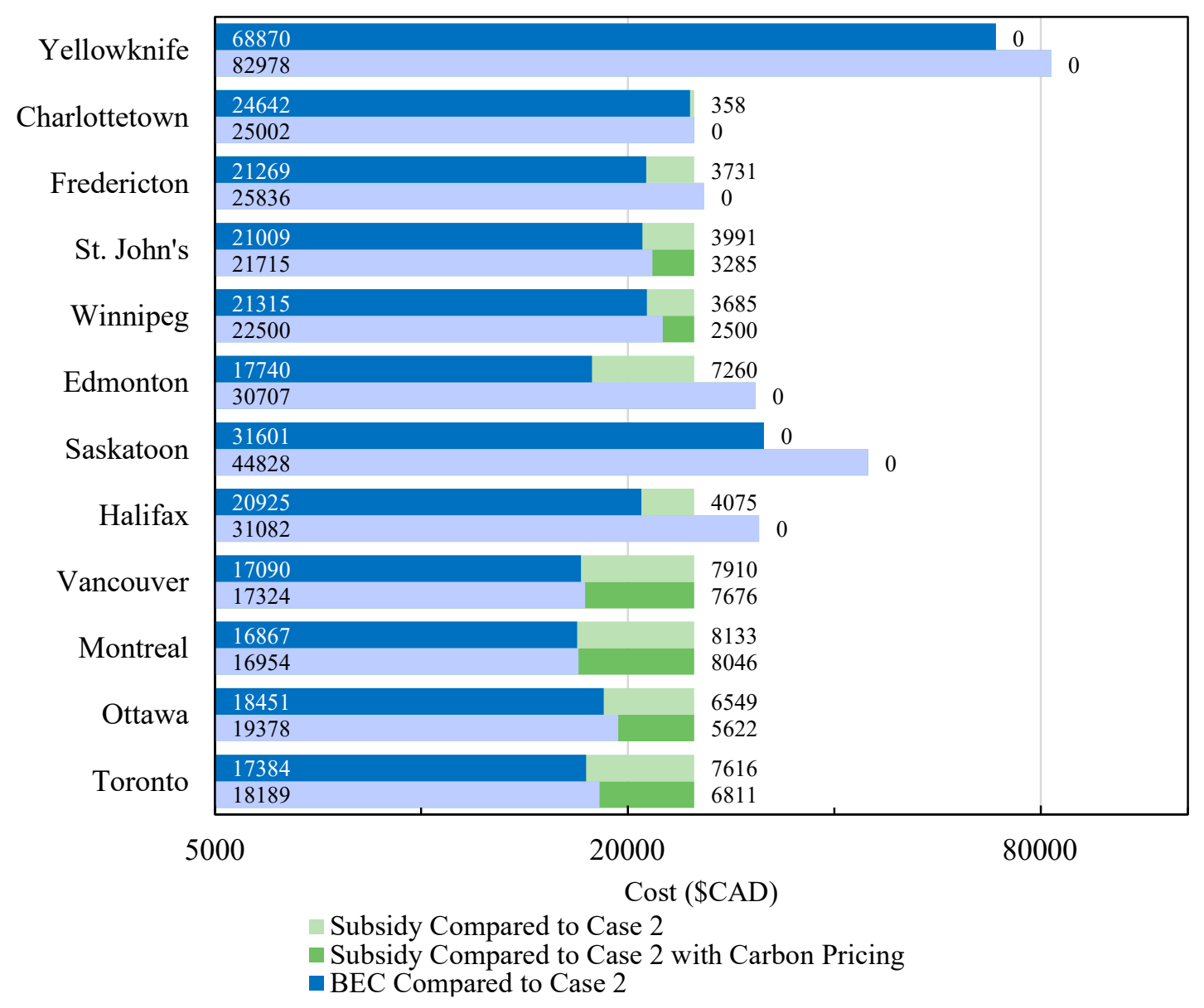

Figure 6.28: Breakeven costs with carbon pricing for an adsorption system without solar

With the implementation of carbon pricing there was found to be 6 cities with no required subsidy to meet the LCC of Case 2, an increase from two cities previously. The effects of carbon pricing are only seen in the cities with large GHG intensity, which were the large emitters of GHG in Case 2. The maximum subsidy required is $\$ 8046$ from $\$ 8133$ without carbon pricing for Montreal, which was the location with the lowest decrease in subsidy value due to the low grid GHG emissions. Some cities such as Edmonton see a decrease in over $\$ 7000$ for the subsidy due to carbon pricing. The data for Case 6 breakeven cost with carbon pricing can be seen in Figure 6.29. 


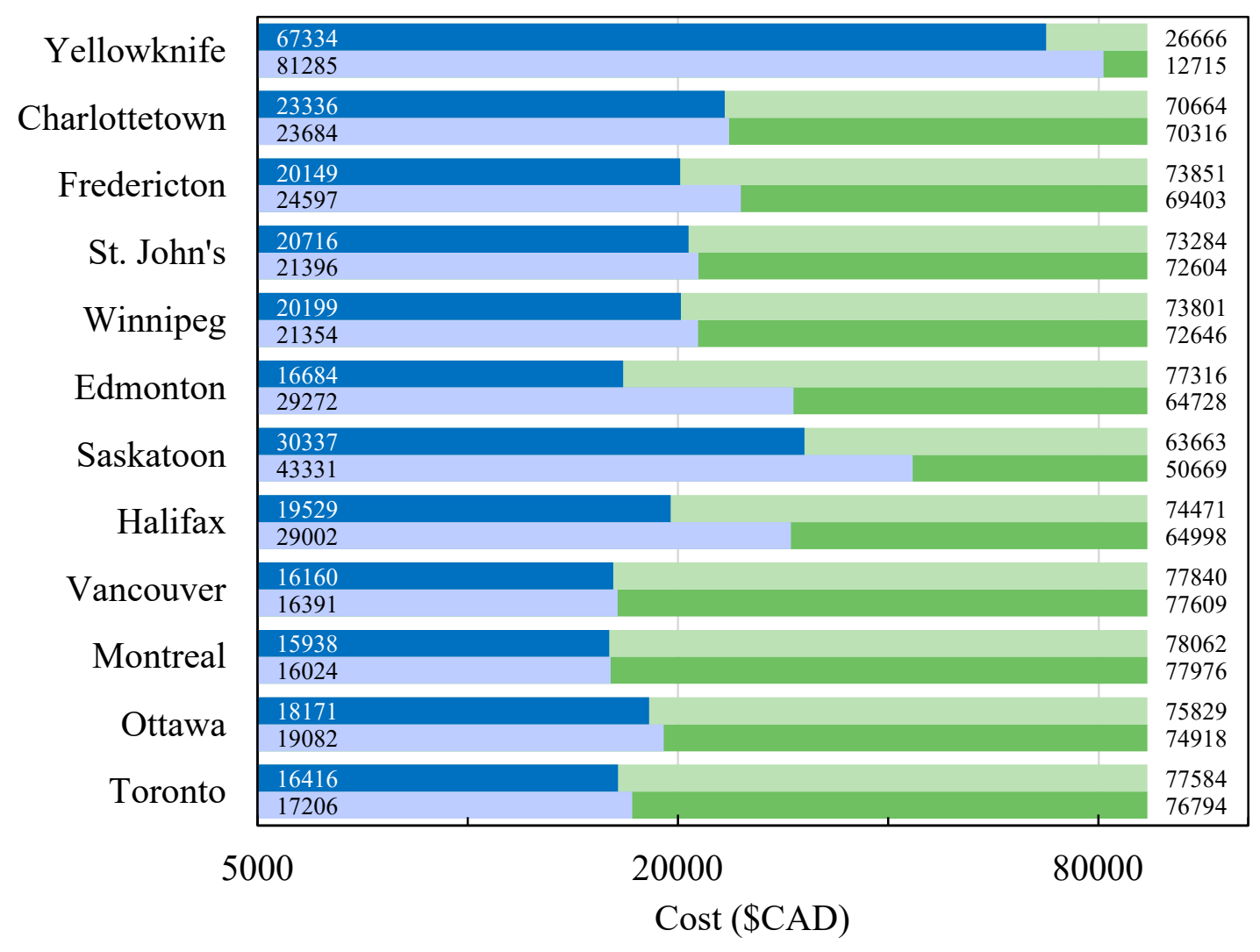

Subsidy Compared to Case 2

- Subsidy Compared to Case 2 with Carbon Pricing

- BE Compared to Case 2

Figure 6.29: Breakeven costs with carbon pricing for an adsorption system with solar

Similar to Case 4, the subsidy for Edmonton was decreased by the largest amount nearly $\$ 8000$. The other cities have slight decreases in their subsidies compared to no carbon pricing, but it is still not a significant amount when compared to the total system costs.

It should be noted that carbon pricing does not make the adsorption systems more economically feasible, but instead makes them more comparable, as their capital costs and LCC still remain quite high. As the carbon tax increases to the $\$ 170$ target in 2030 the economic feasibility of adsorption chillers will also increase. 


\subsection{Key Takeaways}

These results indicate solar adsorption cooling is physically viable in the locations selected, but heavily dependent on the hot water temperature and therefore the solar input to the solar collectors. Environmentally, adsorption cooling can reduce significant amounts of GHGs for any location compared to any commonly found HVAC system. The adsorption chiller with a district heating system is feasible in most cities compared to a system with an electric furnace, especially when the GHGs are low. This system also has potential in regions where the price of fuel is high such as the Maritimes. Solar adsorption cooling is not economically feasible yet for residential use, but as the price of technology and solar collectors are reduced, it may become more compelling. 


\section{Chapter 7: Conclusions and Future Work}

\subsection{Conclusions}

This study involved the installation, experimental testing, and simulation of an adsorption chiller; with the goal to determine system feasibility in residential applications in Canada. The solar adsorption system was compared to current HVAC systems such as a heat pump, electrical/natural gas furnace, and vapour compression cooling.

The experimental setup with a 16-kW adsorption chiller was tested, and the cooling capacity and temperature relationship was proven to be linear across the operational range. This allowed for a performance map to be generated and linear interpolation to be used to determine the cooling power and COP. The experimental data indicated that variations in the temperatures have a greater effect on performance than the same percent change in the flow rates. This indicates the importance of maintaining adequate temperatures in residential applications. The chiller was able to provide stable and continuous cooling, of up to $13 \mathrm{~kW}_{\text {th }}$ when a constant temperature heat source was provided. This indicates that the unit is a suitable source for cooling when paired with district heating. When combined with a flat plate solar collector, the chiller can provide significant cooling power, however, the hot water inlet temperature is a function of solar radiation, which means the cooling capacity varies throughout the day when the storage tank does not maintain the same temperature. This causes the average cooling capacity of the chiller to vary from the results of the CIT tests because of the reduced performance during lower driving heat temperatures. When the adsorption chiller is used in residential applications with a heat source that varies the hot water temperature, such as a solar water heater, the average cooling capacity in the mid-range hot water temperature $\left(60\right.$ to $\left.70^{\circ} \mathrm{C}\right)$ is less than that with 
a constant hot water temperature. This difference is diminished as the average hot water temperature is increased above $75^{\circ} \mathrm{C}$.

TRNSYS was used to develop a model for the purpose of determining the performance of an adsorption chiller in various residential applications in Canada. The TRNSYS component, Type-909, for adsorption chillers was found to be representative of the tested adsorption chiller's integrated heat transfer over test periods. This allowed the adsorption chiller model of the experimental unit to be used with a validated house model. The house model was then modified for different cases of heating and cooling configurations with heat pumps, standard air conditioners, flat plate collectors, and adsorption chillers. It was found that adsorption cooling driven by a flat plate collector which was also hooked up to the heat pump reduced electrical consumption while providing significant cooling. The limiting factor in the system is the temperature of the hot water tank, where a constant temperature of $75^{\circ} \mathrm{C}$ would have provided cooling potential equivalent to that of the base cases. The simulations allowed for results to be compared across Canadian cities for both performance and economic feasibility. It was found that the performance of the adsorption system in both district and solar heating configurations has the potential to meet heating and cooling loads, while producing a reduction in electrical consumption for each city. When the economic results of the different cases studied were compared, it was apparent that a system with a standard air conditioner and natural gas furnace is currently the most cost effective for most cities excluding those with high gas rates, such as the maritime provinces. These results will differ depending on regional effects and location but ultimately the trends found within this study will remain similar for modern adsorption chillers. 
The PBP analysis showed that adsorption cooling on a district heating system is cost effective compared to a system with an air conditioner and electric heating as the payback period in the cities were around 10 to 15 years. The LCC also showed the slight increase for the total costs for an adsorption chiller on district heating compared to, natural gas/electric heating and air conditioner, and a heat pump system. The GHG reduction that results from using an adsorption cooling system compared to the other cases studied was the most significant for cities that have high GHG intensity electrical grids, such as Alberta, Saskatchewan, and Prince Edward Island. In regions where the GHG intensity from the electrical grid is low, there was the highest percent reduction in GHG emissions from switching to an adsorption system from one with natural gas.

Overall, the adsorption chiller was found to provide sufficient cooling power in a Canadian climate when used with a solar collector, provided that the solar collection system is sized optimally. Environmentally, adsorption cooling systems have a high capacity to reduce GHG emissions compared to other commonly found HVAC systems, especially in regions with "dirty" electrical grids. Regions with high electricity rates can benefit the most economically from using adsorption cooling, especially if a district heating system is used. As there is a push toward a more sustainable future, the feasibility of adsorption cooling becomes more likely, as it is best suited to replace electric heating, especially when the increasing cost of electricity is considered.

\subsection{Future Work}

This study can be expanded to areas with warmer ambient conditions to test the limits of where the performance of the adsorption chiller is capable of meeting cooling demands such as the southern United States. Future analysis can be done to model a system 
that is optimized for each location to determine a more detailed economic and performance result for a real-world scenario. Additionally, the system sizing and control scheme can be optimized to maximize the heat input from the solar collectors, and the hot water and coldwater storage.

The heat pump and adsorption with district heating cases should also have additional components added to them where the heat input to these systems is selected based off location and incorporated into the economic analysis. This direction of study can also lead into configurations for remote off-grid communities where the heat supply could be from waste heat or other available sources, to analyze the potential GHG and economic benefits that could be realized.

In the future, another study can be done parallel to this study where a vacuum tube solar collector is used in the modelling and simulation process rather than a flat-plate collector to compare performance and economics differences.

In this study, only the cooling performance of the adsorption chiller was studied, where in future work the heat pump capabilities of the chiller should be experimentally determined and modelled to produce annual simulation results for an adsorption chiller based off data obtained experimentally. 


\section{References}

[1] Natural Resources Canada, Energy Use Data Handbook: 1990 - 2010, 11th ed. Ottawa, 2013. ISSN: 1910-4413.

[2] Natural Resources Canada, Energy Use Data Handbook: 1990 - 2014, 14th ed. Ottawa, 2014. ISSN: 1910-4413.

[3] J. Proctor, "Air Conditioning, Peak Demand, And Public Goods Funds," Proctor Engineering Group, Ltd. San Rafael, CA, 2005. Accessed: Oct. 26, 2020. [Online] https://www.proctoreng.com/dnld/D101.pdf.

[4] Independent Electricity System Operator, "Power Data," 2019. Accessed: Oct. 26, 2020. [Online]. Available: http://www.ieso.ca/power-data.

[5] Dakin Global, "Increasing Air Conditioner Efficiency." Accessed: Oct. 26, 2020. [Online]. Available:

https://www.daikin.com/csr/environment/climatechange/air_conditioner.html.

[6] M. Armstrong, "Air Conditioning Biggest Factor in Growing Electricity Demand," Statista, 2020. Accessed: Oct. 26, 2020. [Online]. Available:

https://www.statista.com/chart/14401/growing-demand-for-air-conditioning-andenergy/.

[7] Ontario Hydro, "Ontario Hydro Rates." Accessed: Nov. 28, 2020. [Online]. Available: http://www.ontario-hydro.com/current-rates.

[8] Ontario Energy Board, "Regulated Price Plan (RPP)| Ontario Energy Board," 2016. Accessed: Mar. 17, 2019. [Online]. Available: https://www.oeb.ca/industry/policy-initiatives-and-consultations/regulated-priceplan-rpp.

[9] Ontario Energy Board, "Historical electricity rates," 2019. Accessed: Mar. 17, 2019. [Online]. Available: https://www.oeb.ca/rates-and-your-bill/electricityrates/historical-electricity-rates.

[10] Legislative Assembly of the Province of Ontario. 2017, June 1. c.16 - Bill 132, Fair Hydro Act, 2017. Accessed: Oct. 19, 2020. [Online]. Available: https://www.ontario.ca/laws/statute/s17016.

[11] C. Baldwin and C. A. Cruickshank, "Assessing the Potential for Reduction in Peak Residential Electrical Loads Using a Heat Pump and Thermal Storage," Int. Compress. Eng. Refrig. Air Cond. High Perform. Build. Conf., West Lafayette, 2016, pp. 1-10.

[12] K. M. Bataineh and S. Alrifai, "Recent trends in solar thermal sorption cooling system technology," Adv. Mech. Eng., vol. 7, no. 5, pp. 1-20, 2015, doi: $10.1177 / 1687814015586120$. 
[13] U. Jakob, "Overview on Small Capacity Systems," SolarNext AG, Rimsting, Germany, 2008.

[14] D. Hosansky, "Adsorption Cooling," in Britannica. Encyclopaedia Britannica, Sept. 9, 2014. Accessed: Dec. 20, 2020. [Online]. Available: https://www.britannica.com/topic/adsorption-chiller.

[15] SorTech AG, “Adsorption Chiller Aggregate: eCoo 2.0," Halle, Germany, 2015.

[16] Araner, "How do adsorption chillers work," Aug. 13, 2019. Accessed: Dec. 20, 2020. [Online]. Available: https://www.araner.com/blog/how-do-absorptionchillers-work/.

[17] Inoplex, "What's the difference between absorption and adsorption chillers," 2018. Accessed: Dec. 20, 2020. [Online]. Available:

https://www.inoplex.com.au/information/whats-the-difference-betweenabsorption-and-adsorption-chillers.

[18] D. Thorp, Solar Technology: The Earthscan Expert Guide to Using Solar Energy for Heating, Cooling and Electricity. Earthscan, 2011.

[19] Fahrenheit, “Cooling Innovation.," Tech. Inf. Sheet, Munich, Germany, 2017.

[20] M. Souad, E. G. Mohammed, G. Najeh, G. Slimane, and B. Riad, "Performance of silica gel-water solar adsorption cooling system," Case Stud. Therm. Eng., vol. 8, no. June, pp. 337-345, 2016, doi: 10.1016/j.csite.2016.07.002.

[21] S. Thomas, S. Hennaut, S. Maas, and P. Andre, "Experimentation and simulation of a small-scale adsorption cooling system in temperate climate," Energy Procedia, vol. 30, pp. 704-714, 2012, doi: 10.1016/j.egypro.2012.11.080.

[22] Solair, "Adsorption Chillers," 2009. Accessed: Mar. 17, 2019. [Online]. Available: http://www.solair-project.eu/142.0.html.

[23] International Energy Agency, "Solar Heat Worldwide - Global market data and trends," Solar Heating \& Cooling Programme, 2018. Accessed Oct. 20, 2020. [Online]. Available: http://solarheateurope.eu/2018/08/04/solar-heat-worldwideglobal-market-data-and-trends-increased-use-of-solar-heat-for-large-buildingsand-industry/.

[24] International Energy Agency, "Country Report Germany: Status of Solar Heating/Cooling and Solar Buildings - 2020," Solar Heating \& Cooling Programme, 2020. Accessed: Oct. 20, 2020. [Online]. Available: https://www.iea-shc.org/country-report-germany. 
[25] Coherent Market Insights, "Global Solar Air Conditioning Market to Surpass US\$ 39.22 Billion by 2026 - Coherent Market Insights," Intrado - Global Newswire, 2019. Accessed: Oct. 20, 2020. [Online]. Available:

https://www.globenewswire.com/news-release/2019/03/05/1748179/0/en/GlobalSolar-Air-Conditioning-Market-to-Surpass-US-39-22-Billion-by-2026-CoherentMarket-Insights.html.

[26] H. Liu, W. Wang, Y. Zhao, and Y. Deng, "Field Study of the Performance for a Solar Water Heating System with MHPA-FPCs," Energy Procedia, vol. 70, pp. 79-86, 2015, doi: 10.1016/j.egypro.2015.02.101.

[27] M. Koussa et al., "Effect of parallel and series connection configuration of solar collector on the solar system performances," IREC2015 The Sixth International Renewable Energy Congress, Sousse, 2015, pp. 1-6, doi: 10.1109/IREC.2015.7110957.

[28] R. P. Sah, B. Choudhury, and R. K. Das, "Study of a two-bed silica gel-water adsorption chiller: performance analysis," Int. J. Sustain. Energy, vol. 37, no. 1, pp. 30-46, 2018, doi: 10.1080/14786451.2016.1173696.

[29] N. Thielen et al., "Adsorption energy systems library - Modeling adsorptionbased chillers, heat pumps, thermal storages and desiccant systems," Proceedings of the 10th International Modelling Conference, Lund, Sweden, vol. 96, pp. 875883, March 10-12, 2014, doi: 10.3384/ecp14096875.

[30] M. Schicktanz and T. Núñez, "Modelling of an adsorption chiller for dynamic system simulation," Int. J. Refrig., vol. 32, no. 4, pp. 588-595, 2009, doi: 10.1016/j.ijrefrig.2009.02.011.

[31] A. M. Reda, A. H. H. Ali, M. G. Morsy, and I. S. Taha, "Design optimization of a residential scale solar driven adsorption cooling system in upper Egypt based," Energy Build., vol. 130, pp. 843-856, 2016, doi: 10.1016/j.enbuild.2016.09.011.

[32] D. Pandit, B. Choudhury, and J. P. Sarkar, "Modelling Analysis of Silica Gel / Water Adsorption Chiller Systems : A Review," Int. J. Res. Sci. Innov., vol. III, no. Vi, pp. 18-26, 2016, [Online]. Available: http://www.rsisinternational.org/IJRSI/Issue28/18-26.pdf.

[33] H. T. Chua, K. C. Ng, W. Wang, C. Yap, and X. L. Wang, "Transient modeling of a two-bed silica gel-water adsorption chiller," Int. J. Heat Mass Transf., vol. 47, no. 4, pp. 659-669, 2004, doi: 10.1016/j.ijheatmasstransfer.2003.08.010.

[34] S. S. Alrwashdeh and H. Ammari, "Life cycle cost analysis of two different refrigeration systems powered by solar energy," Case Stud. Therm. Eng., vol. 16, no. November, p. 100559, 2019, doi: 10.1016/j.csite.2019.100559. 
[35] U. Eicker, D. Pietruschka, M. Haag, and A. Schmitt, "Energy and economic performance of solar cooling systems worldwide," Energy Procedia, vol. 57, pp. 2581-2589, 2014, doi: 10.1016/j.egypro.2014.10.269.

[36] M. Narayanan, "Techno-economic analysis of solar absorption cooling for commercial buildings in India," Int. J. Renew. Energy Dev., vol. 6, no. 3, pp. 253262, 2017, doi: 10.14710/ijred.6.3.253-262.

[37] A. Alahmer, X. Wang, and K. C. A. Alam, "Dynamic and Economic Investigation of a Solar Thermal-Driven Two-Bed Adsorption Chiller under Perth Climatic Conditions," Energies, vol. 13, no. 4, p. 1005, Feb. 2020, doi: 10.3390/en13041005.

[38] World Bank Group, "Global Solar Atlas,” 2016. Accessed: Mar. 17, 2019. [Online]. Available: https://globalsolaratlas.info/.

[39] Apricus Solar Co. Ltd, "Technical Information: FPC-A32 Solar Collector." 2013.

[40] Tri Oracle Group, “TriSolar," 2009. Accessed: Oct. 20, 2020. [Online]. Available: http://trisolar.ca/Content/Understanding_IAM.php.

[41] C. Baldwin, "Design and Construction of an Experimental Apparatus to Assess the Performance of a Solar Absorption Chiller with Integrated Thermal Storage," MaSc thesis, MAAE, Carleton University, Ottawa, Canada, 2013.

[42] Omega, "Revised Thermocouple Reference Tables," Accessed: Oct. 16, 2020. [Online]. Available: https://assets.omega.com/resources/thermocouple-ref-tablest-c.pdf.

[43] C. Baldwin, "The Integration of Heat Pumps and Thermal Storage for Residential Demand Side Management," PhD thesis, MAAE, Carleton University, Ottawa, Canada, 2020.

[44] Furnace Compare, "Electric \& Forced Air Furnaces | Your Best Guide," Jun. 16, 2020. Accessed: Dec. 20, 2020. [Online]. Available: https://www.furnacecompare.com/furnaces/electric-furnaces/.

[45] O. Comstock, "Gas furnace efficiency has large implications for residential natural gas use - Today in Energy - U.S. Energy Information Administration (EIA)," U.S. Energy Information Administration, Dec. 05, 2013. Accessed: Oct. 16, 2020. [Online]. Available: https://www.eia.gov/todayinenergy/detail.php?id=14051.

[46] McQuay Inc., "Air Cooled Fluid Coolers,” vol. 690. p. 15, 1984, Accessed: Oct. 16, 2020. [Online]. Available: https://oslo.daikinapplied.com/api/sharepoint/getdocument/Doc100/CAT690.pdf/.

[47] Natural Resources Canada, Heating with Oil, M144-60/20 ed. Ottawa, 2012. ISBN: 978-1-100-19264-2 
[48] R. Urban, "Electricity Prices in Canada," energyhub.org, Feb. 14, 2020. Accessed Oct. 16, 2020. [Online] https://energyhub.org/wp-content/uploads/ElectricityPrices-in-Canada-2020.pdf.

[49] Prince Edward Island Regulatory \& Appeals Commission, "Petroleum Prices." Accessed: Oct. 16, 2020. [Online]. Available: http://www.irac.pe.ca/document.aspx?file=petrol/currentprices.asp.

[50] Alberta Utilities Commission, "Current rates and terms and conditions." Accessed: Oct. 16, 2020. [Online]. Available: http://www.auc.ab.ca/pages/current-rates-electric.aspx.

[51] B.-J. MacKinnon, "Residential customers could see their Enbridge Gas bill drop by 7\% | CBC News," CBC News, New Brunswick, Aug. 07, 2019.

[52] efficiency Nova Scotia, "Home Heating Cost Comparison for Nova Scotia." Accessed: Oct. 16, 2020. [Online]. Available: https://www.efficiencyns.ca/toolsresources/guide/heating-comparisons/.

[53] Énergir, "Natural Gas Price.” Accessed: Oct. 16, 2020. [Online]. Available: https://www.energir.com/en/business/price/natural-gas-price/.

[54] Ontario Energy Board, "Natural gas rates." Accessed: Oct. 16, 2020. [Online]. Available: https://www.oeb.ca/rates-and-your-bill/natural-gas-rates.

[55] EnergyRates.ca, "Explaining Your Saskatchewan Electricity \& Natural Gas Rates - EnergyRates.ca." Accessed: Oct. 16, 2020. [Online]. Available: https://energyrates.ca/saskatchewan/explaining-your- saskatchewan-electricitynatural-gas-rates/.

[56] FortisBC, "Residential natural gas rates." Accessed: Oct. 16, 2020. [Online]. Available: https://www.fortisbc.com/accounts-billing/billing-rates/natural-gasrates/residential-rates.

[57] Centra Gas Manitoba Inc., "Residential rates - Natural Gas," Manitoba Hydro. Accessed: Oct. 16, 2020. [Online]. Available: https://www.hydro.mb.ca/accounts_and_services/rates/residential_rates/.

[58] C. Rockenbaugh et al., "High Performance Flat Plate Solar Thermal Collector Evaluation," National Renewable Energy Laboratory. April 2016. Accessed: Oct. 20, 2020. [Online]. Available: https://www.nrel.gov/docs/fy16osti/66215.pdf.

[59] Shipton's Heating and Cooling, "Do You Have an Annual HVAC Maintenance Budget?" Accessed: Oct. 16, 2020. [Online]. Available: https://shiptons.ca/shiptons-blog/do-you-have-an-annual-hvac-maintenancebudget-why-you-need-one-now/149. 
[60] HomeAdvisor, "HVAC System Replacement \& New Unit Installation Cost." Accessed: Oct. 16, 2020. [Online]. Available:

https://www.homeadvisor.com/cost/heating-and-cooling/.

[61] T. Wong and J. Leber, "Analysis of Various Water Heating Systems.” California Energy Commission. 1996 Summer Study on Energy Efficiency in Buildings, vol. 1, pp. 255-263. Washington. Accessed: Oct. 16, 2020. [Online]. Available: https://www.aceee.org/files/proceedings/1996/data/papers/SS96_Panel1_Paper26. pdf.

[62] P. D. Lavappa and J. D. Kneifel, "Energy Price Indices and Discount Factors for Life-Cycle Cost Analysis - 2020 Annual Supplement to NIST Handbook 135," Apr. 2020. https://doi.org/10.6028/NIST.IR.85-3273-35 (accessed Oct. 16, 2020).

[63] P. Bagnoli, C. Matier, M. Askari, N. Beauchamp, and J. Scrim, "The Impact of a Pan-Canadian Carbon Pricing Levy on PBO's GDP Projection," Ottawa, Apr. 2018. www.pbo-dpb.gc.ca (accessed Oct. 16, 2020).

[64] Thermal environmental conditions for human occupancy, ASHRAE Standard 552013, Dec. 1, 2014. ISSN:1041-2336.

[65] The National Institute for Occupational Safety and Health, "Indoor Environmental Quality," Centers for Disease Control and Prevention, 2015. Accessed: Oct. 20, 2020. [Online]. Available:

https://www.cdc.gov/niosh/topics/indoorenv/temperature.html.

[66] O. Edenhofer, R. Pichs-Madruga, Y. Sokona, K. Seyboth, P. Matschoss, S. Kadner, T. Zwichel, P. Eickemeier, G. Hansen, S. Schlömer and C. v. Stechow, "IPCC Special Report on Renewable Energy Sources and Climate Change Mitigation," Cambridge University Press, Cambridge, United Kingdom, 2011.

[67] Canada Energy Regulator, "Provincial \& Territorial Energy Profiles," 2020. [Online]. Available: https://www.cer-rec.gc.ca/en/data-analysis/energymarkets/provincial-territorial-energy-profiles/index.html.

[68] Environmental Defense Fund, "The true cost of carbon pollution." Accessed: Oct. 16, 2020. [Online]. Available: https://www.edf.org/true-cost-carbon-pollution.

[69] A. Harvie, M. Devost, G. Smeijers, M. Collett, "Canada to increase carbon taxes by 566\%," Norton Rose Fulbright LLP. Canada. Dec. 15, 2020. Accessed: Dec. 19, 2020. [Online]. Available:

https://www.nortonrosefulbright.com/en/knowledge/publications/d58ef644. 


\section{Appendices}

Appendix A - Full Experimental Schematic (Spans two pages)

The experimental schematic is shown in Figure 7.1 and shows all of the piping and instrumentation in both the laboratory (first part) and mechanical room (second part).

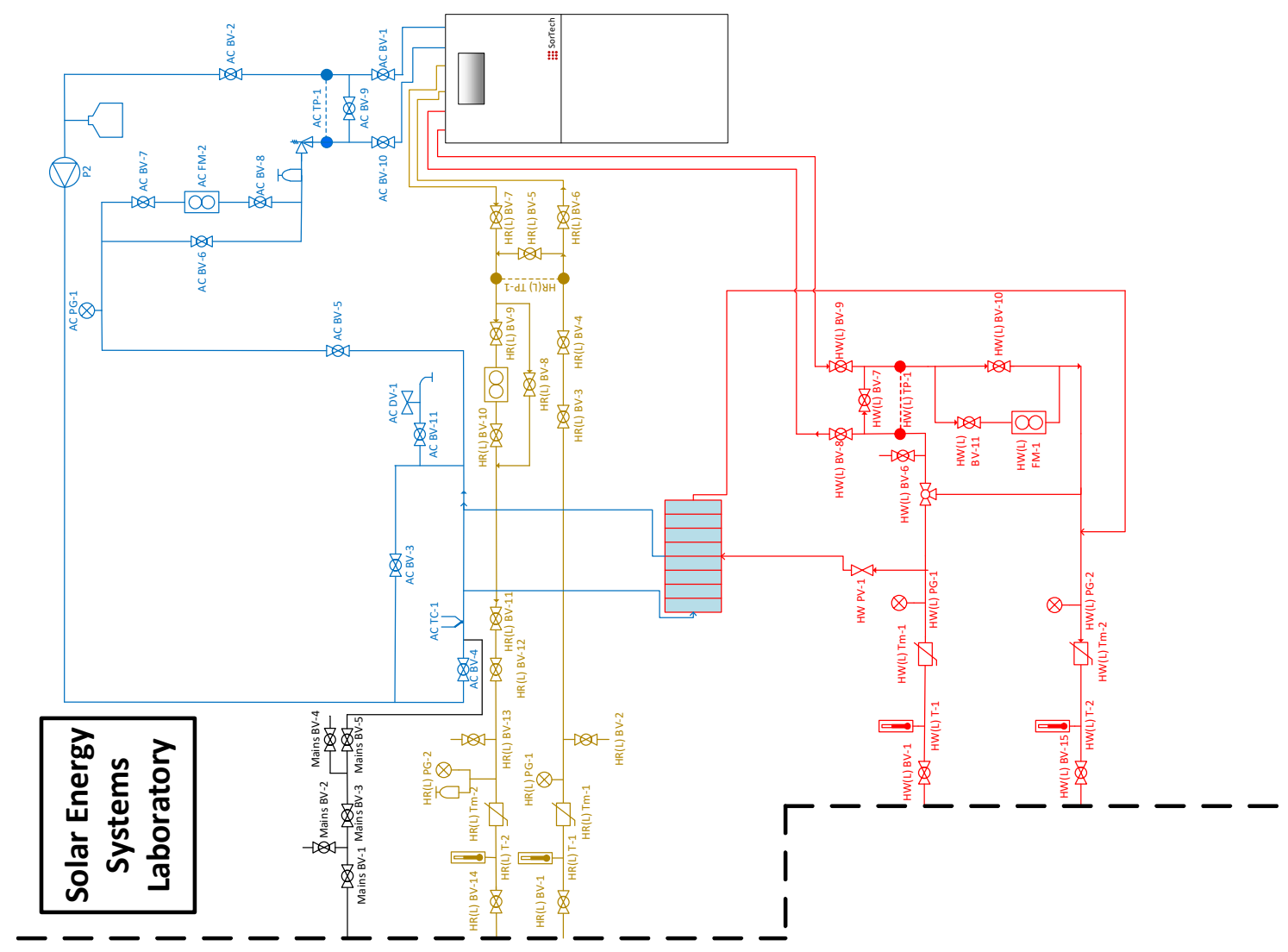




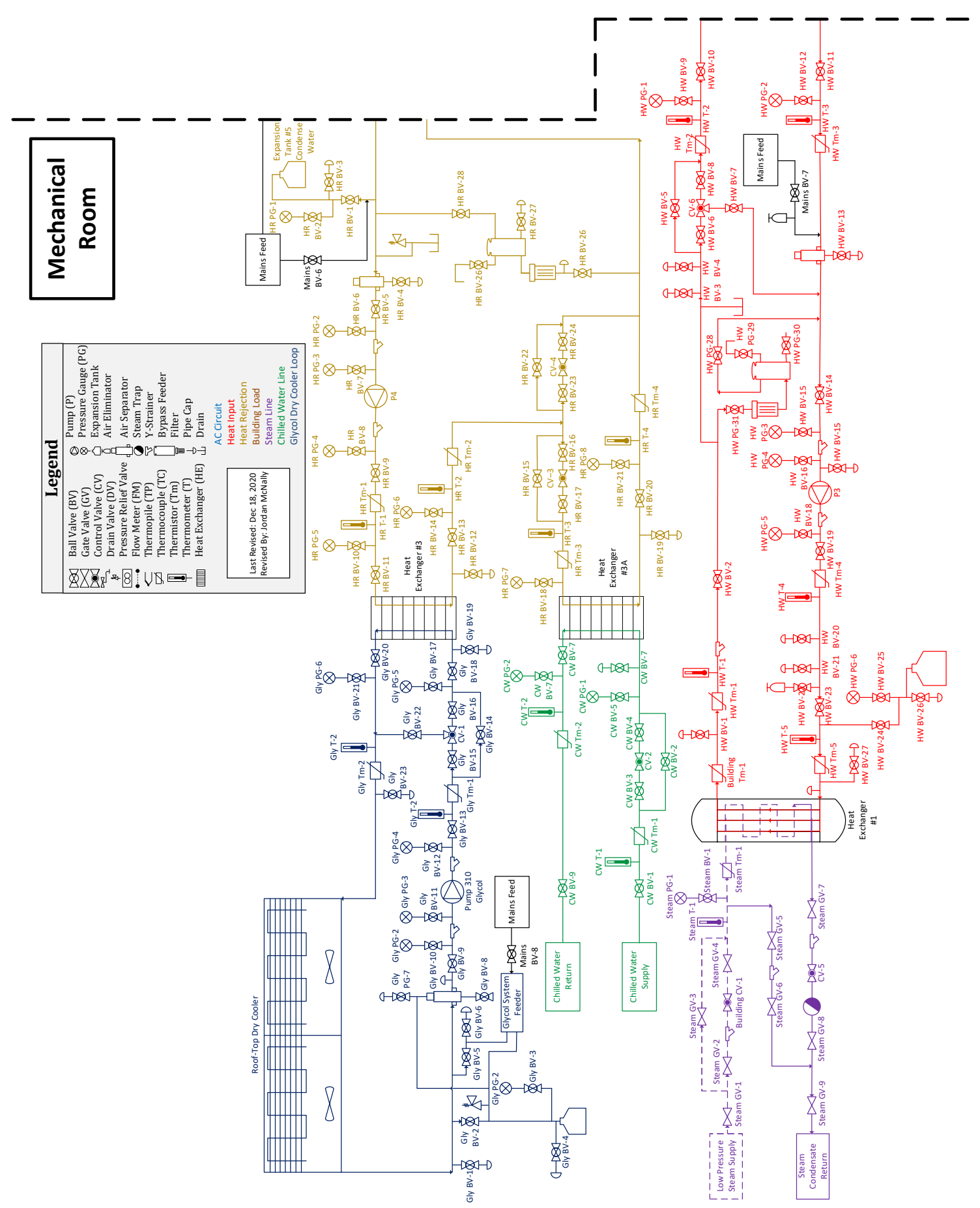

Figure 7.1: Laboratory and mechanical room schematic 


\section{Appendix B - Adsorption Performance Map Input File}

This is the data from the dat file used to input the performance data for the adsorption

chiller. The data is normalized to a cooling capacity of $14 \mathrm{~kW}_{\text {th }}$ and $0.55 \mathrm{COP}$.

455060708090 !Hot water temperatures

$22252730 \quad$ !Cooling water temperatures

10141822 !Chilled water temperatures

0.1130 .517 !Normalized Capacity and COP at CHWT $=10 \quad \mathrm{CWT}=22 \quad \mathrm{HWT}=45$

0.2200 .715 !Normalized Capacity and COP at CHWT $=14 \mathrm{CWT}=22 \mathrm{HWT}=45$

0.3640 .881 !Normalized Capacity and COP at CHWT $=18 \mathrm{CWT}=22 \mathrm{HWT}=45$

0.3960 .981 !Normalized Capacity and COP at CHWT $=22 \mathrm{CWT}=22 \mathrm{HWT}=45$

0.0010 .001 !Normalized Capacity and COP at CHWT $=10 \quad \mathrm{CWT}=25 \mathrm{HWT}=45$

0.0910 .459 !Normalized Capacity and COP at CHWT $=14 \mathrm{CWT}=25 \mathrm{HWT}=45$

0.2000 .787 !Normalized Capacity and COP at CHWT $=18 \quad \mathrm{CWT}=25 \mathrm{HWT}=45$

0.3420 .978 !Normalized Capacity and COP at CHWT $=22 \mathrm{CWT}=25 \mathrm{HWT}=45$

0.0010 .001 !Normalized Capacity and COP at CHWT $=10 \quad \mathrm{CWT}=27 \mathrm{HWT}=45$

0.0010 .001 !Normalized Capacity and COP at CHWT $=14 \mathrm{CWT}=27 \mathrm{HWT}=45$

0.0780 .449 !Normalized Capacity and COP at CHWT $=18 \quad \mathrm{CWT}=27 \mathrm{HWT}=45$

0.2460 .891 !Normalized Capacity and COP at CHWT $=22 \mathrm{CWT}=27 \mathrm{HWT}=45$

0.0010 .001 !Normalized Capacity and COP at CHWT $=10 \quad \mathrm{CWT}=30 \mathrm{HWT}=45$

0.0010 .001 !Normalized Capacity and COP at CHWT $=14 \mathrm{CWT}=30 \mathrm{HWT}=45$

0.0010 .001 !Normalized Capacity and COP at CHWT $=18 \quad \mathrm{CWT}=30 \mathrm{HWT}=45$

0.0740 .786 !Normalized Capacity and COP at CHWT $=22 \quad \mathrm{CWT}=30 \mathrm{HWT}=45$

0.1460 .546 !Normalized Capacity and COP at CHWT $=10 \quad \mathrm{CWT}=22 \mathrm{HWT}=50$

0.2710 .779 !Normalized Capacity and COP at CHWT $=14 \mathrm{CWT}=22 \mathrm{HWT}=50$

0.4220 .938 !Normalized Capacity and COP at CHWT $=18 \quad \mathrm{CWT}=22 \mathrm{HWT}=50$

0.5040 .988 !Normalized Capacity and COP at CHWT $=22 \mathrm{CWT}=22 \mathrm{HWT}=50$

0.0580 .253 !Normalized Capacity and COP at CHWT $=10 \quad \mathrm{CWT}=25 \mathrm{HWT}=50$

0.1440 .547 !Normalized Capacity and COP at CHWT $=14 \quad \mathrm{CWT}=25 \mathrm{HWT}=50$

0.2620 .808 !Normalized Capacity and COP at CHWT $=18 \mathrm{CWT}=25 \mathrm{HWT}=50$

0.4170 .990 !Normalized Capacity and COP at CHWT $=22 \quad \mathrm{CWT}=25 \mathrm{HWT}=50$

0.0010 .001 !Normalized Capacity and COP at CHWT $=10 \quad \mathrm{CWT}=27 \mathrm{HWT}=50$

0.0580 .253 !Normalized Capacity and COP at CHWT $=14 \quad \mathrm{CWT}=27 \mathrm{HWT}=50$

0.1570 .561 !Normalized Capacity and COP at CHWT $=18 \quad \mathrm{CWT}=27 \mathrm{HWT}=50$

0.3300 .938 !Normalized Capacity and COP at CHWT $=22 \quad \mathrm{CWT}=27 \mathrm{HWT}=50$

0.0010 .001 !Normalized Capacity and COP at CHWT $=10 \quad \mathrm{CWT}=30 \mathrm{HWT}=50$

0.0010 .001 !Normalized Capacity and COP at CHWT $=14 \mathrm{CWT}=30 \mathrm{HWT}=50$

0.0510 .311 !Normalized Capacity and COP at CHWT $=18 \mathrm{CWT}=30 \mathrm{HWT}=50$

0.1580 .805 !Normalized Capacity and COP at CHWT $=22 \quad \mathrm{CWT}=30 \mathrm{HWT}=50$

0.2430 .606 ! Normalized Capacity and COP at CHWT $=10 \quad \mathrm{CWT}=22 \mathrm{HWT}=60$

0.3830 .738 !Normalized Capacity and COP at CHWT $=14 \mathrm{CWT}=22 \mathrm{HWT}=60$

0.5470 .886 !Normalized Capacity and COP at CHWT $=18 \mathrm{CWT}=22 \mathrm{HWT}=60$

0.6871 .044 !Normalized Capacity and COP at CHWT $=22 \quad \mathrm{CWT}=22 \mathrm{HWT}=60$

0.1430 .464 !Normalized Capacity and COP at CHWT $=10 \quad \mathrm{CWT}=25 \mathrm{HWT}=60$

0.2950 .724 !Normalized Capacity and COP at CHWT $=14 \quad \mathrm{CWT}=25 \mathrm{HWT}=60$

0.4480 .844 !Normalized Capacity and COP at CHWT $=18 \quad \mathrm{CWT}=25 \mathrm{HWT}=60$

0.6010 .986 !Normalized Capacity and COP at CHWT $=22 \mathrm{CWT}=25 \mathrm{HWT}=60$

0.0630 .244 !Normalized Capacity and COP at CHWT $=10 \quad \mathrm{CWT}=27 \quad \mathrm{HWT}=60$

0.2140 .630 !Normalized Capacity and COP at CHWT $=14 \mathrm{CWT}=27 \mathrm{HWT}=60$

0.3550 .784 !Normalized Capacity and COP at CHWT $=18 \quad \mathrm{CWT}=27 \mathrm{HWT}=60$

0.4950 .926 !Normalized Capacity and COP at CHWT $=22 \mathrm{CWT}=27 \mathrm{HWT}=60$ 
0.0010 .001 !Normalized Capacity and COP at CHWT $=10 \quad \mathrm{CWT}=30 \mathrm{HWT}=60$ 0.0770 .414 !Normalized Capacity and COP at CHWT $=14 \mathrm{CWT}=30 \mathrm{HWT}=60$ 0.2290 .698 !Normalized Capacity and COP at CHWT $=18 \mathrm{CWT}=30 \mathrm{HWT}=60$ 0.3650 .860 !Normalized Capacity and COP at CHWT $=22 \quad \mathrm{CWT}=30 \mathrm{HWT}=60$ 0.3190 .596 !Normalized Capacity and COP at CHWT $=10 \quad \mathrm{CWT}=22 \mathrm{HWT}=70$ 0.4840 .724 !Normalized Capacity and COP at CHWT $=14 \quad \mathrm{CWT}=22 \mathrm{HWT}=70$ 0.6610 .898 !Normalized Capacity and COP at CHWT $=18 \quad \mathrm{CWT}=22 \mathrm{HWT}=70$ 0.9501 .180 !Normalized Capacity and COP at CHWT $=22 \quad \mathrm{CWT}=22 \mathrm{HWT}=70$ 0.2440 .602 !Normalized Capacity and COP at CHWT $=10 \quad \mathrm{CWT}=25 \quad \mathrm{HWT}=70$ 0.3930 .656 !Normalized Capacity and COP at CHWT $=14 \quad \mathrm{CWT}=25 \mathrm{HWT}=70$ 0.5610 .814 !Normalized Capacity and COP at CHWT $=18 \quad \mathrm{CWT}=25 \mathrm{HWT}=70$ 0.7911 .023 !Normalized Capacity and COP at CHWT $=22 \quad \mathrm{CWT}=25 \mathrm{HWT}=70$ 0.1800 .608 !Normalized Capacity and COP at CHWT $=10 \quad \mathrm{CWT}=27 \mathrm{HWT}=70$ 0.3500 .651 !Normalized Capacity and COP at CHWT $=14 \mathrm{CWT}=27 \mathrm{HWT}=70$ 0.5040 .788 !Normalized Capacity and COP at CHWT $=18 \quad \mathrm{CWT}=27 \quad \mathrm{HWT}=70$ 0.6710 .969 !Normalized Capacity and COP at CHWT $=22 \quad \mathrm{CWT}=27 \mathrm{HWT}=70$ 0.0600 .295 !Normalized Capacity and COP at CHWT $=10 \quad \mathrm{CWT}=30 \mathrm{HWT}=70$ 0.2050 .624 !Normalized Capacity and COP at CHWT $=14 \quad \mathrm{CWT}=30 \mathrm{HWT}=70$ 0.3750 .686 !Normalized Capacity and COP at CHWT $=18 \quad \mathrm{CWT}=30 \mathrm{HWT}=70$ 0.5250 .825 !Normalized Capacity and COP at CHWT $=22 \quad \mathrm{CWT}=30 \mathrm{HWT}=70$ 0.3900 .675 !Normalized Capacity and COP at CHWT $=10 \quad \mathrm{CWT}=22 \mathrm{HWT}=80$ 0.5690 .866 !Normalized Capacity and COP at CHWT $=14 \mathrm{CWT}=22 \mathrm{HWT}=80$ 0.7831 .016 ! Normalized Capacity and COP at CHWT $=18 \quad \mathrm{CWT}=22 \mathrm{HWT}=80$ 0.9681 .112 !Normalized Capacity and COP at CHWT $=22 \mathrm{CWT}=22 \mathrm{HWT}=80$ 0.3600 .644 !Normalized Capacity and COP at CHWT $=10 \quad \mathrm{CWT}=25 \mathrm{HWT}=80$ 0.5510 .829 !Normalized Capacity and COP at CHWT $=14 \mathrm{CWT}=25 \mathrm{HWT}=80$ 0.6780 .919 !Normalized Capacity and COP at CHWT $=18 \quad \mathrm{CWT}=25 \mathrm{HWT}=80$ 0.8520 .947 !Normalized Capacity and COP at CHWT $=22 \quad \mathrm{CWT}=25 \mathrm{HWT}=80$ 0.2490 .560 !Normalized Capacity and COP at CHWT $=10 \quad \mathrm{CWT}=27 \quad \mathrm{HWT}=80$ 0.4780 .795 !Normalized Capacity and COP at CHWT $=14 \mathrm{CWT}=27 \mathrm{HWT}=80$ 0.6120 .812 !Normalized Capacity and COP at CHWT $=18 \quad \mathrm{CWT}=27 \mathrm{HWT}=80$ 0.7680 .892 !Normalized Capacity and COP at CHWT $=22 \quad \mathrm{CWT}=27 \mathrm{HWT}=80$ 0.0920 .307 !Normalized Capacity and COP at CHWT $=10 \quad \mathrm{CWT}=30 \mathrm{HWT}=80$ 0.3370 .670 !Normalized Capacity and COP at CHWT $=14 \mathrm{CWT}=30 \mathrm{HWT}=80$ 0.5060 .706 !Normalized Capacity and COP at CHWT $=18 \quad \mathrm{CWT}=30 \mathrm{HWT}=80$ 0.6500 .843 !Normalized Capacity and COP at CHWT $=22 \quad \mathrm{CWT}=30 \mathrm{HWT}=80$ 0.4460 .611 !Normalized Capacity and COP at CHWT $=10 \quad \mathrm{CWT}=22 \mathrm{HWT}=90$ 0.6940 .852 !Normalized Capacity and COP at CHWT $=14 \mathrm{CWT}=22 \mathrm{HWT}=90$ 0.9041 .012 !Normalized Capacity and COP at CHWT $=18 \quad \mathrm{CWT}=22 \mathrm{HWT}=90$ 1.0501 .080 !Normalized Capacity and COP at CHWT $=22 \mathrm{CWT}=22 \mathrm{HWT}=90$ 0.4010 .655 !Normalized Capacity and COP at CHWT $=10 \quad \mathrm{CWT}=25 \mathrm{HWT}=90$ 0.5890 .794 !Normalized Capacity and COP at CHWT $=14 \quad \mathrm{CWT}=25 \mathrm{HWT}=90$ 0.7760 .930 !Normalized Capacity and COP at CHWT $=18 \quad \mathrm{CWT}=25 \mathrm{HWT}=90$ 0.9221 .043 !Normalized Capacity and COP at CHWT $=22 \quad \mathrm{CWT}=25 \mathrm{HWT}=90$ 0.4110 .704 !Normalized Capacity and COP at CHWT $=10 \quad \mathrm{CWT}=27 \mathrm{HWT}=90$ 0.6990 .876 !Normalized Capacity and COP at CHWT $=14 \mathrm{CWT}=27 \mathrm{HWT}=90$ 0.8451 .018 !Normalized Capacity and COP at CHWT $=18 \quad \mathrm{CWT}=27 \mathrm{HWT}=90$ 0.8761 .025 !Normalized Capacity and COP at CHWT $=22 \mathrm{CWT}=27 \mathrm{HWT}=90$ 0.1230 .319 !Normalized Capacity and COP at CHWT $=10 \quad \mathrm{CWT}=30 \mathrm{HWT}=90$ 0.3400 .688 !Normalized Capacity and COP at CHWT $=14 \quad \mathrm{CWT}=30 \mathrm{HWT}=90$ 0.5640 .852 !Normalized Capacity and COP at CHWT $=18 \quad \mathrm{CWT}=30 \mathrm{HWT}=90$ 0.7220 .959 !Normalized Capacity and COP at CHWT $=22 \mathrm{CWT}=30 \mathrm{HWT}=90$ 


\section{Appendix C - Supplementary Data}

\section{C.1 Alternative Fuel Costs}

The rates for electricity and fuel for each region used for this study using rates of $\$ / \mathrm{L}$ is shown in Table C.1.

Table C.1: Electrical and fuel rates for each city (alternative units) 2019 rates

\begin{tabular}{|c|c|c|c|c|}
\hline City & Province/Territory & $\begin{array}{c}\text { Electricity Rate } \\
(\$ / \mathrm{kWh})[51]\end{array}$ & $\begin{array}{c}\text { Natural Gas } \\
\text { Rate }(\$ / \mathrm{L})\end{array}$ & $\begin{array}{c}\text { Heating Oil } \\
\text { Rate }(\$ / \mathrm{L})[52]\end{array}$ \\
\hline Charlottetown & P.E.I. & 0.168 & $*$ & 0.65 \\
\hline Edmonton & Alberta & 0.072 & $0.0714[53]$ & \\
\hline Fredericton & New Brunswick & 0.112 & $0.73[54]$ & \\
\hline Halifax & Nova Scotia & $\begin{array}{c}\text { Standard: } 0.15603 \\
\text { Off-peak: } 0.0876 \\
\text { On-peak: } 0.19961\end{array}$ & $0.34[55]$ & \\
\hline Montreal & Quebec & $\begin{array}{c}\text { Tier 1: } 0.0608 \text { up } \\
\text { to } 40 \mathrm{kWh} / \text { day } \\
\text { Tier 2: } 0.0938\end{array}$ & $0.135[56]$ & \\
\hline Ottawa & Ontario & $\begin{array}{c}\text { Peak: } 0.134 \\
\text { Mid: } 0.094\end{array}$ & $0.12[57]$ & \\
& & Off: 0.065 & & \\
\hline Saskatoon & Saskatchewan & 0.152 & $0.14[58]$ & \\
\hline St. Johns & Newfoundland & 0.122 & $*$ & 0.65 \\
\hline Toronto & Ontario & $\begin{array}{c}\text { Peak: } 0.134 \\
\text { Mid: } 0.094\end{array}$ & $0.12[57]$ & \\
& & Off: 0.065 & & \\
\hline Vancouver & British Colombia & $\begin{array}{c}\text { Tier } 1: 0.0945 \text { up } \\
\text { to 22.2kWh/day }\end{array}$ & $0.28[59]$ & \\
& & Tier 2: 0.1417 & & \\
\hline Winnipeg & Manitoba & 0.0874 & $0.1[60]$ & \\
\hline Yellowknife & N.W.T. & 0.301 & $/$ & \\
\hline
\end{tabular}




\section{C.2 Case 7 Electrical Consumption}

Case 7 was omitted from majority of the results in Chapter 6 because the simulation's control strategy proved to be unoptimized and allowed for the auxiliary heater to be used much more often than excepted, the electrical consumption is shown in Figure C.1.

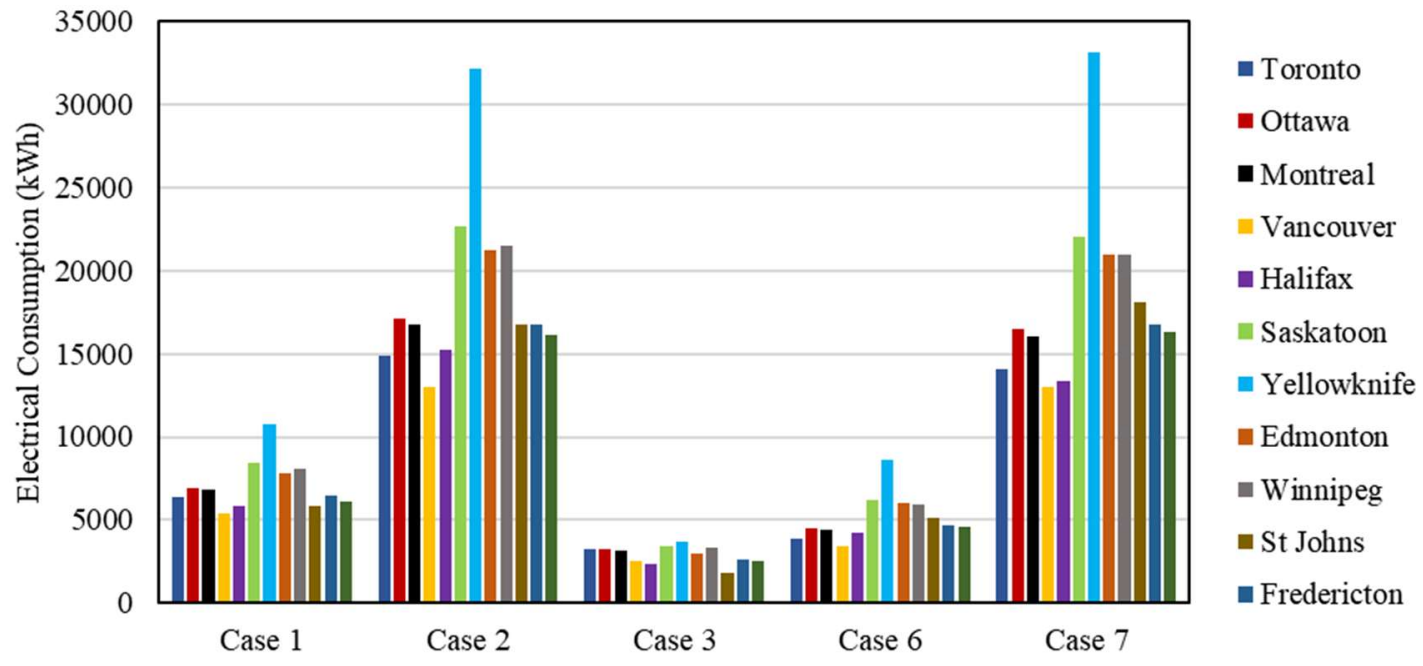

Figure C.1: Electrical consumption for different cities with Case 7

Electrical consumption was much higher in Case 7 due to the electric auxiliary heater and DHW draws from the system using a moderate profile. The consumption is primary due to the auxiliary heater and is higher than Case 2 due to the large number of additional pumps required this complex system. Demonstrates the importance of system sizing and the control system to manage the flows to optimally gain and deliver heat and therefore cooling. 